\title{
Current Trends in Nanomaterials for Metal Oxide-Based Conductometric Gas Sensors: Advantages and Limitations. Part 1: 1D and 2D Nanostructures
}

\author{
Ghenadii Korotcenkov \\ Department of Theoretical Physics, Moldova State University, MD-2009 Chisinau, Moldova; ghkoro@yahoo.com \\ Received: 7 June 2020; Accepted: 13 July 2020; Published: 17 July 2020 \\ check for \\ updates
}

\begin{abstract}
This article discusses the main uses of 1D and 2D nanomaterials in the development of conductometric gas sensors based on metal oxides. It is shown that, along with the advantages of these materials, which can improve the parameters of gas sensors, there are a number of disadvantages that significantly limit their use in the development of devices designed for the sensor market.
\end{abstract}

Keywords: nanowires; nanobelts; nanosheets; individual 1D structures; nanowire array; synthesis; fabrication; stability; improvement

\section{Introduction}

In the literature, one can find a large number of works aimed at promoting the advantages of nanomaterials for various applications [1-21]. As a rule, these articles promote the idea that the use of nanomaterials such as 1D and 2D nanomaterials, as well as hierarchical structures will solve the main problems of devices made on the basis of conventional materials. In this review, we will not follow this tradition. We will try to give a realistic look at the problem of using nanomaterials and show that, along with obvious advantages, 1D and 2D nanomaterials have disadvantages, which in some cases can significantly limit their application.

As an object for consideration, we chose the metal oxide-based gas, vapor and humidity sensors of conductometric type [15,22-28]. First, metal oxide conductometric sensors are simple, compact, and durable devices that allow controlling the presence in the atmosphere of various toxic and explosive gases and vapors [27-33]. These sensors are easy-to-manufacture and characterized by low production costs. This means that metal oxide conductometric gas sensors can be mass-produced at a reasonable cost. The principles of their functioning, based on adsorption-desorption processes and catalytic reactions, taking place on the surface of metal oxides and accompanied by an electronic exchange between adsorbed particles and the bulk of metal oxide, are well known. As a result of these reactions, a decrease or increase in the resistance (conductivity) of the gas-sensitive layer occurs, which is proportional to the concentration of the test gas [22-27,34]. The processes occurring on the surface of metal oxides during interaction with gases and vapors are repeatedly and in detail described in reviews and books [27,28,35-61]. Second, metal oxide conductometric gas sensors from the very beginning of their development were based on the use of nanomaterials. Metal oxide crystallites forming a gas sensitive layer always have a size of less than $100 \mathrm{~nm}[29,62]$. Third, the crystallite size reduction is one of the most common approaches used to improve gas sensor parameters [62-64].

As for the metal oxides themselves suitable for gas sensors design, the experiment showed that a variety of materials such as binary oxides $\left(\mathrm{SnO}_{2}, \mathrm{In}_{2} \mathrm{O}_{3}, \mathrm{WO}_{3}, \mathrm{TiO}_{2}, \mathrm{Cu}_{2} \mathrm{O}, \mathrm{Fe}_{2} \mathrm{O}_{3}, \mathrm{~V}_{2} \mathrm{O}_{5}\right.$, etc.), complex metal oxides $\left(\mathrm{CdIn}_{2} \mathrm{O}_{4}, \mathrm{NiTa}_{2} \mathrm{O}_{6}, \mathrm{CoTa}_{2} \mathrm{O}_{6}, \mathrm{CuTa}_{2} \mathrm{O}_{6}, \mathrm{BaSnO}_{3}, \mathrm{LnFeO}_{3}\right.$, etc.), and nanocomposites $\left(\mathrm{SnO}_{2}-\mathrm{Fe}_{2} \mathrm{O}_{3}, \mathrm{SnO}_{2}-\mathrm{WO}_{3}, \mathrm{In}_{2} \mathrm{O}_{3}-\mathrm{Fe}_{2} \mathrm{O}_{3}\right.$, etc. $)$ can be used for these purposes [25,60,65-71]. At that 
point, it was established that we do not have an ideal gas-sensitive material [65,72,73]. All the materials have their advantages and disadvantages. Some have low selectivity, others have increased sensitivity to humidity, some are stable only at low temperatures, some require elevated temperatures for efficient operation, etc. Therefore, when choosing a metal oxide-based gas sensing material, it is necessary to take into account the type of sensor being developed, the nature of the gas tested, the technologies used in the manufacture of the sensor, and operating conditions [65,74-76].

It should also be borne in mind that metal oxides suitable for the manufacture of gas sensors can form a wide variety of metal oxide nanostructures, which also have their own pronounced features. These are 0D, 1D, 2D, and 3D structures, which include nanodots, nanorods, nanowires, nanotubes, nanobelts, nanosheets, nanofibers, and various hierarchical structures such as nanospheres, nanowhiskers, nanorings, nanoflowers, core-shells, etc. [3,9,67,71,77-86]. SEM images of some nanostructures are shown in Figure 1.
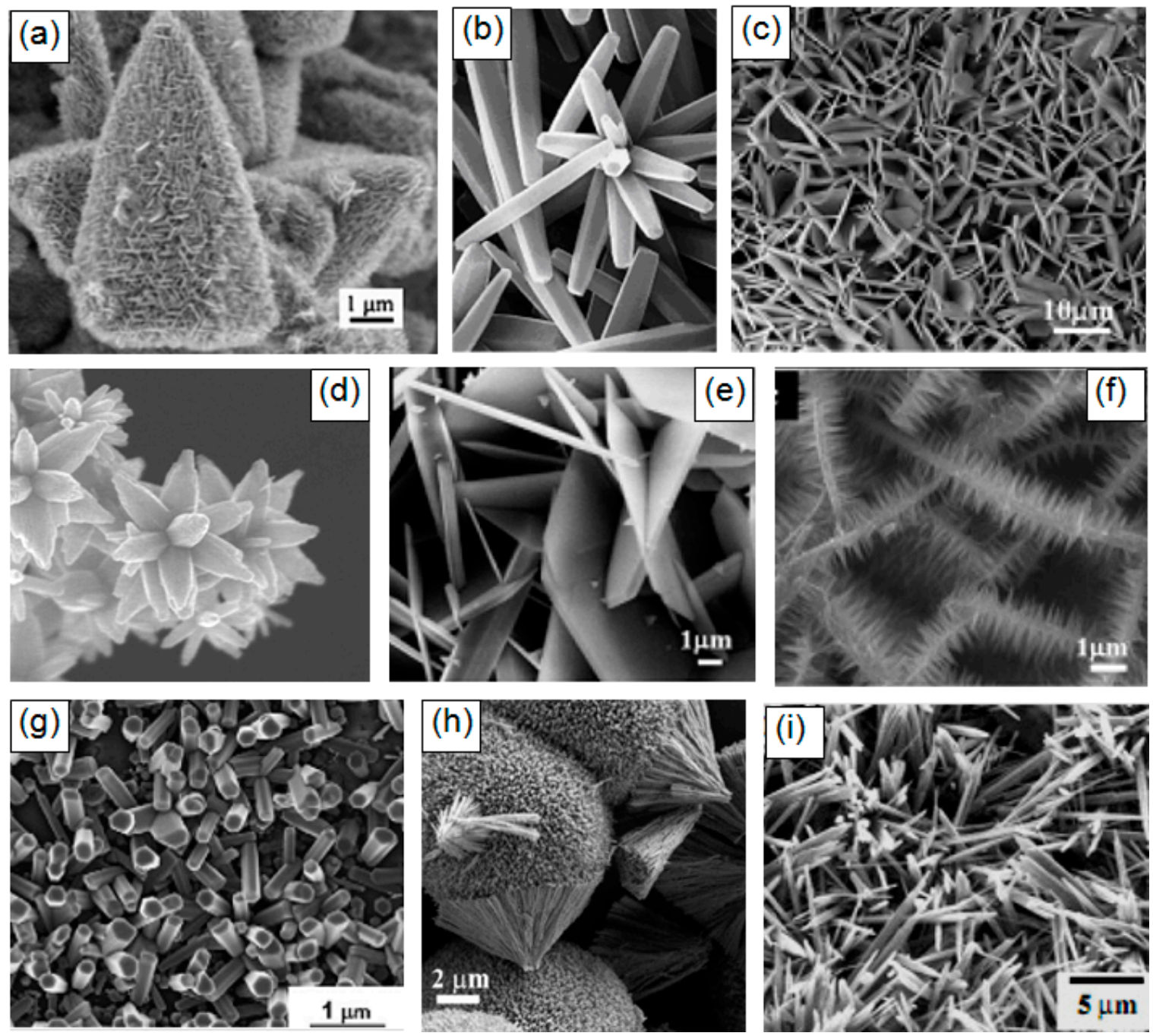

Figure 1. SEM images of $\mathrm{ZnO}$ and $\mathrm{Cu}_{2} \mathrm{O}$ nanostructures synthesized by different methods. Reproduced with permission from (a) Lu et al. [87]. Copyright 2008: Willey-VCH Verlag GmbH; (b) Li et al. [88]. Copyright 2008: Elsevier; (c,e,f) Xu et al. [89]. Copyright 2007: ACS; (d) Sepulveda-Guzman et al. [90]. Copyright 2009: Elsevier; (g) Krunks et al. [91]. Copyright 2006: Elsevier; (h) Orel et al. [92]. Copyright 2007: ACS; (i) Dev et al. [93]. Copyright 2006: Institute of Physics.

It is seen that the indicated $0 \mathrm{D}, 1 \mathrm{D}, 2 \mathrm{D}$, and 3D nanomaterials due to the structural features will form gas-sensitive layers, which can radically differ from each other even when using the same metal 
oxide. This means that the choice of a nanomaterial with the necessary structure can become one of the additional methods for optimizing parameters of gas sensors, which forces us to consider in more detail the specifics of gas sensors based on these 0D, 1D, 2D, and 3D nanomaterials. In this review, however, we will not consider OD structures or nanodots, since almost all nanocrystallites used in the development of conventional gas sensors fall under the definition of nanodots. The properties of these materials and devices based on them are examined in detail and systematized in many reviews and books [23,24,65-67,74,94]. In particular, it was shown that, in order to achieve optimal sensor parameters, the sensitive material must have a certain set of properties [26-28,65,67,76,94-97]. First, the sensitive material must have a certain combination of electrophysical, chemical, and catalytic properties [38,65]. Second, for gas sensors to be commercially viable, the gas-sensitive material must be stable during the operation regardless of the surrounding atmosphere and give a reproducible response to the test gas for a prolonged period of time $[29,65,67]$. Third, to achieve high sensitivity the gas sensitive material must be porous with high gas permeability and a large active surface area. Generally, the surface area of nanomaterials increases as the nanoparticle size decreases. In addition, the crystallite size should be comparable with the Debye length [34]. Therefore, crystallites forming a gas-sensitive layer should have a size less than 20-30 nm and they should not be strongly agglomerated [74]. Otherwise, "dead" or closed zones inaccessible to the gas are formed [74,95]. Fourth, for a fast response and small hysteresis, the pore diameter should be maximal.

The mentioned above testifies that for conventional gas sensors designed on the base of polycrystalline metal oxides, there are quite specific requirements for parameters of gas-sensitive materials. However, it must be borne in mind that the simultaneous fulfillment of all these requirements is not necessary to achieve the desired result. For example, when developing humidity sensors, special attention should be paid to the formation of a material with a certain distribution of pore diameter [28,97]. Too small a pore diameter gives high sensitivity, but in this case the sensor response is slow and it is characterized by large hysteresis, and a narrow range of measured humidity. If the pores of a large diameter predominate in metal oxides, the response will be fast with a small hysteresis, but the sensors can only work in the range of very high humidity, without the ability to detect low humidity levels [98]. A sufficiently detailed description of other approaches that can be used to optimize the parameters of conventional metal oxide-based gas sensors is given in [65,99-105].

Based on the above, in this review we will focus only on 1D, 2D, and 3D nanostructures. In this review, we will also not analyze the approaches used for functionalizing these nanomaterials in order to improve their gas-sensitive characteristics such as selectivity and sensitivity [106-112]. They are no different from the approaches used in the manufacture of conventional metal oxide-based gas sensors and based on (i) functionalization with noble-metal catalysts, (ii) tuning the operation temperature, (iii) using heterojunctions, (iv) forming nanocomposites, (v) light activation, and (vi) using filters of various types. A description of these approaches can be found in [99,101,113-123].

Taking into account the wide variety of nanomaterials and the large amount of information obtained during the development of gas sensors based on them, our review will be divided into two parts. The first part, i.e., this article will be devoted to the consideration of 1D and 2D nanomaterials, and the second part will be devoted to the consideration of mesaporous-macroporous materials, hierarchical structures, and nanofibers.

\section{1D Structures}

\subsection{D Metal Oxide Nanomaterials and Their Synthesis}

One-dimensional metal oxide nanostructures, such as nanowires, nanotubes, and nanobelts most often attract the attention of gas sensor developers [81,86,124-127]. At present, the use of individual $1 \mathrm{D}$ nanostructures for gas sensor design is considered as one of the most promising approaches to develop a new generation of gas sensors with an improved stability and reduced temporal drift of the parameters in comparison with conventional devices [128,129]. 
There are many different techniques that can be used to prepare 1D metal oxide nanostructures, but essentially, they can be grouped into two broad classes (see Figure 2): "Top-down" and "bottom-up" approaches $[6,7,130]$. The basic idea of the "top-down" approach is to use existing technology developed in the semiconductor industry. This class of techniques uses deposition, etching, and ion beam milling on planar substrates in order to reduce the dimensions of the structures to a nanometer size. The electron beam, focused ion beam, X-ray lithography, nano-imprinting, and scanning probe microscopy techniques are used for the selective removal processes. When using these techniques, it is possible to obtain highly ordered nanostructures [131-133], but they are very expensive in terms of both costs and preparation times.

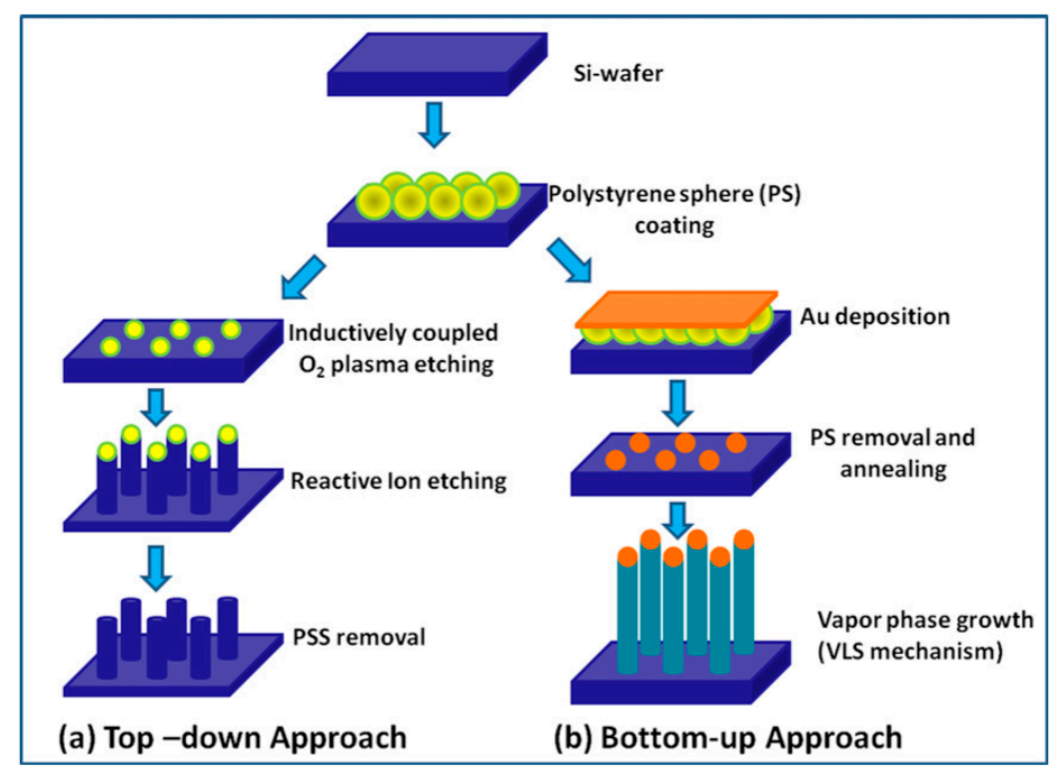

Figure 2. Schematic presentation of general steps involved in the fabrication of nanowires (NWs) using (a) top-down and (b) bottom-up approaches. Reproduced with permission from Ramgir et al. [130]. Copyright 2013: Elsevier.

The second approach is the "bottom-up", which consists of the assembly of molecular building blocks. Among many strategies for the synthesis of oxide 1D structures, a bottom-up growth from the vapor phase is traditionally considered the most cost-effective method of producing 1D structures in large quantities [7,84,130,134,135]. In many cases, this method is called the Vapor-Liquid-Solid (VLS) method, because the growth of 1D structures usually occurs by the vapor-liquid-solid mechanism [136,137]. The growth process is typically accomplished in a low pressure and high temperature furnace. The temperature near the source is elevated sufficiently to melt the source material so it can evaporate. A carrier gas flow brings the vapor to the substrate where nanowires grow with the assistance of catalysts. The catalyst material can be pre-deposited to the substrate for growing or may spontaneously form during the VLS growth process. Therefore, this process can be classified as a metal catalyst or non-metal catalyst VLS. In the metal catalyst VLS method, metals such as Au, Fe, Co, and Ni are used as catalysts. Metal catalysts can be mixed with the source material or spread on the substrate where nanowires grow. Metal catalysts play a crucial role in the synthesis procedure, acting as nucleation sites and promoting the growth of metal oxide nanowires. It is interesting, that during this process, the catalyst particle tends to remain at the tip of the growing nanowire. During this process, the size and density of nanowires on the substrate, used for their growing, can be controlled via changing the dimension and the density of the metal catalyst seeds.

The Vapor-Solid (VS) growth mechanism is different from the VLS growth mechanism, since no catalytic liquid metal is required to promote the growth of 1D metal oxide nanostructures. [138]. Only vapor and solid phases are involved in the growth of 1D nanostructures. Self-catalysis is one 
of the main factors of this growth. Since there are no catalytic liquid metals, the crystalline solids gain material directly from the vapor without the intermediate liquid phase. As a consequence of the VS growth mechanism, materials anisotropically grow along the preferential axis forming a 1D morphology. One of the main disadvantages of this method is the poor growth control and insufficient ability to integrate 1D nanostructures into fully functional devices. In addition, the high temperature, required for growth, may be a limitation for process substrates or wafers with metals already on top. The advantages of this method include the low cost of the experimental setup, the reduced diameter of the 1D structures, and the high purity of the materials.

Various approaches can be used for the controlled formation of metal catalyst seeds on the substrate surface. $[130,135]$. Two of them are shown in Figures $2 b$ and 3. Both methods allow controlling the size of metal seeds, and, therefore, controlling the diameter of the nanowires. In the first case (Figure 2), this is achieved through a change in the diameter of polystyrene spheres, and in the second (Figure 3) through a change in the pore diameter in the alumina template [135]. Vertically aligned arrays of carbon nanoposts obtained from nanoporous alumina templates, are used as the nanoscales tamps for printing catalyst nanoparticles.

In contrast to the vapor-gas-phase growth, another main stream of the 1D system synthesis is a solution-phase growth. Growth in the solution phase is a simple and cost-effective way to produce large quantities of 1D nanostructures. There are many different approaches to the production of 1D materials in liquid chemicals, including the polyol method [139], the surfactant method [140], and the hydrothermal/solvothermal technique [141]. Among these methods, the hydrothermal technique, usually carried out in an autoclave, is one of the most versatile and conventional methods, realized in industrial applications because of its high yield, low cost, and moderate-temperature processes. This technology requires simply precursors, mixed with the solution and heated to the required temperature in the autoclave. The desired 1D materials are then obtained as a result of chemical reactions. The disadvantage of this hydrothermal approach is its long synthesis time, which usually takes several hours.

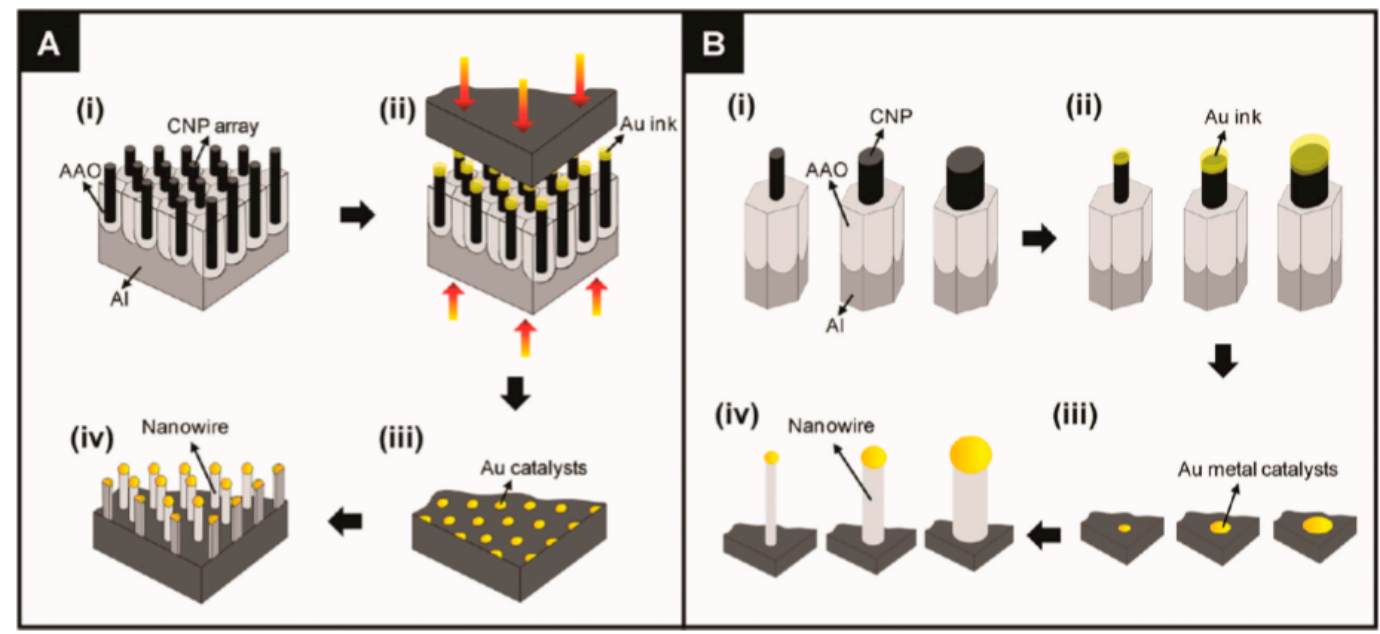

Figure 3. The schematic diagrams depict (A) the entire procedure, which includes (i) the fabrication of the carbon nanopost (CNP) stamps, (ii) the contact-printing of the Au ink, (iii) the preparation of the Au metallic catalysts, and (iv) the growth of the semiconductor NWs over the contact-printed Au catalysts via the vapor-liquid-solid (VLS) process; and (B) the conceptual model of the size-controlled fabrication of semiconductor NWs via the contact-printing process using the CNP stamps with different tip diameters: (i) Different-sized CNP tips, (ii) Au ink that was loaded onto the CNP tips, (iii) contact-printed Au catalysts from the CNP tips, and (iv) NWs grown over the size-controlled Au catalysts. The variation of the CNP diameter, which was used as the stamps for contact-printing of the Au catalysts, directly controls the diameter of the NWs that are grown over the printed Au particles. Reproduced with permission from Lee et al. [135]. Copyright 2010: American Chemical Society. 
At present, a variety of $1 \mathrm{D}$ nanostructures, such as $\mathrm{ZnO}, \mathrm{In}_{2} \mathrm{O}_{3}, \mathrm{CuO}, \mathrm{Ga}_{2} \mathrm{O}_{3}, \mathrm{MnO}_{2}, \mathrm{CeO}_{2}, \mathrm{TiO}_{2}$, and $\mathrm{WO}_{3}$, among others, have been explored [88,142-146]. However, the largest number of articles is devoted to the consideration of $\mathrm{SnO}_{2}, \mathrm{In}_{2} \mathrm{O}_{3}$, and especially $\mathrm{ZnO} 1 \mathrm{D}$ structures. Interest in the 1D $\mathrm{ZnO}$ structures is stimulated by the easy synthesis of high-quality and single crystalline $1 \mathrm{D} \mathrm{ZnO}$ nanostructures [147]. It has been reported that the synthesis of 1D nanostructures based on other gas sensitive metal oxides, such as $\mathrm{TiO}_{2}$ and $\mathrm{WO}_{3}$, is difficult compared to the mentioned above oxides.

\subsection{Sensors Based on Individual Metal Oxide 1D Structures and Their Advantages}

It should be noted that sensors based on individual metal oxide 1D structures have a specific configuration and manufacturing technology, which is radically different from the traditional technology used for the manufacture of conventional gas sensors. A typical example of a sensor based on individual $1 \mathrm{D}$ structures is shown in Figure 4.

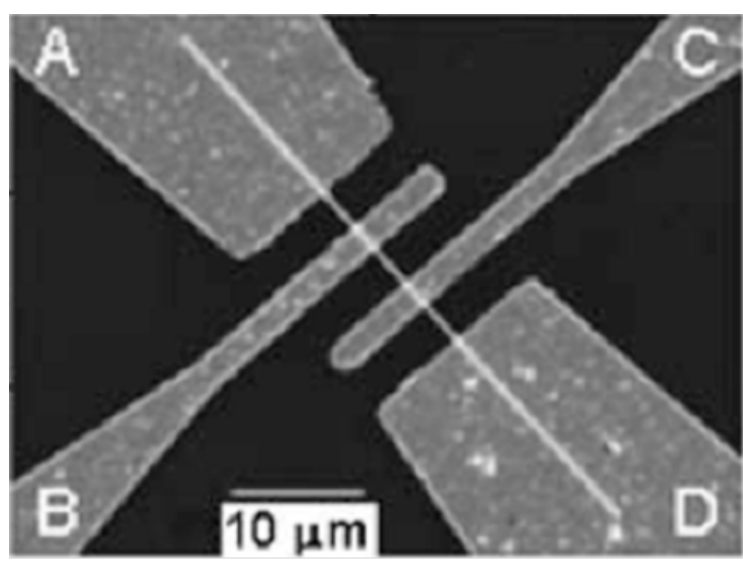

(a)

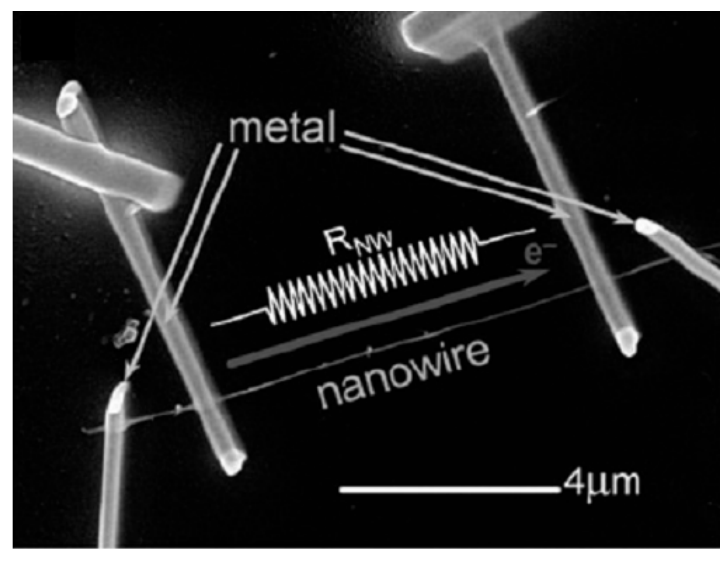

(b)

Figure 4. SEM images of gas sensors based on single metal oxide nanobelts and nanowires. (a) Reprinted with permission from Fields et al. [148]. Copyright 2006: American Institute of Physics. (b) Reproduced with permission from Hernandez-Ramirez et al. [149]. Copyright 2009: Royal Society of Chemistry.

The interest in using individual 1D structures in gas sensors was due to the following:

(i) It was assumed that a well-defined geometry, single-crystallinity, small diameter of 1D structures, and a large area-to-volume ratio will provide a high sensitivity of sensors [108,150]. As is known, a decrease in crystallite size and an increase in surface area is one of the basic requirements for achieving a high sensitivity of conductometric gas sensors [62,63,74,115,151]. Experiments and simulations have shown that the surface and interfacial reactions play a critical role in gas adsorption and related gas sensing processes. Therefore, the increase in an area-to-volume ratio significantly increases the number of atoms that are on the surface of metal oxides and available for reactions with gas molecules. Some of the achievements in the development of 1D structure-based gas sensors are shown in Table 1. These results indicate that 1D structure-based gas sensors can indeed be highly sensitive to various gases.

(ii) It was assumed that due to the lack of necks and grain boundaries (see Figure 5), such sensors would solve the problem of instability and temporal drift of the parameters of polycrystalline-based thin and thick-film sensors, caused by the interaction and mass transfer on these intergrain interfaces during increased temperatures $[129,149]$. These processes may contribute to structural changes in the sensors $[96,100,102]$. The high crystallinity of the nanowires and nanobelts structure should also contribute to the improvement of thermal and therefore, temporal stability of the device parameters. 
(iii) It was assumed that response dynamics should be faster compared to their polycrystalline counterpart since there is no need for gas diffusion in the gas sensing matrix preliminary to the surface reaction [149]. The absence of nooks and crannies in nanowire-based devices contributes to the direct adsorption/desorption of gas molecules from the surface of 1D structures.

(iv) It was assumed that through the use of individual 1D structures and self-heating effects it would be possible to significantly reduce the power consumed by the sensor, and thereby facilitate the integration of the sensors in portable systems $[108,149,168,169]$. It was found that the suspended nanowires (see Figure 6) are nearly ideal substances for this approach since their large length and small cross-section dramatically reduce the thermal losses to the metal leads and support. According to Meier et al. [167] and Hernandez-Ramirez et al. [158], such approach allows reducing the required power consumption from the milliwatt, in the case of micromachining technology, to the microwatt range in the case of self-heating of an individual 1D structure. It is necessary to note that the idea of self-heating was also successfully tested for thin film-based gas sensing devices (see as an example, [170]). However, the inevitable significant thermal losses to the support of the thin film sensing element impeded the implementation of this method. The major advantage of the metal oxide nanowires with respect to self-heated thin film sensors $[170,171]$ is their small thermal capacitance and drastic reduction of thermal losses to electrodes and gas environment [168]. As seen in Figure 7, in such sensors, to achieve operating temperatures in the range of $300-400{ }^{\circ} \mathrm{C}$, currents of only $10^{-6} \mathrm{~A}$ are required. In addition, self-heating effects enable an experimental methodology to improve the selectivity of metal oxide-based sensors. It was found that the thermal response time of these devices, due to a small thermal inertia, is very short-only a few milliseconds. [172]. This enables the use of higher modulation frequencies of their temperature profile, making available the direct observation of the kinetics associated with the chemical interactions between the metal oxide and the gases of interest [172]. This means that in this case, one can use the analysis of the dynamics of the sensor response, which is specific for each gas and can be considered as a marker of this gas [173].

(v) It was assumed that the control of the shape of 1D structures (metal oxide 1D structures have a clearly defined cut depending on the synthesis conditions) would also improve the sensitivity and selectivity of the sensors. It is known that every crystallographic plane has a unique combination of structural, electronic, catalytic, and adsorption/desorption process parameters [174,175]. It is these parameters that control the operating characteristics of all types of metal oxide-based gas sensors $[46,50,74,115,151,176-182]$. Thus, the determination of crystallographic planes with optimal combinations of adsorption/desorption and catalytic parameters, and the development of methods for crystallites deposition with indicated faces can be considered as an important task for any technology used for the synthesis or deposition of metal oxides applied to a metal oxide gas sensor. Gao and Zhang [183] have summarized the recent progress in engineering crystal structures and confirmed this statement. They concluded that for the same type of metal oxides, neither surface morphology nor a specific surface area value can totally determine their sensing ability to a particular gas. Only the crystal planes exposed on the surface are a fundamental factor in determining the response of a sensor. Moreover, Gao and Zhang [183] concluded that the crystal surface with more unsaturated metal cations is the most promising approach to realize a superior gas sensing performance. According to Gao and Zhang [183], such preferred crystallographic planes are the (0001) facet for wurzite-type $\mathrm{ZnO}$, (332) facet for rutile-type $\mathrm{SnO}_{2}$, (001) facet for anatase-type $\mathrm{TiO}_{2}$, (113) facet for hematite $\left(\alpha-\mathrm{Fe}_{2} \mathrm{O}_{3}\right),(111)$ facet for $\mathrm{NiO}$, and (110) facet for $\mathrm{Cu}_{2} \mathrm{O}$. Understandably, the preparation of polycrystalline metal oxides with the necessary grain faceting is difficult to control, but it is achievable for one-dimensional structures. One-dimensional structures are crystallographically perfect and have clear faceting with a fixed set of planes, which can be modified by controlling the synthesis parameters [154,184-186].

(vi) It was assumed that the measurement of individual 1D structures with well-known properties can allow us to understand better the fundamentals of the gas-sensing effect $[74,106,187,188]$. 
Semiconducting one-dimensional structures of metal oxides with a well-defined geometry and ideal crystallinity can be a perfect family of model materials for systematic experimental studies and theoretical simulation of gas-sensing effects in metal oxides. The random aggregation of nanoparticles in poly(nano)crystalline MOXs, as well as the scatter in their size, make it difficult to accurately study the phenomena of gas transduction at the nanoscale. At the same time, many parameters such as film thickness, texturing, porosity, grain size, grain network, grain boundary, agglomeration, and crystallite faceting, used to characterize polycrystalline materials, lose their value for one-dimensional structures. The main structural and morphologic parameters that characterize one-dimensional structures are geometric size, characterizing the profile of one-dimensional structures, and crystallographic planes, framing these one-dimensional structures. This feature of the structure primarily refers to nanobelts. Nanobelts are thin and plain belt-type structures with a rectangular cross-section (Figure 8). At present, nanobelts are available for practically all basic oxides used in chemical sensors. There is information about the synthesis of nanobelts based on $\mathrm{SnO}_{2}, \mathrm{In}_{2} \mathrm{O}_{3}, \mathrm{ZnO}, \mathrm{Ga}_{2} \mathrm{O}_{3}, \mathrm{TiO}_{2}$, etc. [78-80,124,189-194]. The synthesis of nanobelts can be performed using various methods [77,195-197], which creates good conditions for the expanding research on such nano-size materials. The minimal distance between faceting planes in nanobelts plays the same role in gas-sensing effects as the grain size in a polycrystalline material. Undoubtedly, the decreased number of parameters that control the sensor response of one-dimensional structures should contribute to a better understanding of the nature of the observed effects, since the use of 1D structures facilitates the interpretation of experimental data. Theoretical simulation of gas-sensing effects in this case can also become much simpler. [198-200]. As noted above, usually only one or two planes participate in gas-sensing effects in one-dimensional structures. This means that in simulations one-dimensional structures should be considered as single crystals with limited sizes. It is also important to note that currently there is already extensive experience in the synthesis of nanobelts with the growth of metal oxides in the desired crystallographic direction. For example, in Refs. $[154,184,185,193]$ it was reported that, depending on the synthesis route, it was possible to synthesize $\operatorname{In}_{2} \mathrm{O}_{3}$ nanobelts with $\{100\},\{120\},\{111\},\{110\}$, and $\{001\}$ growth directions. At that point, $\operatorname{In}_{2} \mathrm{O}_{3}$ nanobelts grown in the $\{100\}$ and $\{120\}$ direction had the top and bottom surfaces being (001), while the $\{100\}$ nanobelts had a side surface of (010) and a rectangular cross-section [186]. The $\{120\}$ nanobelts had a parallelogram cross-section. $\mathrm{In}_{2} \mathrm{O}_{3}$ nano-belts grown in the $\{111\}$ and $\{110\}$ directions had the other set of planes; the side and top surfaces were $(100)$ planes $[127,184]$. In the case of a $\{001\}$ growth direction, $\mathrm{In}_{2} \mathrm{O}_{3}$ nanobelts were enclosed by the (100) and (010) planes [201]. The crystallographic geometry of other metal oxide one-dimensional nanostructures is presented in Table 2. Thus, the presented results indicate that when using nanobelts, we really have the ability to control the faceting planes of 1D structures of metal oxides, which is necessary both to improve the parameters of the sensors, and to better simulate gas-sensitive effects. In addition, nanobelts do not have the mechanical strength of nanotubes. Their crystallographic perfection is a very good advantage of this material. Since there are no defects in their structure, there is no problem, as is the case with nanotubes, when defects can destroy the quantum-level properties. A suitable nanobelts geometry is also an important advantage for mass production. They have a high structural homogeneity and long length. Typical nanobelts have a width of 30-300 nm, a thickness of 10-15 nm, and a length from a few micrometers to hundreds or even several thousand micrometers. [190,201]. Moreover, nanobelts are flexible and therefore can be bent $180^{\circ}$ without damage. This fact provides additional benefits to these materials for the design of devices. The use of nanobelts, due to the specifics of their geometry, also facilitates the task of forming low-resistance contacts (see Figure 9). However, it should be noted that despite the undeniable advantages of nanobelts, nanowires are mainly used in the development of gas sensors. 
(vii) It was assumed that the use of $1 \mathrm{D}$ structures will allow realizing the new functionality of metal oxide conductometric sensors [108]. These expectations were partially met. In particular, it was shown that:

(a)

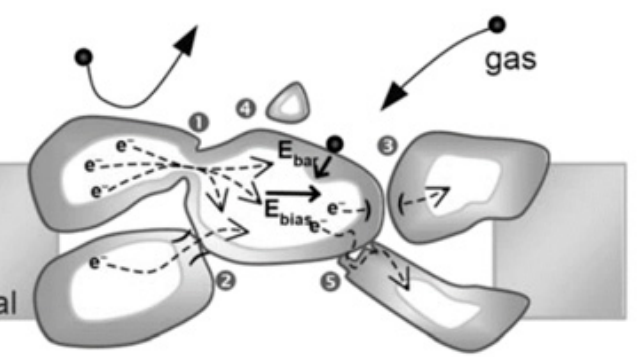

(b)

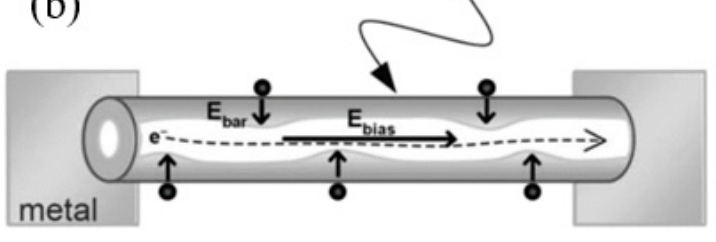

Figure 5. Diagrams illustrating the difference in gas sensing effects in (a) the polycrystalline material and (b) individual nanowires: One can see that any intergrain necks or boundaries are absent in 1D-based sensors. Moreover, $E_{\mathrm{bar}}$ and $E_{\mathrm{bias}}$ fields are always orthogonal and independent. Reproduced with permission from Hernandez-Ramirez et al. [149]. Copyright 2009: Royal Society of Chemistry.

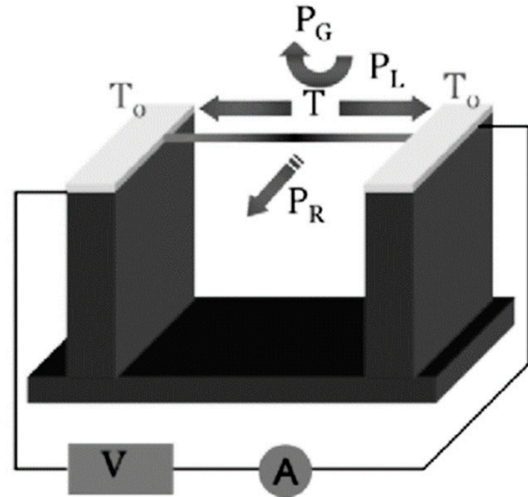

(a)

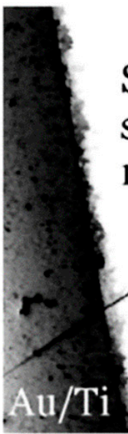

$\mathrm{SnO}_{2}$ suspended nanowire

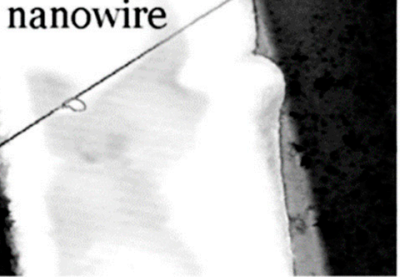

(b)

Figure 6. (a) The sensor setup and principal thermal losses in the suspended nanowire heated by the Joule heat: $P_{\mathrm{L}}$-losses to the contacts, $P_{\mathrm{G}}$ - losses to the ambient gas, and $P_{\mathrm{R}}$-radiation losses; (b) SEM image of the suspended $\mathrm{SnO}_{2}$ chemiresistor. Reproduced with permission from Strelcov et al. [168]. Copyright 2009: American Institute of Physics.

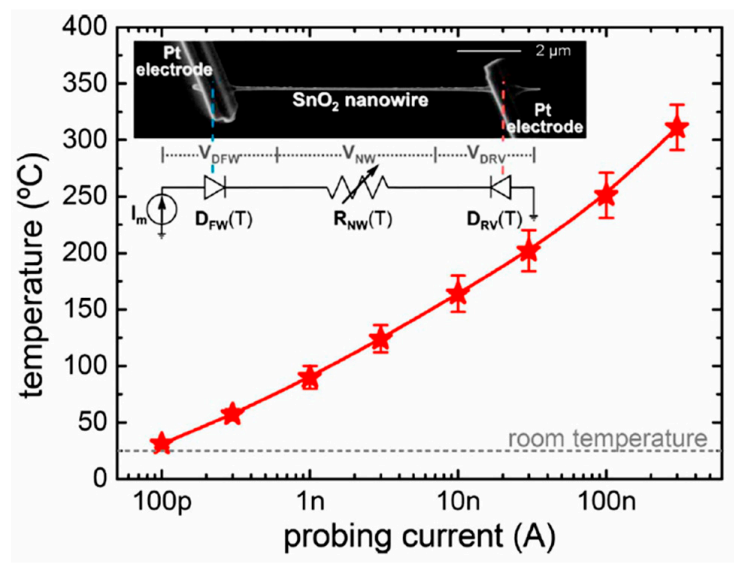

Figure 7. Estimated temperature of the devices at different $I_{m}$. $\left(r_{n w} \sim 35 \mathrm{~nm}\right)$ (inset) SEM image of a SnO 2 nanowire connected to two Pt microelectrodes fabricated with a focused ion beam. The equivalent circuit of this structure corresponds to two back-to-back diodes in a series with the nanowire resistance. These three components dissipate electrical power and contribute to the self-heating of the device. Reproduced with permission from Prades et al. [169]. Copyright 2008: American Institute of Physics. 


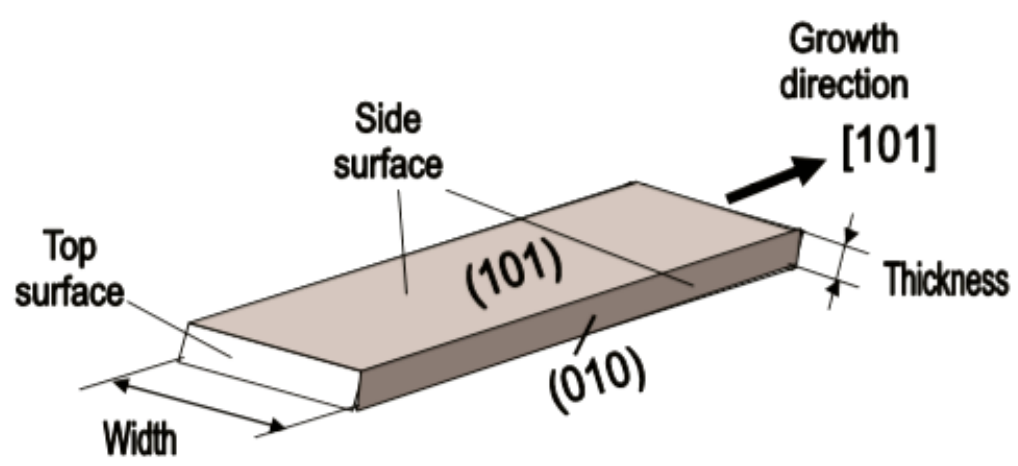

Figure 8. Schematic diagram of the geometric configuration of $\mathrm{SnO}_{2}$ nanobelts. Reproduced with permission from Korotcenkov [74]. Copyright 2008: Elsevier.

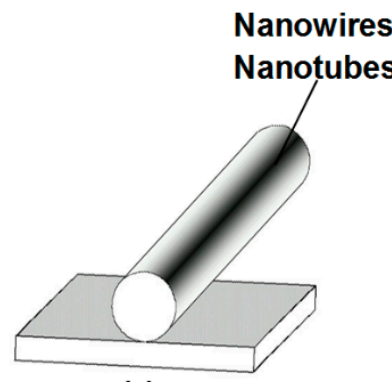

(a)

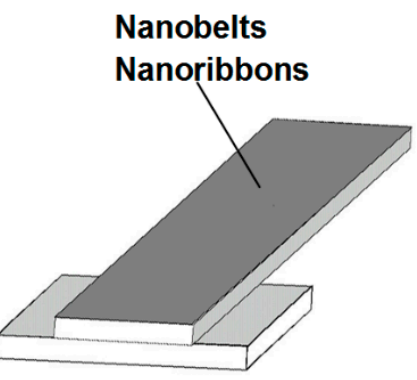

(b)

Figure 9. Position of (a) nanowires or nanotubes and (b) nanobelts on the contact pad. Reproduced with permission from Korotcenkov [74]. Copyright 2008: Elsevier.

Table 1. Several examples of a highly sensitive gas sensor based on one-dimensional (1D) nanostructures.

\begin{tabular}{|c|c|c|c|c|c|c|c|c|}
\hline Gas & Material & $\mathrm{D}, \mathrm{nm}$ & Sensor Type & $\begin{array}{l}\mathrm{T}_{\text {oper }} \\
{ }^{\circ} \mathrm{C}\end{array}$ & DL, ppm & Response & $\begin{array}{c}\tau_{\text {res }} \\
\mathrm{s}\end{array}$ & Ref. \\
\hline \multirow{5}{*}{$\mathrm{NO}_{2}$} & \multirow{2}{*}{$\mathrm{SnO}_{2}$ (NWs) } & \multirow{2}{*}{$35-45$} & \multirow{2}{*}{$\mathrm{R}$} & 25 (UV) & \multirow{2}{*}{$<0.1$} & $2 @ 5$ ppm & \multirow{2}{*}{$\sim 60$} & \multirow[t]{2}{*}{ [152] } \\
\hline & & & & 175 & & $\sim 2 @ 10 \mathrm{ppm}$ & & \\
\hline & $\mathrm{SnO}_{2}$ (NWs) & $30-100$ & $\mathrm{R}$ & 240 & $<0.01$ & $500 @ 1$ ppm & $\sim 60$ & [153] \\
\hline & $\mathrm{In}_{2} \mathrm{O}_{3}$ (NWs) & $\sim 10$ & FET & 25 & 0.5 & $10^{6} @ 100$ ppm & $5-600$ & [154] \\
\hline & $\mathrm{In}_{2} \mathrm{O}_{3}(\mathrm{NWs})$ & $\sim 10$ & FET & 25 & 0.005 & $\sim 1.6 @ 200 \mathrm{ppb}$ & $50-1000$ & [155] \\
\hline $\mathrm{H}_{2}$ & $\mathrm{SnO}_{2}(\mathrm{NWs})$ & 50-200 & $\mathrm{R}$ & 300 & $<5.0$ & $25 @ 50$ ppm & $<120$ & [156] \\
\hline \multirow{3}{*}{$\mathrm{CO}$} & $\mathrm{SnO}_{2}$ (NBs) & 60 & $\mathrm{R}$ & 400 & $\sim 5.0$ & $70 @ 250$ ppm & 30 & [157] \\
\hline & $\mathrm{SnO}_{2}(\mathrm{SNW})$ & $25-70$ & $\mathrm{R}$ & 300 & $<1.0$ & $2.1 @ 200$ ppm & N/A & $\begin{array}{l}158, \\
159]\end{array}$ \\
\hline & ZnO:Pd (NWs) & $60-70$ & $\mathrm{R}$ & 20 & $<0.1$ & $1.2 @ 0.1$ ppm & $>240$ & [160] \\
\hline \multirow{4}{*}{$\mathrm{H}_{2} \mathrm{~S}$} & $\mathrm{SnO}_{2}: \mathrm{Cu}(\mathrm{NWs})$ & 10-100 & $\mathrm{R}$ & 150 & $<1.0$ & $\sim 10^{7} @ 80 \mathrm{ppm}$ & N/A & [161] \\
\hline & $\mathrm{In}_{2} \mathrm{O}_{3}$ (NWs) & $30-100$ & FET & 120 & $<1.0$ & $\sim 12 @ 20$ ppm & $>300$ & {$[162]$} \\
\hline & $\mathrm{CuO}(\mathrm{NWs})$ & $20-40$ & $\mathrm{R}$ & 325 & $\sim 0.01$ & $4 @ 500$ ppb & $\sim 600$ & [163] \\
\hline & $\mathrm{ZnO}(\mathrm{NWs})$ & $\sim 20$ & $\mathrm{R}$ & 300 & 0.005 & $\sim 2 @ 200$ ppb & $\sim 270$ & [164] \\
\hline \multirow{2}{*}{$\mathrm{C}_{2} \mathrm{H}_{5} \mathrm{OH}$} & $\mathrm{ZnO}: \mathrm{Mg}(\mathrm{NWs})$ & $\sim 120$ & $\mathrm{R}$ & 350 & $\sim 0.01$ & $343 @ 5$ ppm & $\sim 20 \mathrm{~s}$ & [165] \\
\hline & $\mathrm{SnO}_{2}(\mathrm{NWs})$ & $30-100$ & $\mathrm{R}$ & 300 & $<1.0$ & $100 @ 20$ ppm & $<20 \mathrm{~s}$ & [153] \\
\hline \multirow{2}{*}{$\mathrm{NH}_{3}$} & $\mathrm{WO}_{3}(\mathrm{NWs})$ & $\sim 5$ & $\mathrm{R}$ & 25 & $\sim 0.1$ & $1.1 @ 5$ ppm & $\sim 50 \mathrm{~s}$ & [166] \\
\hline & $\mathrm{SnO}_{2}(\mathrm{SNW})$ & $\sim 100$ & $\mathrm{R}$ & 300 & $\sim 0.1$ & $\sim 2 @ 100 \mathrm{ppm}$ & $\sim 25 \mathrm{~s}$ & [167] \\
\hline
\end{tabular}

D-diameter; DL—detection limit; FET—field effect transistor; NWs—nanowires; R-resistive; SNW—single NW;

$\mathrm{T}_{\text {oper }}$-operation temperature; Response $-\mathrm{R}_{\text {air }} / \mathrm{R}_{\mathrm{gas}}$. 
Table 2. Crystallographic geometry of one-dimensional oxide nanostructures.

\begin{tabular}{|c|c|c|c|c|}
\hline Nanostructures & Crystal Structure & Growth Direction & Top Surface & Side Surface \\
\hline $\mathrm{ZnO}$-belt & Wurtzite & (0001)or $(01 \overline{1} 0)$ & $\pm(2 \overline{110} 0)$ & $\pm(01 \overline{1} 0)$ or $\pm(0001)$ \\
\hline $\mathrm{Ga}_{2} \mathrm{O}_{3}$-belt & Monoclinic & $(001)$ or $(010)$ & $\pm(100)$ & $\pm(010)$ or $\pm(10 \overline{1})$ \\
\hline $\mathrm{Ga}_{2} \mathrm{O}_{3}$-sheet & Monoclinic & (101) (normal) & $\pm(100)$ & $\pm(10 \overline{1})$ and $\pm(21 \overline{2})$ \\
\hline $\mathrm{t}-\mathrm{SnO}_{2}$-belt & Rutile & (101) & $\pm(10 \overline{1})$ & $\pm(010)$ and $\pm(10 \overline{1})$ \\
\hline $\mathrm{SnO}_{2}$-belt & Rutile & (100) & $\pm(001)$ & \\
\hline $\mathrm{t}-\mathrm{SnO}_{2}$-wire & Rutile & (101) & $\pm(10 \overline{1})$ & $\pm(010)$ \\
\hline $\begin{array}{c}\mathrm{SnO}_{2} \text {-belt } \\
\text { (zigzag-initial) } \\
\text { (zigzag-final) }\end{array}$ & $\begin{array}{l}\text { Rutile } \\
\text { Rutile }\end{array}$ & $\begin{array}{l}(101) \\
(101)\end{array}$ & $\begin{array}{l} \pm(010) \\
\pm(010)\end{array}$ & $\begin{array}{c} \pm(10 \overline{1}) \text { and } \pm(100) \\
\pm(100)\end{array}$ \\
\hline$\alpha$-SnO $\mathrm{S}_{2}$-wire & Orthorhombic & $(010)$ & $\pm(100)$ & $\pm(001)$ \\
\hline $\mathrm{SnO}_{2}$-diskette & Tetragonel & $\pm(100)$ and $\pm(110)$ & $\pm(001)$ & $\pm(100)$ and $\pm(110)$ \\
\hline $\mathrm{SnO}_{2}$-ribbon & Rutile & (101) & $(10 \overline{\overline{1}}) /(\overline{1} 01)$ & $(010) /(0 \overline{1} 0)$ \\
\hline $\begin{array}{l}\mathrm{SnO}_{2} \text {-ribbon } \\
\text { (sandwich) }\end{array}$ & Rutile/orhorom & $(110)_{\mathrm{o}} /(6 \overline{5} 3)_{\mathrm{t}}$ & $\pm(100)_{\mathrm{o}} / \pm(231)_{\mathrm{t}}$ & $\pm(001)_{\mathrm{o}} / \pm(10 \overline{1})_{\mathrm{t}}$ \\
\hline
\end{tabular}

Source: Data from $[74,185,201-203]$.

1. 1D-based sensors are able to operate at room temperature [204,205]. The development of room-temperature gas sensors can have very important advantages such as a low power consumption, simple system configuration, reduced explosion hazards, and longer device lifetime;

2. the specificity of the mechanical properties of nanowires and especially nanobelts allows the implementation of flexible sensors on their basis [206,207]. Courbat et al. [208] and Oprea et al. [209] have studied the continuous operation of a metal oxide polycrystalline gas sensor on polyimide hotplates for several months and found out that comparable or even better results may be expected from nanowire-based devices. Single-crystalline nanowires and especially nanobelts are much more resistant to the bending stress because of their flexibility;

3. the coupling of an individual nanowire (or a mat) chemiresistor with a micro-fabricated micro-hot plate reduces the inertia of the micro-hot plate and thereby simplifies gas detection by testing the dynamics of the sensor response [210];

4. on the base of individual nanowires, an ultra-miniature e-nose system was realized [211,212]. In its usual configuration an ultra-miniature e-nose is based on a microarray of electrodes which probe the mono-type semiconductor film, where a temperature gradient has been established. The temperature gradient induces the deviations between the responses of individual electrode pairs; and an entire array of 20 pairs of electrodes provides the required degree of orthogonality [212]. Sysoev et al. [213] showed that in such an e-nose instead of a thin film, metal oxide nanowire mats can be used. This version of the Karlsruhe Electronic Micronose (KAMINA) system is represented in Figure 10. It was established that such an e-nose had the ability to detect gases in the ppb level with an excellent stability, reproducibility, and discriminating power to effectively distinguish different target gases.

That is why since 2000, the development of gas sensors based on 1D structures has become one of the most popular areas of research in the field of gas sensors $[5,86,106,144,145,149,214-216]$. If there is an interest only in the performances of 1D-based gas sensors, then I recommend referring to the reviews [144,204,217-225], where such information is presented. As with conventional gas sensors, based on nanostructured crystallites, the sensing properties of individual NWs are affected by the NW diameter, the NW synthesis procedure, the feature of surface functionalization, and the reactions that occur on the NW surfaces. 


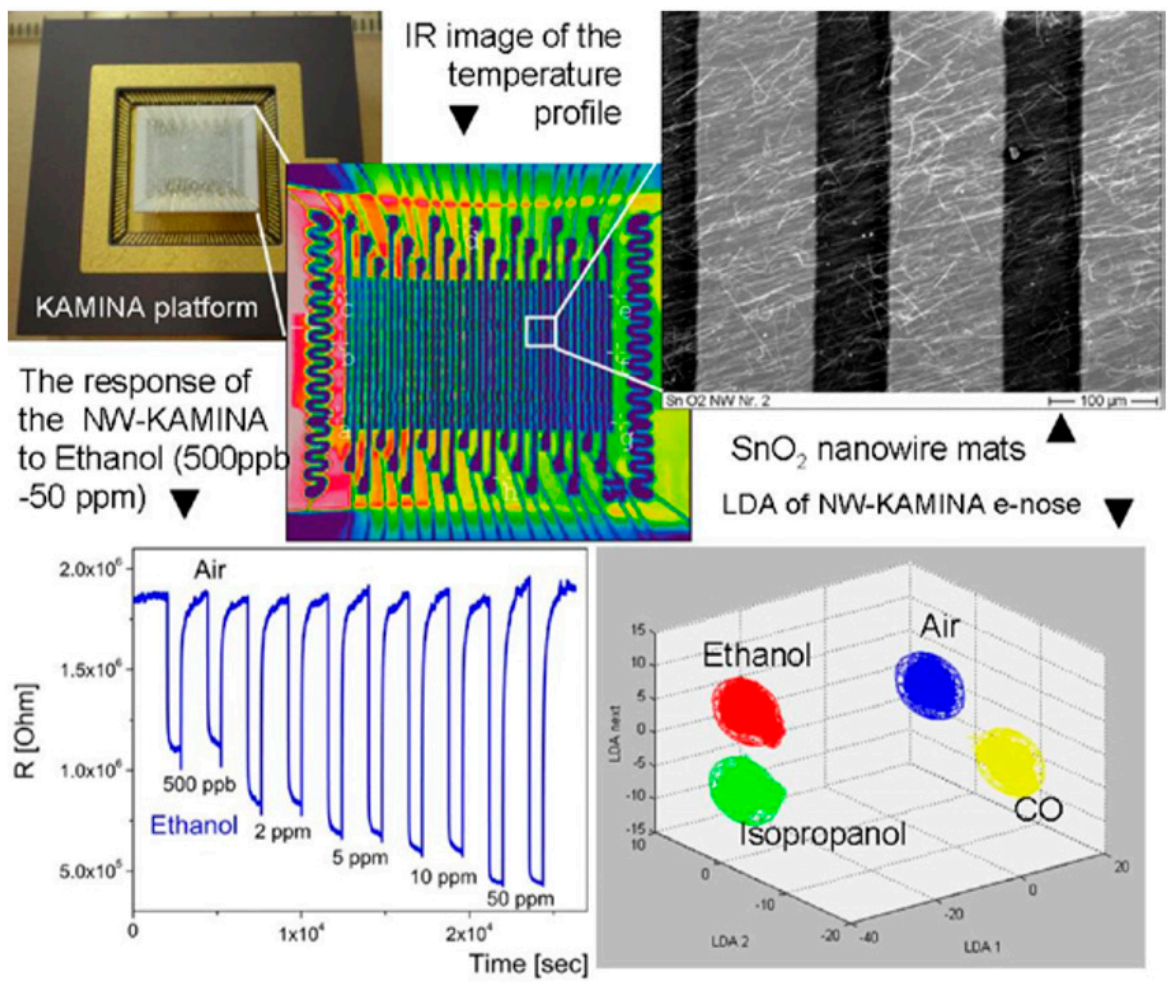

Figure 10. A demonstration of the KAMINA e-nose system performance with $\mathrm{SnO}_{2}$ nanowires as a sensing media. Reproduced with permission from Sysoev et al. [213]. Copyright 2007: American Chemical Society.

\subsection{Features of the Fabrication of Gas Sensors Based on Individual 1D Structures}

As follows from previous discussions, most processes used to synthesize a one-dimensional structure are incompatible with the electrical characterization of individual nanostructures. For this purpose, an additional processing is required to remove the nanowires, nanobelts, or nanotubes from their growth substrate and then place them onto a platform that allows studying single wires and using them as a sensing element. Thus, one of the most important problems in the manufacturing of 1D structure-based sensors is their integration with electrodes [7]. An electrical contact to the sensors based on single 1D structures is often realized using a "pick and place" approach. 1D structures are first dispersed into solvents such as methanol, ethanol, isopropanol, or water in very low concentrations (Figure 11). Then, a drop of dilute suspension of 1D structures is placed on a substrate and dried [226,227]. The substrate with 1D structures are then located under an optical microscope or SEM, and the contacts are made using various methods. For example, markers are made on the substrate before applying the suspension of 1D structures, so that the position and angle of the nanowires regarding electrodes can be controlled by SEM observation. Then, a lift-off process or deposition through the mask is applied to pattern metallic contacts to the nanowires. Thereafter, 1D structures are subjected to annealing for better adherence to the electrode material. The stages of manufacturing these sensors are shown in Figure 12. This method is suitable for studying fundamental properties of the nanowires. However, it is a complicated and costly method and, therefore, not suitable for mass production of gas sensors. In some other cases, as shown in Figure 11, the metal electrodes are made before applying the nanowire to the substrate [228,229]. However, the successful placement of nanowires between the pre-fabricated electrodes requires good luck. In addition, the contact barriers between the electrodes and the nanowires are usually very high, which makes the method irreproducible and unsuitable for many device applications where low resistive contacts are required. 


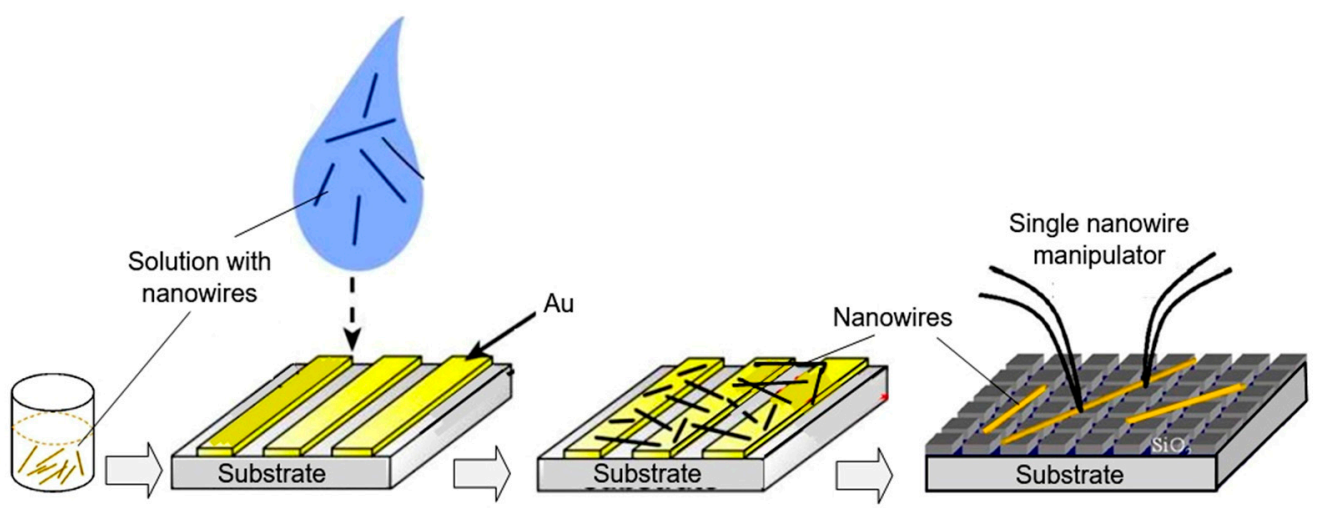

Figure 11. Illustration of the process of transferring 1D structures to the surface of the substrate: Nanowires are removed into a suspension of the solvent. A drop of the nanowire solution is dispersed on a template substrate and evaporated under a vacuum. Finally, nanowires with manipulator tips can be moved from a template substrate to the right place.

Undoubtedly, 1D structures can be moved to the right place using special manipulators [230] (Figure 11). For example, Li et al. [231] suggested using electrostatic forces for this. Jimenez-Diaz et al. [232] for these purposes used the AC dielectrophoretic manipulation of nanowires [228,229]. A solution, containing nanowires, is dropped on the top of the electrode array. The nanowires are aligned along the direction of an electric field. Different species such as a nanowire or contaminant species will respond to different frequencies of an AC bias. Therefore, applying an AC bias with a corrective frequency offers the advantage of selectively choosing nanowires from other contaminant species in the solution [233]. Such an approach to the formation of contacts to one-dimensional structures has several advantages, since its implementation both allows one-dimensional structures to be correctly positioned in a given place of the substrates, and can significantly reduce the manufacturing time of the sensor [232]. However, the mentioned above approaches are very laborious and require special equipment. In addition, in many cases, the transfer is possible for either too small or too large nanowires. This means that sensors based on such large nanowires will have low sensitivity. Therefore, as a rule, in order to simplify the technology of manufacturing sensors, nanowires, after application to the substrate, are preferred not to be exposed to any additional displacements.

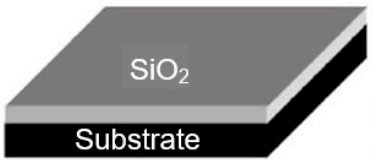

(a)

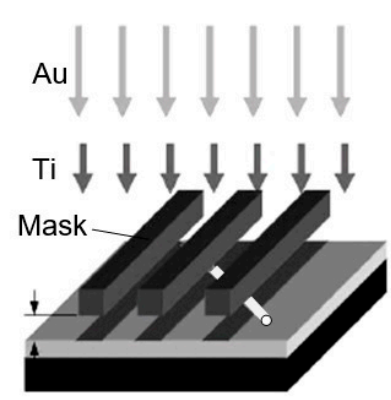

(c)

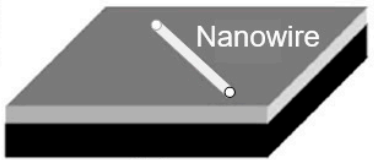

(b)

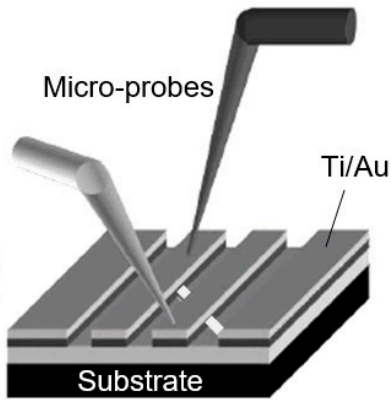

(d)

Figure 12. Protocol for a resist-free fabrication of 1D metal oxide nanowire-based chemiresistors and chemFETS: (a) Pristine $\mathrm{Si} / \mathrm{SiO}_{2}$ wafer; (b) nanostructures placed on wafer mechanically; (c) shadow masking to determine metal contacts; (d) microprobes can be used to explore transport and sensing properties of the individual nanoresistors. Idea from [234]. 
Currently, metal strips with clearly defined shapes in the nanometer range and a high electrical quality, shown in Figure 13, are easily manufactured using various techniques such as focused ion beam (FIB) [158,159,230,235] (Figure 12), focused electron beam (FEB) [230,235], ultraviolet and shadow-mask lithography [236], and shadow mask sputtering [210,213]. Shadow mask sputtering (see Figure 12c) enables fast engineering of advanced proof-of-concept devices. However, metallic contacts directly deposited over the nanowire bundles are unstable and do not guarantee the formation of a continuous metallic layer, thus inhibiting the direct bonding of nanowires and a good electron transport. Electrical contacts, fabricated using, for example, focused ion or electron beams, are much better.

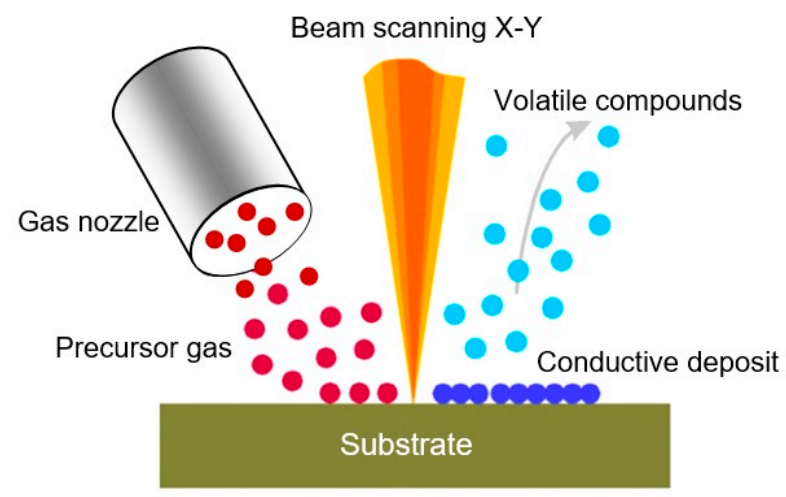

Figure 13. Schematic representation of local deposition, assisted by the focused ion beam (FIB). The gas precursor introduced by the capillary is decomposed by the secondary electrons generated by the interaction of the primary ion beam with the target. Reproduced with permission from Gierak [237]. Copyright 2009: Institute of Physics.

The Focused Ion Beam (FIB) is a powerful technology developed in the late 1970s and early 1980s to create a pattern, and then, to deposit materials with a resolution in the range of tens of $\mathrm{nm}$. This technique is widely used in circuit editing, mask repairing, microsystem technology processes, and material characterization [237-239]. The basic principle of this technique is a focused ion beam of high-energy particles that scans the sample's surface and sputters the material on the exposed area [240]. The scanning can be performed, similarly to a SEM, using electrostatic lenses and, thus, the milling occurs without the need of masks. Currently, gallium $\left(\mathrm{Ga}^{+}\right)$ions accelerated to $30 \mathrm{kV}$ are the most used particles in the FIB technique. Gallium is a metallic element with a low melting temperature. This feature of Ga makes it possible to fabricate a durable, high-brightness, and reliable source of metal ions (LMIS) required in the FIB technique. In addition, the element gallium is located in the center of the periodic table; therefore, its momentum transfer ability is optimal for a wide range of materials. In contrast, lighter elements would be less efficient in milling heavier elements.

On the other hand, if a metalorganic compound is introduced in the beam path using the so-called microneedle-based gas delivery system, the decomposition of this compound occurs due to the interaction of the compound with both secondary electrons and ions that originated during the $\mathrm{Ga}^{+}$ion bombardment (Figure 13). Part of the compound after decomposition can be deposited on the sample's surface (ion-assisted deposition) or can reactively assist the milling process (gas assisted etching), while the other part is removed by a vacuum system. Thus, conductive and isolating materials can be easily deposited using the FIB with a nanometer accuracy $[237,241]$.

Many types of precursor gases can be used in the FIB for the manufacture of various metal and ceramic structures. For example, the precursor gases $\mathrm{WF}_{6}$ (or $\mathrm{W}(\mathrm{CO})_{6}$ ), $\mathrm{C}_{7} \mathrm{H}_{7} \mathrm{~F}_{6} \mathrm{O}_{2} \mathrm{Au}$ (or $\mathrm{AuClPF}_{3}$ ), $\left(\mathrm{CH}_{3}\right)_{3} \mathrm{NAlH}_{3}, \mathrm{C}_{9} \mathrm{H}_{16} \mathrm{Pt}, \mathrm{Cr}\left(\mathrm{C}_{6} \mathrm{H}_{6}\right)_{2}$, and $\mathrm{TMOS}+\mathrm{O}_{2}(\mathrm{TMOS}=$ tetramethyloxysilane $)$ were used to produce $\mathrm{W}, \mathrm{Au}, \mathrm{Al}, \mathrm{Pt}, \mathrm{Cr}$, and $\mathrm{SiO}_{2}$ layers, respectively [242]. Although the purity of the deposition is usually lower compared with conventional methods of deposition (usually the layer deposited using the metalorganic decomposition is contaminated with other elements such as oxygen or carbon from 
the background gas in the vacuum chamber, and elements that form the ion beam), the main advantage of this technique is its flexibility due to direct recording capabilities without using any masks [237,240].

However, it is important to note that the ion bombardment necessary to decompose the metalorganic precursor for fabricating nanocontacts can produce the damage in the nanowires [243,244]. Therefore, Hernandez-Ramirez et al. [230] believed that the development of the so-called dual or cross-beam systems (conventional FIB with a scanning electron microscope (SEM)) is very promising. This approach, enabling the in situ capture of electron images and simultaneous dissociation of metalorganic compounds with secondary electrons (SE), generated by the incident electron beam, can significantly facilitate the use of FIB nanolithography during gas sensor fabrication [188,245-247]. Taking into account the fact that the interaction between electrons and the sample is less destructive than using ions, the electron-assisted deposition of metals can avoid both undesired surface damage and structure modification of the nanomaterial that occur during the formation of electrical contacts on the nanostructure. Despite its advantages, the electron and ion-beam combination during deposition is sparsely used, and therefore, detailed studies of the quality of electrical contacts, formed by this method, with a purpose to avoid false interpretations of the electrical properties of nanowires, caused by the influence of contact resistance, are required [248].

It is seen that the discussed above techniques are not scalable and do not meet the requirements necessary for the transition to commercialization. A typical view of the device based on the individual nanowire is shown in Figure 14. It is seen that sensors with this configuration are really difficult to implement using methods developed for mass production. The mentioned above approaches to sensor fabrication are suitable only for research and development of prototype devices. However, device prototypes are not intended for the market. For this reason, the problem of the scalability of 1D structure-based sensors and 1D structure-based electronic circuits is one of the main ones when considering the prospects for the emergence of these devices on the market. Several approaches were developed for resolving this problem. They include self-assembly of 1D structures [249,250], roll-transfer printing [251], and microcontact/ink-jet printing [252,253]. In the self-assembly approach, metal oxide 1D structures are deposited directly by a high-voltage-driven injection nozzle onto the electrodes. During printing, the metal electrodes are precisely placed on top of the 1D structures. However, all these fabrication techniques are still in a preliminary stage of development, despite some promising results that have recently been reported [254-261].

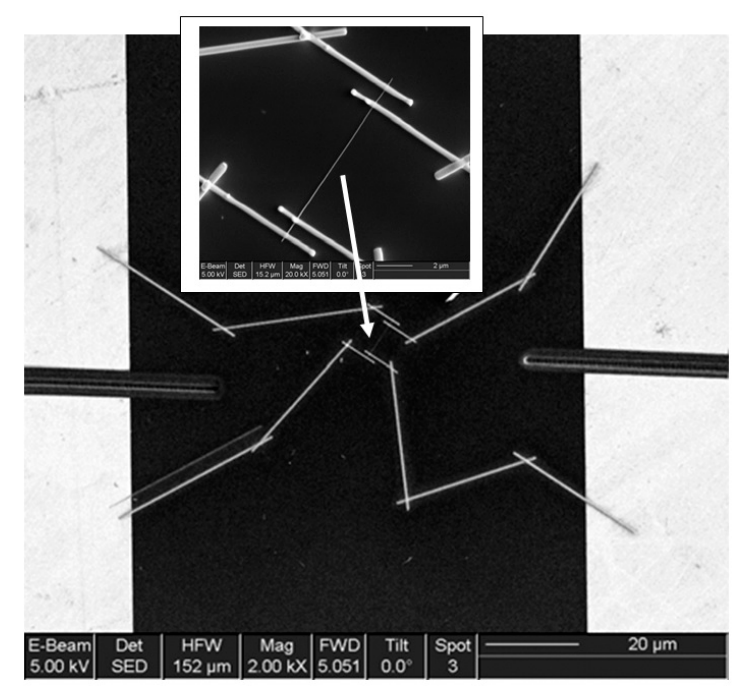

Figure 14. General view of the final device based on the $\mathrm{SnO}_{2}$ individual nanowire (dimensions: $\mathrm{L}=11 \mu \mathrm{m}$ (length) and $\mathrm{D}=55 \pm 5 \mathrm{~nm}$ (diameter)) with $\mathrm{Au} / \mathrm{Ti} / \mathrm{Ni}$ microelectrodes. The position of the contacted NW is indicated by the arrow. Reproduced with permission from Hernandez-Ramirez et al. [159]. Copyright 2007: Elsevier. 


\subsection{Limitations of Technology Based on Individual 1D Nanostructures}

\subsubsection{Nanowires Alignment}

As mentioned earlier, at the first stage of the study of 1D nanostructures, most designers believed that the use of single crystalline individual nanowires (NWs) as a gas sensing material would significantly improve the parameters of gas and vapor sensors [129,149,150]. However, it turned out that the controlled separation, manipulation, and characterization of 1D nanostructures are not straightforward processes due to the intrinsic problems of working at the nanoscale. These procedures are complex and require well-established methodologies, which are not yet fully developed. In this regard, many attempts have been made to simplify this process. In particular, several techniques have been developed to allow the alignment or orientate 1D structure assemblies. It turned out that for these purposes one can use micro fluidics, electrostatic or magnetic fields, surface pre-pattering, self-assembly, and templating. These approaches, which allowed the design of gas sensor prototypes, were comprehensively considered in [219,249,262-269]. The advantages and disadvantages of the mentioned above methods of nanowires alignment are briefly summarized in Table 3.

As an example, in Figure 15 a diagram is shown, illustrating a method based on micro fluidics [270]. By flowing a stream of fluid across a substrate surface, nanowires can be reoriented towards the flow direction and become quasi-aligned. Parallel nanowire arrays are achieved by flowing a nanowire suspension inside the microchannel with a controlled flow rate for a set duration. The degree of the alignment can be controlled by the flow rate: The angular distribution of the nanowires narrows substantially with the increasing flow rates. The nanowire density increases systematically with the flow duration. The crossed nanowire arrays can be obtained by alternating the flow in orthogonal directions in a two-step flow assembly process. The important feature of this layer-by-layer assembly scheme is that each layer is independent of the others and, therefore, a variety of homo- and hetero-junctions, including p-n junctions, can be obtained at the crossed points. The weakness of this technique is that the area for nanowires alignment is limited by the size of the fluidic microchannels. It will be more difficult to establish a uniform shear force in a large channel.

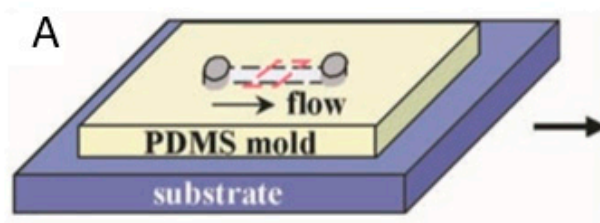

B

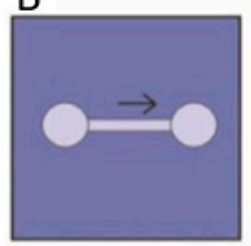

First layer

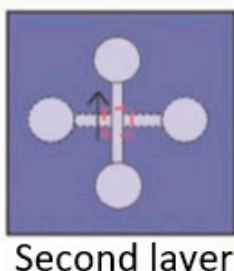

Second layer

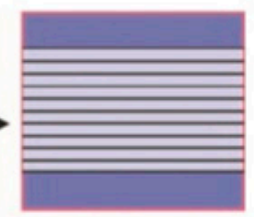

Parallel array
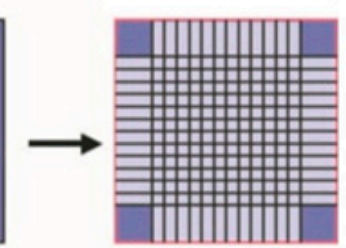

Crossed array

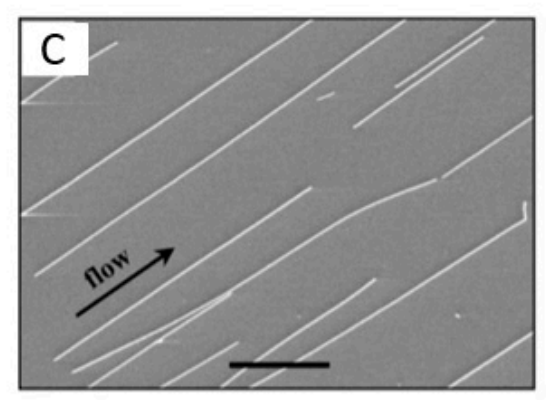

Figure 15. Schematic of fluidic channel structures for flow assembly: (A) A channel formed when the polydimethylsiloxane (PDMS) mold was brought in contact with a flat substrate. The NW assembly was carried out by flowing a NW suspension inside the channel with the controlled flow rate for a set duration. Parallel arrays of NWs are observed in the flow direction on the substrate when the PDMS mold is removed. (B) The multiple crossed NW array can be obtained by changing the flow direction sequentially in a layer-by-layer assembly process. (C) SEM image of the parallel assembly of NW arrays formed using the micro fluidics method. Reproduced with permission from Huang et al. [270]. Copyright 2001: AAAS. 
Table 3. Summary of the NW assembly technologies.

\begin{tabular}{|c|c|c|}
\hline $\begin{array}{l}\text { NW Assembly } \\
\text { Technologies }\end{array}$ & Advantages & Disadvantages \\
\hline $\begin{array}{l}\text { Flow-assisted alignment in } \\
\text { microchannels }\end{array}$ & $\begin{array}{l}\text { (1) parallel and crossed NW arrays } \\
\text { can be assembled; } \\
\text { (2) compatible with both rigid and } \\
\text { flexible substrates. }\end{array}$ & $\begin{array}{l}\text { (1) area for NW assembly is } \\
\text { limited by the size of fluidic } \\
\text { microchannels; } \\
\text { (2) difficult to achieve a very high } \\
\text { density of NW arrays; } \\
\text { (3) NW suspension needs to be } \\
\text { prepared first. }\end{array}$ \\
\hline Bubble-blown technique & $\begin{array}{l}\text { (1) area for NW assembly is large; } \\
\text { (2) compatible with both rigid and } \\
\text { flexible substrates. }\end{array}$ & $\begin{array}{l}\text { (1) it is difficult to achieve } \\
\text { high-density NW arrays; } \\
\text { (2) NW suspension needs to be } \\
\text { prepared first. }\end{array}$ \\
\hline Contact printing & $\begin{array}{l}\text { (1) area for NW assembly is large; } \\
\text { (2) high-density NW arrays can be } \\
\text { achieved; } \\
\text { (3) parallel and crossed NW arrays } \\
\text { can be assembled; } \\
\text { (4) direct transfer of NW from the } \\
\text { growth substrate to the receiver } \\
\text { substrate; } \\
\text { (5) compatible with both rigid and } \\
\text { flexible substrates; } \\
\text { (6) NW assembly process is fast. }\end{array}$ & $\begin{array}{l}\text { (1) the growth substrate needs to } \\
\text { be planar; } \\
\text { (2) the process works best for long } \\
\text { NWs. }\end{array}$ \\
\hline Differential roll printing & $\begin{array}{l}\text { (1) area for NW assembly is large; } \\
\text { (2) high-density NW arrays can be } \\
\text { achieved; } \\
\text { (3) direct transfer of the NW from } \\
\text { the growth substrate to the } \\
\text { receiver substrate; } \\
\text { (4) compatible with both rigid and } \\
\text { flexible substrates; } \\
\text { (5) NW assembly process is fast. }\end{array}$ & $\begin{array}{l}\text { (1) the growth substrate needs to } \\
\text { be cylindrical; } \\
\text { (2) the process works best for long } \\
\text { NWs. }\end{array}$ \\
\hline $\begin{array}{l}\text { Langmuir-Blodgett } \\
\text { technique }\end{array}$ & $\begin{array}{l}\text { (1) area for NW assembly is large; } \\
\text { (2) high-density NW arrays can be } \\
\text { achieved; } \\
\text { (3) parallel and crossed NW arrays } \\
\text { can be assembled; } \\
\text { (4) compatible with both rigid and } \\
\text { flexible substrates. }\end{array}$ & $\begin{array}{l}\text { (1) NWs typically need to be } \\
\text { functionalized with the surfactant; } \\
\text { (2) the assembly process is slow } \\
\text { and has to be carefully controlled; } \\
\text { (3) NW suspension needs to be } \\
\text { prepared first. }\end{array}$ \\
\hline $\begin{array}{l}\text { Electric field-assisted } \\
\text { orientation }\end{array}$ & $\begin{array}{l}\text { (1) NWs can be placed at a specific } \\
\text { location; } \\
\text { (2) compatible with both rigid and } \\
\text { flexible substrates; } \\
\text { (3) NW assembly process is fast. }\end{array}$ & $\begin{array}{l}\text { (1) patterned electrode arrays are } \\
\text { needed; } \\
\text { (2) area for NW assembly is } \\
\text { limited by the electrode patterning; } \\
\text { (3) NW density is limited; } \\
\text { (4) it works the best for conductive } \\
\text { NWs; } \\
\text { (5) NW suspension needs to be } \\
\text { prepared first. }\end{array}$ \\
\hline
\end{tabular}

Source: Reproduced with permission from Liu et al. [267]. Copyright 2012: American Chemical Society.

The Langmuir-Blodgett technique is another NW assembly technology (see Figure 16). According to this technique, when a solid surface is vertically dipped into a liquid containing a Langmuir monolayer and then pulled out properly, the monolayer (Langmuir-Blodgett (LB) film) will deposit homogeneously onto the surface. Usually this technique is used for preparing thin organic monolayers. However, the LB layer of metal oxide nanowires can also be formed. To implement 
this method, metal oxides must meet the following requirements: (i) They must be soluble in water-immiscible solvents, and (ii) they must be able to form stable floating monolayers at the surface of the sub-phase with an internally oriented, cohesive, and compact structure that are sheer resistant. To meet these requirements, the nanowires used to form LB films are usually functionalized by the surfactants. Without functionalization, the nanowires do not form stable suspensions in the organic solvents and sink into water. A nanowire-surfactant monolayer is initially formed on a liquid (usually water) surface in an LB trough. The formed nanowire monolayers resemble a microscopic version of "logs-on-a-river". The monolayer of the aligned nanowires is then transferred onto a substrate through vertical-dipping (i.e., LB) or horizontal-lifting (i.e., Langmuir-Schaefer (LS)) techniques. The spacing between the parallel nanowires can be adjusted by the lifting speed and by the pressure of the monolayer compression.

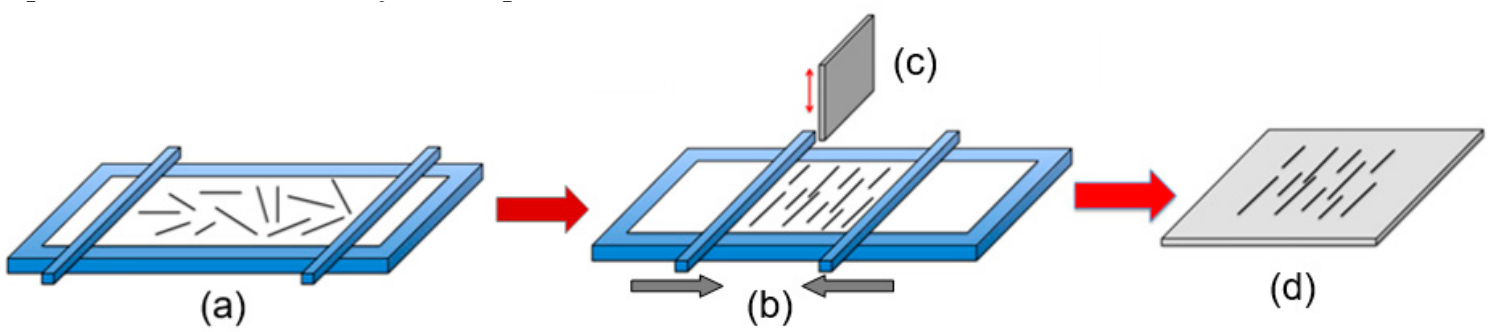

Figure 16. Schematic diagram of the Langmuir-Blodgett technique for NWs alignment. (a) Random nanowires suspended in the Langmuir-Blodgett trough; (b) monolayer compression; (c) wafer being pulled vertically from the suspension in parallel with the lateral motion of the barrier; (d) resulting parallel nanowire array on the substrate.

The features of the roll printing technique and contact printing technology are shown in Figures 17 and 18, respectively.

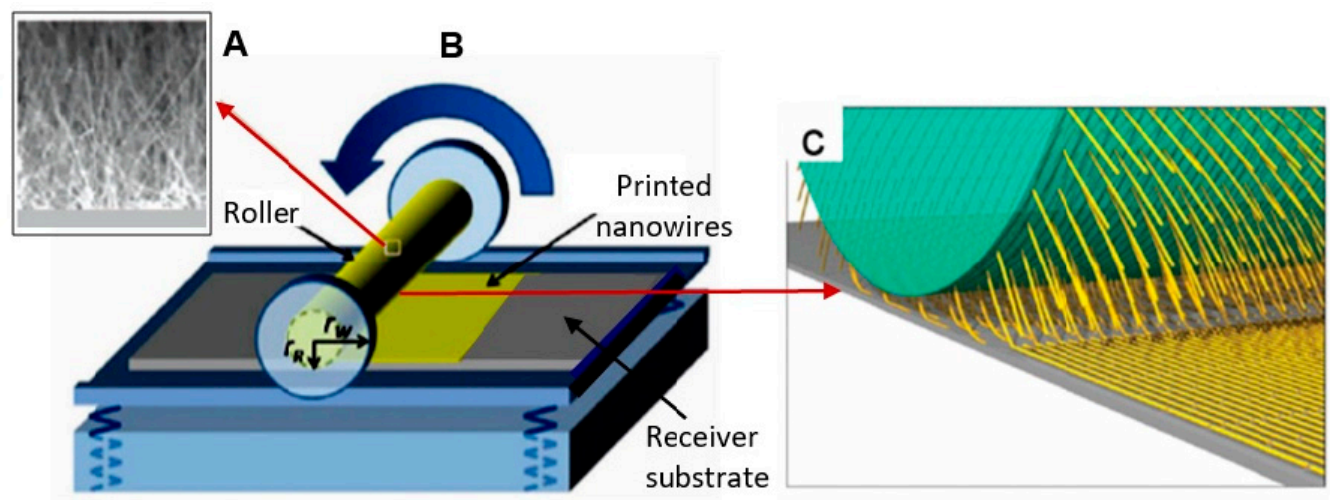

Figure 17. Schematic diagram illustrating the roll printing technique for NWs alignment: (A) SEM image of NWs grown perpendicularly to the surface of the cylindrical substrate; (B) installation for NWs alignment; $(\mathbf{C})$ the mechanism of a nanowire transfer. The NWs are oriented and transferred to the receiving substrate by applying a directional shear force, resulting in the printing of sub-monolayer parallel NW arrays on the receiving substrate. Reproduced with permission from Hu et al. [269]. Copyright 2020: Royal Society of Chemistry. 


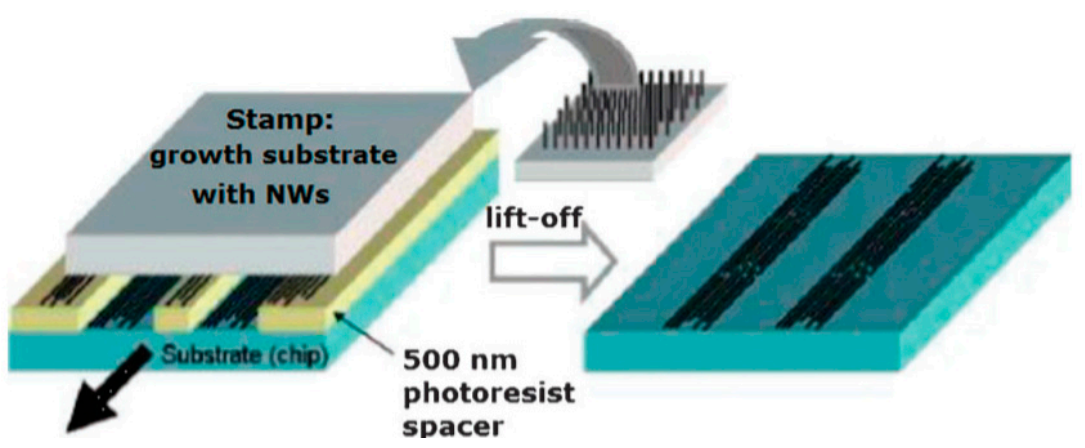

Figure 18. Contact printing of NWs from a growth substrate on a prepatterned substrate. In general, NWs are grown perpendicularly to substrate with a random orientation, but they can be well-aligned by shear forces during the printing process. Reproduced with permission from Javey et al. [271]. Copyright 2007: Royal Society of Chemistry.

In regards to the orientation of nanowires in an external electric field, this effect is caused by the fact that all metal and semiconductor nanostructures have a dielectric constant that differs from that of the surrounding medium (air or liquid). The resulting image forces produce a rotational moment, causing the nanostructure to align in the direction of the electric field. Ruda and Shik [272] showed that the alignment depends dramatically on the relationship between the nanowire length $L$, separation between electrodes $a$, and electrode width $b$, as well as on the nanowire dielectric constant $\varepsilon$ compared to that of environment $\varepsilon_{0}$.

However, it must be recognized that all fabrication routes, developed for nanowires alignment, are not perfect processes and do not apply to fully completed technologies. Moreover, the listed techniques work with an array of 1D nanostructures, and they do not guarantee the fixation of individual 1D structures in the required place. Thus, the use of 1D nanostructures in real devices is still at a preliminary stage and needs a breakthrough in order to integrate them with low-cost industrial processes $[149,267,269,273]$.

\subsubsection{Sensor Performances}

The low sensitivity of most individual 1D-based sensors in comparison with conventional nanocrystallite-based sensors can also be attributed to the shortcomings of these devices. As in polycrystalline sensors, the sensitivity of 1D-based sensors depends on the diameter of nanowires or nanobelts (see Figure 16); the smaller the diameter, the higher the sensitivity $[128,158,159,274]$. The experiment and simulation have shown that in order to achieve a maximum response, the NW radius must be compared with the Debye length $\left(L_{D}\right)$. For example, Hernandez-Ramirez et al. [158,159] found that in real 1D $\mathrm{SnO}_{2}$ structures the Debye length is $\sim 10-15 \mathrm{~nm}$ and, therefore, the performance of nanowire sensors can be significantly improved only if the diameter of the nanowires is less than $25 \mathrm{~nm}$. However, as a rule, nanowires used for gas sensor fabrication have a diameter in the range of 50-900 nm, while the grain size in polycrystalline-based sensors does not exceed 10-30 nm. Research carried out by Li et al. [126,154] and Zhang et al. [155] confirmed this conclusion. They established that an extremely low detection limit was achieved for $\mathrm{In}_{2} \mathrm{O}_{3}$ and $\mathrm{ZnO}$ nanowires with a diameter of only $10 \mathrm{~nm}$. Unfortunately, currently nobody wants to work with individual nanowires with a size less than 30-50 nm $[128,158,159,275,276]$. Firstly, the controlled growth of very thin nanowires and the fabrication of devices based on such nanostructures is still an experimental problem [108,277]. Secondly, separation and manipulation of such small objects is too difficult [158,159]. In addition, there are technological difficulties with the growth of such thin nanowires $(d<10 \mathrm{~nm})$ with a longer length. However, if the nanowire is short, the length of nanowires can be insufficient to create a bridge between two bonding pads on the measuring platform [276].

Kolmakov et al. [278] have found that one of the most promising solutions to this problem is the fabrication of a single-crystal quasi-1D chemiresistor with one (or a few) very thin segments, 
which adheres to the $r \sim L_{D}$ condition, where $r$ is the radius of the nanowire in this place. Since the narrow segment(s) will control the electron transport and sensing performance, such a device would have all the advantages of ultra-thin single crystal nanowires (see Figure 19). Studies carried out by Dmitriev et al. [274] showed that the narrow segments serve as ideal "necks," as observed between particles in conventional polycrystalline thin film gas sensors, but provide the significant advantages of greater morphological integrity and stability. Reports of the methodology of the segmented oxide nanowire (SN) controllable growth via a programmable change in the local vapor supersaturation ratio $\left(\mathrm{Sn}_{x} \mathrm{O}_{y}(x, y=1,2 \ldots)\right)$ in the vicinity of the wires during their vapor solid growth have been published in [278]. This is an interesting but complicated approach to the manufacture of 1D-based sensors.

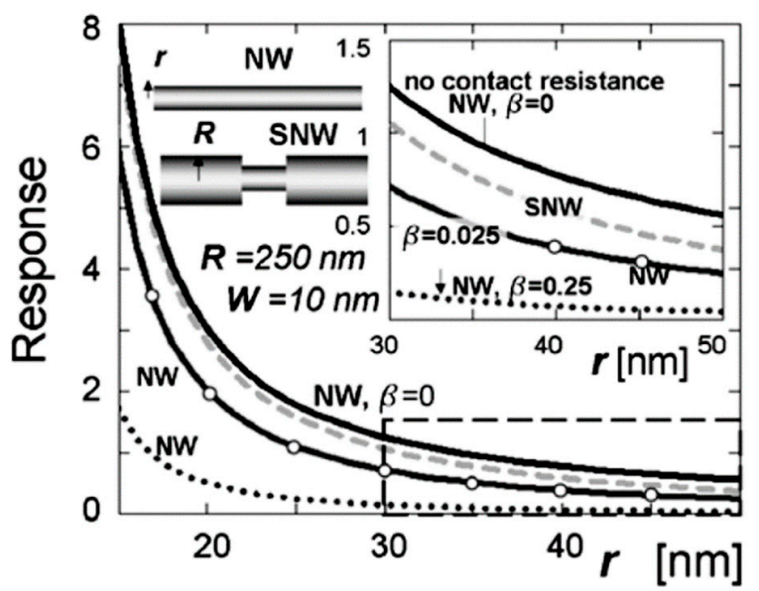

Figure 19. The response of straight and segmented nanowires as a function of their radius at various contact resistances $(b=0,0.025,0.25)$. For segmented nanowires (SNWs), the curve is drawn versus the radius of the smaller segment. The solid curve (top) corresponds to the nanowire with no contact resistance; the dashed curve corresponds to the SNW with thick segments of a $500 \mathrm{~nm}$ diameter and $b=0.025$; the solid curve marked with circles corresponds to the SNW with $b=0.025$; the dotted curve corresponds to the SNW with $b=0.25$. The depletion width is $\sim 10 \mathrm{~nm}$ at all cases. Reproduced with permission from Dmitriev et al. [274]. Copyright 2007: Institute of Physics.

According to Kolmakov [108], the segmentation of NWs can also be organized using approaches such as:

- increased amount of defects and, therefore, increased scattering of the carriers in a selected area;

- lateral inhomogeneity in doping and, therefore, formation of Schottky-like junctions along the length of the nanowire; and

- narrowing of the conductive channel of the nanowire as a result of sputtering.

The creation of a reliable low-resistance electric contact with such thin nanowires is also an essential problem $[273,279]$, since the quality of the contacts directly influences the performance of the sensors. The reduced contact area between metal electrodes and NWs increases the contribution of the electrical properties of the contact in the results of nanowire characterization, which may hide the phenomena occurring on the NW surface due to the interaction with a gas environment $[158,230,244,280,281]$. Therefore, Ebbesen et al. [243] and Hernandez-Ramirez et al. [230] believed that in order to reduce the influence of contacts on sensor readings, it is necessary to use a four-probe contacts configuration of the sensors (see Figure 20a). It is also necessary to monitor the dissipated power on the contacts in the process of testing. Even with powers exceeding $1 \mu \mathrm{W}$ of heat dissipation, local heating is possible, which can originate many physical problems related to material diffusion, transformation, and fusion, that must be avoided to ensure nanosensor stability. Figure 20b shows the final electrical breakdown consequence of this phenomenon. Hernandez-Ramirez et al. [158] have also noted that before arrival to this failure state, the electrical characteristics drifted and showed a strong degradation 
and non-repeatability. Comini et al. [5] believed that the exact technical difficulty, connected with the fabrication of reliable low-resistance electrical contacts on individual 1D nanostructures, is one of the reasons, limiting the number of works on this topic.
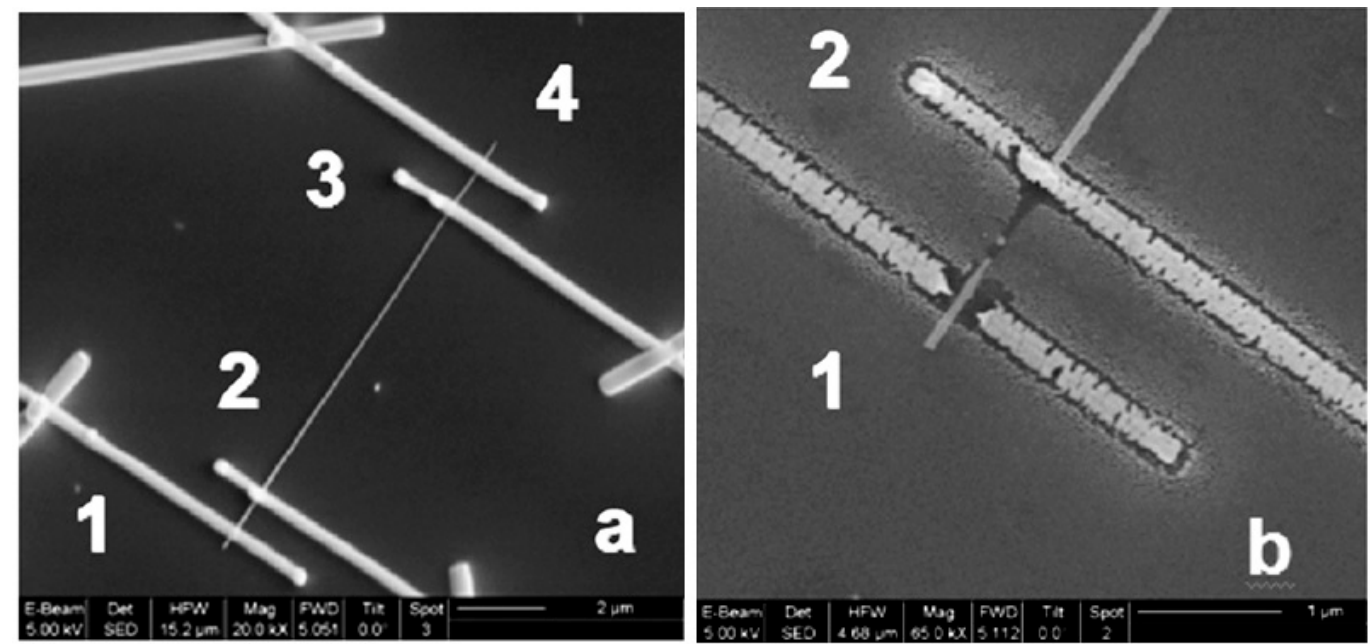

Figure 20. (a) A fabricated FIB four-probes contacted $\mathrm{SnO}_{2}$ nanowire and (b) a detail of the contact after an electrical failure likely caused by the excess of heat dissipation in the contacts. Reproduced with permission from Hernandez-Ramirez et al. [159]. Copyright 2007: Elsevier.

\subsubsection{Stability and Reproducibility}

It should be noted that despite the seemingly indisputable advantages of 1D structures for the development of gas sensors with increased stability, the problem of thermal instability of 1D structures cannot be neglected. If we analyze the results confirming the increased stability of sensors based on 1D structures compared to conventional metal oxide gas sensors (see for example, Figure 19), we will see that all statements, regarding an experimental confirmation of the better stability of the 1D structure-based gas sensors, relate to sensors fabricated using nanowires with the diameter significantly exceeding crystallite sizes in polycrystalline metal oxides. For example, the results presented in Figure 21 were obtained for nanowires with a diameter of 200-900 nm and nanocrystallites with a diameter of $\sim 4 \mathrm{~nm}$.
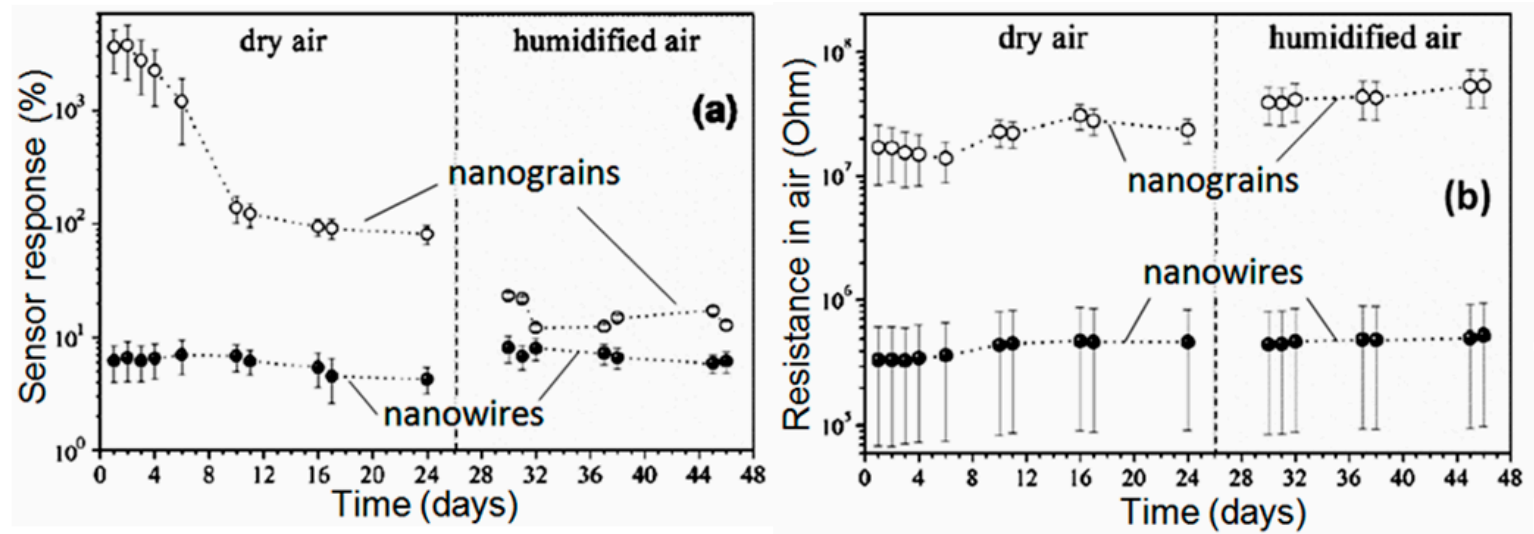

Figure 21. The change of sensing characteristics of the median sensor segment of a $\mathrm{SnO}_{2} 3 \mathrm{D}$ mesoporous nanoparticle (NP) or nanograins (NG) layer and nanowire (NW) mat versus measurement day: (a) Sensitivity or response to 1 ppm of 2-propanol vapors; (b) background resistance in air. Open and filled circles correspond to the NP and NW samples, respectively. Reproduced with permission from Sysoev et al. [129]. Copyright 2009: Elsevier. 
Unfortunately, at present, as we mentioned above, nobody wants to work with individual 1D structures with a characteristic size of less than 20-30 nm [128,158,159,275,276]. Of course, in the future, attempts will be made to increase the response of $1 \mathrm{D}$-based gas sensors by reducing the diameter of the nanowire. In this case, we must be prepared for the fact that if we have the opportunity to fabricate sensors based on nanowires with a diameter of less than 10-15 nm, it is quite possible that we will also face the problem of reducing the stability of these devices. For example, studies carried out on the basis of metal and semiconductor nanowires, showed that $1 \mathrm{D}$ structures with a characteristic size in the range of 10-20 $\mathrm{nm}$ are also unstable [109,282-286]. With a decrease in the diameter of nanowires their melting temperature drops sharply, just as in the case of nanocrystallites [287,288]. For example, the melting of a Ge nanowire with a diameter of $55 \mathrm{~nm}$ begins at a temperature of about $650{ }^{\circ} \mathrm{C}$, while the melting point of bulk Ge is $930{ }^{\circ} \mathrm{C}$ [282]. Given the tendency of thin nanowires to be cut due to melting at a relatively low temperature, we must recognize that sensors, in which such a phenomenon is possible, cannot be considered devices with increased stability. This limitation, undoubtedly, should be taken into account during the analysis of the prospects of 1D structures using conductometric gas sensors developed for operation at elevated temperatures. This limitation may be especially relevant in the development of self-heating sensors [102], where even small variations in the diameter of nanowires and contact resistance or the uncontrolled increase in the current can cause local heating to temperatures close to or above the melting temperature $\left(T_{\mathrm{m}}\right)$. One should also to take into account that due to the nonlinearity of the $\mathrm{I}(\mathrm{V})$ characteristics and because of the reducing resistance of nanowires during the interaction with reducing gases, the Joule power dissipated by the nanowire can be increased even under a constant bias voltage [289]. These processes form a positive feedback and, therefore, they can ultimately destroy the nanowire resistor. This effect is usually observed for metal and highly doped semiconductor nanowires with moderate melting points [290,291].

The instability associated with surface diffusion of the electrode material along the nanowire and the migration of surface clusters used for surface functionality can also be significantly increased; 1D structures do not contain edges and stages, which can serve as particle pinning centers that hinder the diffusion of noble metal clusters on the surface of metal oxide supports.

The reproducibility of the parameters of the 1D nanostructure-based gas sensors should also be improved [273]. Due to the sample to sample variation (see Figure 22), it is very difficult to produce individual 1D structure-based gas sensors with identical parameters. A small change in the size and shape of 1D structures leads to a sharp change in electrophysical, electronic, and surface properties, which will undoubtedly be accompanied by a significant change in sensor performances. However, this is unacceptable for the sensor market. All sensors must have the same parameters.

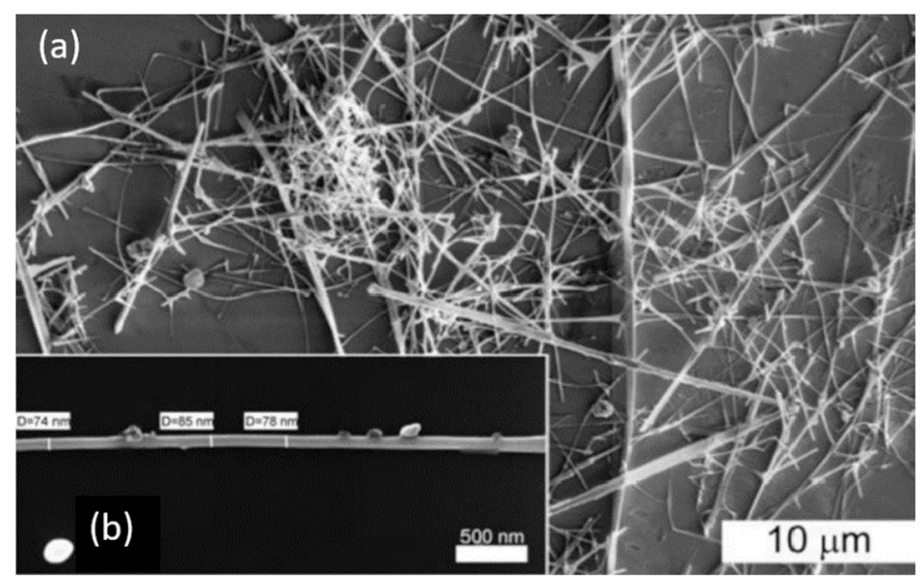

Figure 22. (a) $\mathrm{SEM}$ image of $\mathrm{SnO}_{2}$ nanowires after the synthesis using the gas transport method based on the vapor-liquid-solid (VLS) mechanism, and (b) SEM image of a single $\mathrm{SnO}_{2}$ nanowire. Reproduced from Shaposhnik et al. [292]. Published by Beilstein Sci. as open access. 
The lack of technology for the synthesis of well-controlled one-dimensional structures with an industrial-scale production rate is also a significant limitation [130]. However, the hydrothermal method can be considered as a potential scale-up method for the synthesis of 1D nanomaterials.

There are also difficulties in growing the 1D structures, faceted by crystallographic planes with more unsaturated metal cations. As previously shown, these planes can provide maximum sensitivity for gas sensors. Gao and Zhang [183] noted that the controlled synthesis of metal oxide nanomaterials with exposed high-energy facets is a difficult task since facets with a high surface energy usually grow rapidly and eventually vanish. Although there have been several successful cases, there is still a lack of understanding of the growth mechanism of high-energy facets. More in-depth research should be carried out to investigate the mechanism and find out viable synthesis methods. There are also questions regarding the long-term stability of high-energy facets during the gas sensing process. High-energy crystal surfaces are extremely active. Therefore, it is unclear how long a gas-sensitive metal oxide-based 1D nanostructure with exposed high-energy facets can remain active and exhibit excellent performance?

\subsection{How to Improve 1D Structure-Based Gas Sensors}

\subsubsection{Sensors Based on 1D Structures Array}

The study showed that the application of an array of 1D nanostructures, placed in the form of monolayer mats (see Figure 23a), allows the use of a standard thick-film technology for gas sensor fabrication. It also gives the opportunity to eliminate many of the technological difficulties associated with the manufacture of 1D nanostructure-based sensors and makes it possible to already realize now a number of indisputable advantages of 1D nanostructures usage in gas sensors. That is why this approach is currently the most common in the manufacture of gas sensors based on 1D nanostructures [213]. However, in this case, such gas sensors do not have a fundamental difference from traditional polycrystalline sensors manufactured by the thick-film technology. Impedance spectroscopy studies showed that the gas-sensing mechanism for sensors on the base of networked 1D nanowires involves changes in both the nanowire resistance, and the resistance of inter-nanowire interface [293]. This situation is shown in Figure 23b. The only advantage of such sensors is a large porosity, that is, the better gas permeability of the sensing layer and, as a result, faster response.

(a)

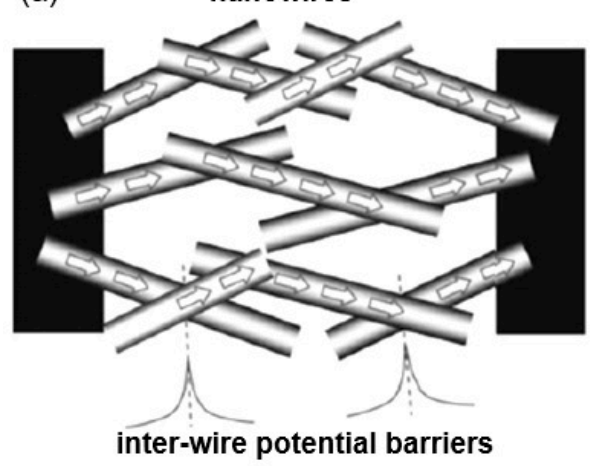

(b)

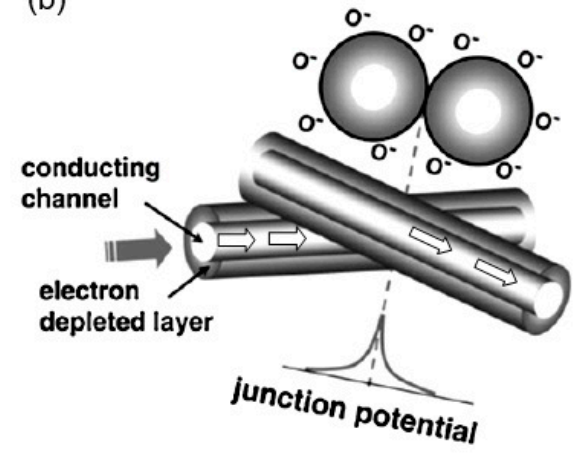

Figure 23. (a) Schematic diagrams for multi-nanowire-based chemical sensors; (b) schematic illustration of the gas sensing mechanism in a network of nanowires. Reproduced with permission from Vomiero et al. [294]. Copyright 2007: American Chemical Society.

Nanowires can be converted to a gas sensitive layer using several methods. The 1D metal oxide NWs mat can be converted to a gas sensitive layer using several methods. Deposition of a slurry containing NWs onto the electrodes and subsequent heat treatment is the simplest method to fabricate the gas sensor [295-297]. However, in this case, the use of transfer media, in most cases liquid, poses potential harm to the unique properties of the nanowires, such as surface reactivity. As is known, 
the surface cleanliness of a nanowire is crucial for gas sensor performances. This means that the reduction or elimination of post-processing of the nanowires during gas sensor fabrication is the best solution of this problem. In this regard, the integration of nanowires into devices by the direct growth of nanowires in the required place of the substrate has an obvious advantage over transfer methods. In this case, the mat-type films can be prepared by simply pressing long NWs grown on a substrate. However, both these methods do not provide a reproducible deposition of the NW network onto a defined area, especially in cases where the gas-sensitive layer must be formed on a sub-millimeter-scale or micrometer-scale area [296]. In addition, the sensor stability against vibrational environments can be deteriorated due to the poor adhesion between the NWs and the electrodes.

The direct growth of oxide NWs on metal or metal oxide electrodes can be an alternative method for manufacturing well-defined metal oxide NWs-based gas sensors [153,294,298]. A strong adhesion between the NWs and electrodes significantly improves not only the electrical contacts between the NWs and electrodes, but also the operation stability against mechanical vibration. In addition, highly miniaturized sensors can be fabricated by the selective growth of NWs within a defined area. Below we will consider these methods in more detail. However, to begin with, we note that the functional arrays of various metal oxide nanowires could be synthesized using either the template-free method or template-assisted strategy. The template-free synthesis provides a fast enough growth of $1 \mathrm{D}$ nanostructure arrays of a big group of metal oxides, suitable for chemical sensors, such as $\mathrm{ZnO}, \mathrm{Ga}_{2} \mathrm{O}_{3}$, $\mathrm{TiO}_{2}$, and $\mathrm{In}_{2} \mathrm{O}_{3}$. Their growth is controlled by adjusting process parameters such as the temperature, process duration, and the type and the concentration of the precursor. In contrast, the template-assisted method, due to the possibility to control the template geometry and pattern distribution, could be more effective in adjusting the morphology and size of nanostructures (length, density, and diameter). The patterned templates as a unique mask could also endow the ability to define the shape and the position of nanoarrays. However, it must be borne in mind that the template-assisted method has limitations on growing nanowires with a minimum diameter. The template-free method is free from this drawback. However, when using the template-free method, due to not using the uniform growth, poor control over the density and distribution of NWs is observed; 1D structures can have a wide variation in their geometric parameters such as length, thickness, or diameter. This significantly limits the possibility of manufacturing sensors with reproducible parameters.

\subsubsection{Sensors with Vertically Oriented Nanomaterials}

One of the progressive approaches to the fabrication of gas sensors, based on 1D structures array, involves growing parallel NWs or nanotubes on the substrates in the perpendicular direction to the surface (see Figure 24). In this case, although the 1D structures array is used, this configuration makes it possible to realize the advantages of the sensors characteristic of devices based on individual 1D nanostructures. In [106,299,300], the application of this approach to the development of devices from $\mathrm{TiO}_{2}$ nanotubes was described. This technique is similar to the manufacture of thin films, but promises higher accuracy in making the columnar nano-elements. Contacts can also be made using electrochemical deposition methods [279].
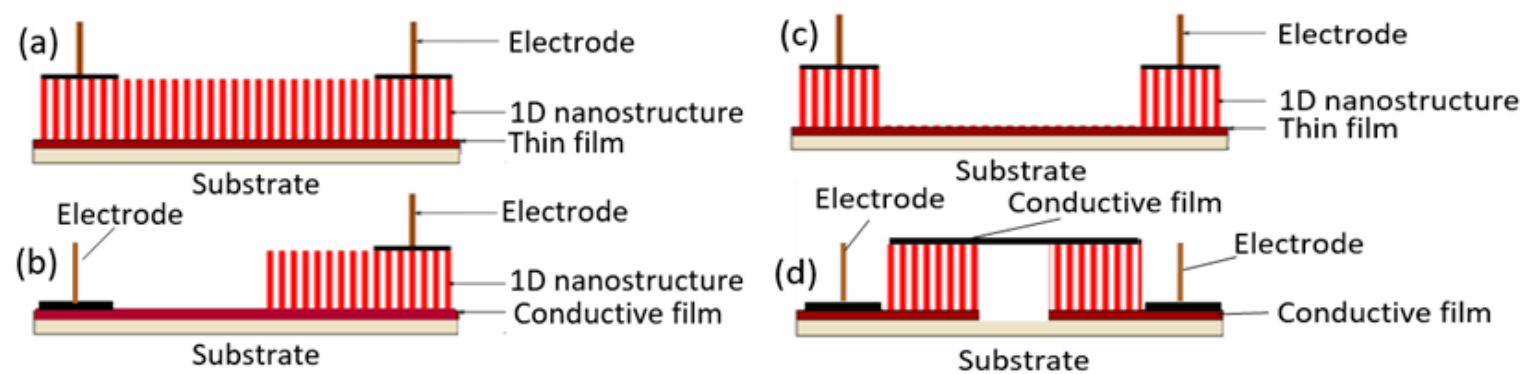

Figure 24. (a-d) Schematic diagrams for a multi-nanowire-based sensor with nanotubes, nanowires, or nanorods oriented in a perpendicular direction. 
A description of other approaches to the formation of vertically oriented nanomaterials as applied to $\mathrm{ZnO}$ can be found in [219,301-303]. For example, such structures can be created using template-assisted techniques, such as filling the membrane pores of porous silicon or anodized alumina [304,305]. This template-based method for nanowire array fabrication provides a low cost technology acceptable for large-area processes. This approach is one of the feasible techniques to form well-defined lateral or vertically oriented nanowires arrays, since it is easy to form electrodes to selected nanowires. However, as a rule, nanowires, grown using the template-based method, are polycrystalline and, in principle, do not apply to the nanomaterials considered in this article. As we indicated earlier, in this article we consider single-crystal 1D nanostructures.

The view of vertically oriented NWs really related to 1D nanomaterials is shown in Figure 25c. The method, developed by Wei et al. [302] for growing vertically oriented ZnO NWs, combines a laser interference pattering technique and hydrothermal synthesis. A hole array is fabricated on the surface of the substrate through laser pattering. The NWs are then formed from these holes in a mixed growth solution, containing $\mathrm{Zn}\left(\mathrm{NO}_{3}\right)_{2}$ and hexamethylenetetramine $\left(\mathrm{HMTA},\left(\mathrm{CH}_{2}\right)_{6} \mathrm{~N}_{4}\right)$ by using a hydrothermal method (Figure 25a,b). However, in order to look this way, NWs must have a diameter much larger than $500 \mathrm{~nm}$, which does not contribute to the high sensitivity of gas sensors made on their basis. With a smaller diameter, vertically oriented nanowires do not look so perfect. In particular, Figure 26 demonstrates vertically aligned $\mathrm{ZnO}$ nanowires directly synthesized on fluorine-doped tin oxide-coated substrates using the Chemical Vapor Deposition (CVD) method. Moreover, even in this case, the diameter of nanowires was quite large. The top and bottom diameters of the needle-shaped $\mathrm{ZnO}$ nanowires were around $100 \mathrm{~nm}$ and $1 \mu \mathrm{m}$, respectively [306].
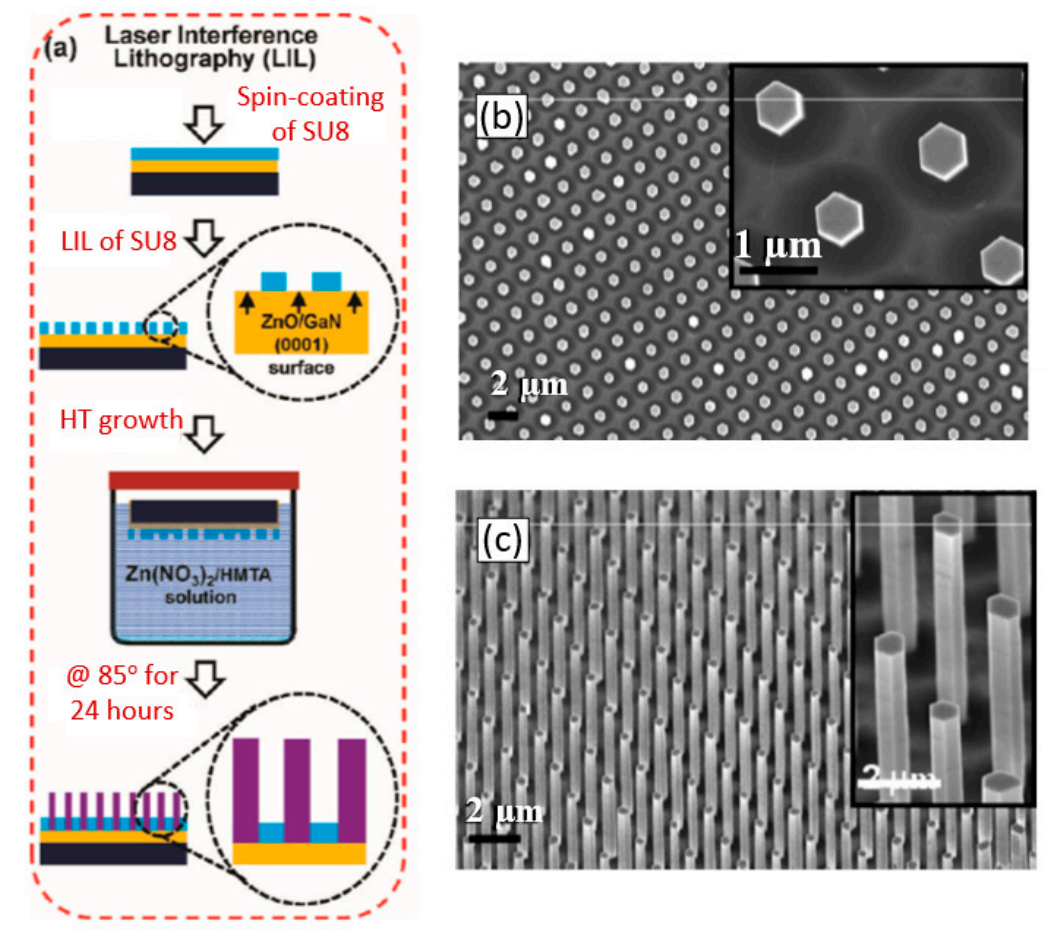

Figure 25. (a) Schematics of the fabrication sequences of vertically aligned $\mathrm{ZnO} \mathrm{NW}$ arrays using laser interference lithography (LIL); (b) optical image of a 2 in. Si wafer with a SU-8 open-hole pattern over the whole surface area. The iridescence dispersion demonstrates the excellent periodicity over the entire wafer surface. (c) The top-view SEM image of the patterned SU-8 film (thickness of $500 \mathrm{~nm}$ ). Inset, the top-view SEM image of the patterned SU-8 film at higher magnification. The area encircled by the black dashed line is the exposed surface of the substrate. Reproduced with permission from Wei et al. [302]. Copyright 2010: American Chemical Society. 
However, in reality, based on 1D nanowires vertically grown without any template, it is difficult to implement the structures shown in Figure 24. The main difficulty lies in the formation of contacts to the top of vertically grown nanowires. The deposition of a metal film by physical vapor deposition, will not work as the metal seeps through the voids between the NWs and shorting with the bottom electrode. Several approaches have been proposed to form such contacts. For example, to eliminate the shorting with the bottom electrode, the NWs can first be embedded in a dielectric layer such as a polymer (see Figure 27). Then, planarization is performed to obtain NWs of the desired length. After etching the polymer with purpose to expose the tips of the NWs, a metal film is deposited on top as a contact pad. The experiment has shown that oxygen plasma etching is the best method for polymer etching and NWs cleaning. After metal deposition, the polymer is completely removed and frees the NWs to interact with the atmosphere [307,308]. As we can see, this is a rather long and laborious process.

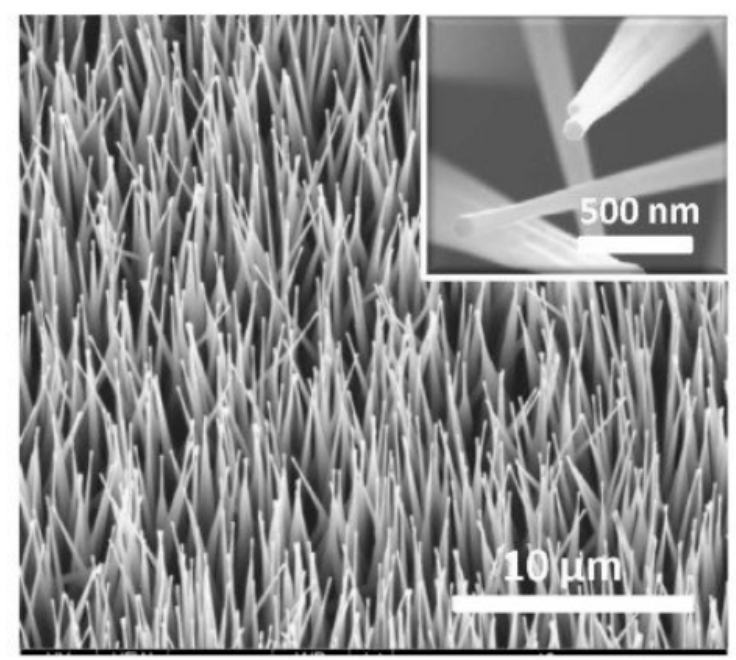

Figure 26. FESEM image (tilted at $15^{\circ}$ ) of a directly synthesized vertically aligned $\mathrm{ZnO}$ nanowire array on a fluorine-doped tin oxide (FTO) substrate. The inset is a higher-magnification image. Reproduced from Lu et al. [306]. Published by Springer as open access.

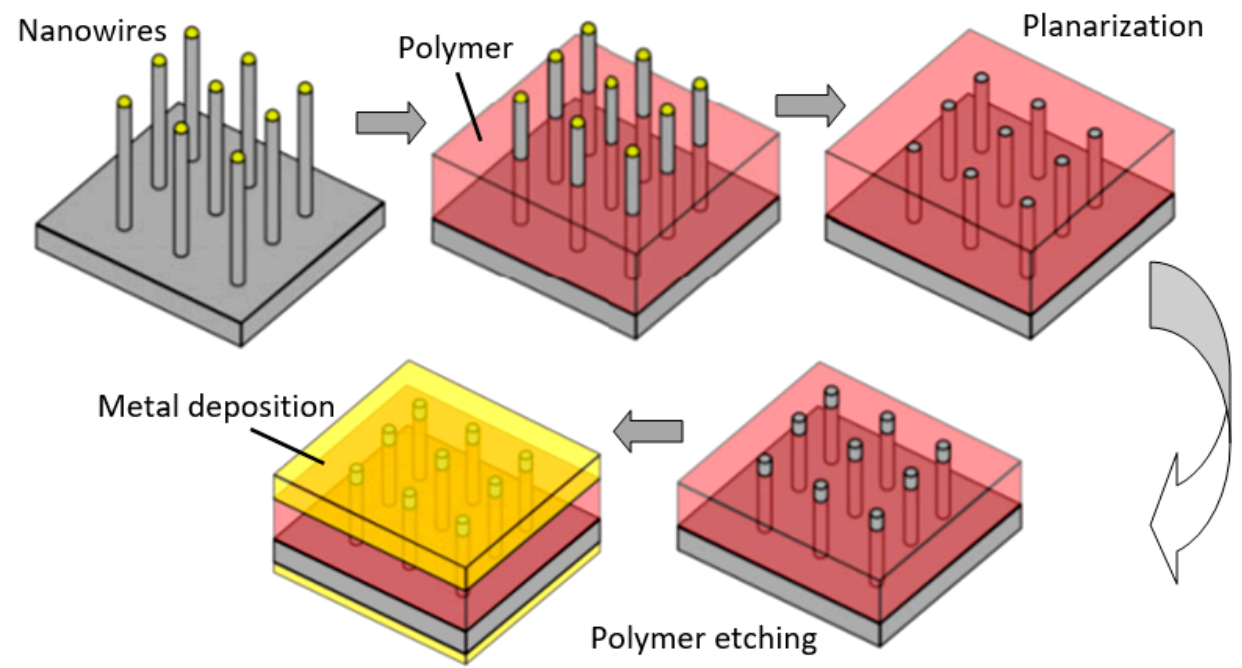

Figure 27. Schematic illustration of the contact forming on the top of vertically grown NWs.

In order not to use any treatments that affect the surface properties of metal oxides, Parthangal et al. [309] proposed a different approach. An electrical contact with the top of the nanowire array is fabricated by creating a continuous conductive film through the electrostatic attachment of 
conductive gold nanoparticles exclusively onto the tips of nanowires (Figure 28). Au nanoparticles were generated through an aerosol spray pyrolysis method. The droplet-containing flow was passed through dehumidifiers and then into a tube furnace maintained at $600{ }^{\circ} \mathrm{C}$ to thermally crack the precursor and form Au particles. The particles were then positively charged with a home-made unipolar charger and introduced into an electrostatic precipitator containing the substrate with the grown nanowire arrays of $\mathrm{ZnO}$. A high negative electric field of $-10 \mathrm{kV} / \mathrm{cm}$ was applied to drive the particle deposition. Parthangal et al. [309] stated that this assembly approach is suitable for any nanowire array that requires an upper contact electrode. However, we must admit that this method of forming contacts is also not simple and does not provide a good process performance (see Figure 28).
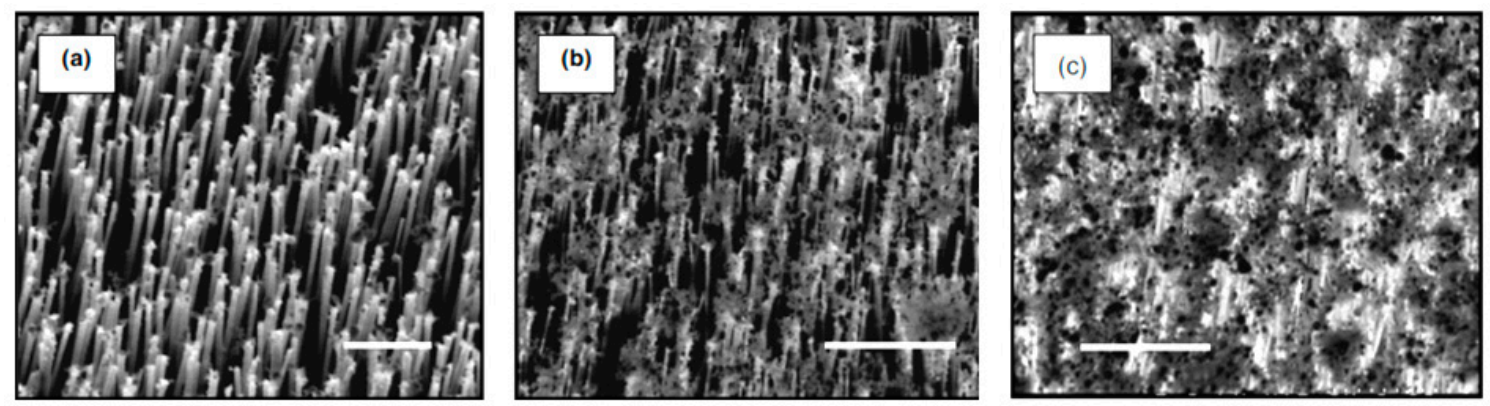

Figure 28. SEM images of Au nanoparticles attached to the tips of the nanowire assembly at different stages of the deposition: (a) $10 \mathrm{~min}$; (b) $1 \mathrm{~h}$; (c) $2 \mathrm{~h}$. Scale bars $=1 \mu \mathrm{m}$. Reproduced with permission from Parthangal et al. [309]. Copyright 2007: Cambridge University Press.

Radha et al. [310] developed another interesting approach to forming contacts to vertically grown nanowires that does not require additional operations. It is schematically represented in Figure 29. To implement it, they used a chemically synthesized single-crystalline Au microplate as the top electrode. The contact is electrically activated, and the formation of the contact is mainly due to electromigration. With this approach, the electrode could ohmically contact several thousand nanowires at once. This method has been developed for InAs nanowires. However, it can undoubtedly be used as applied to metal oxide nanowires, though only for research purposes.

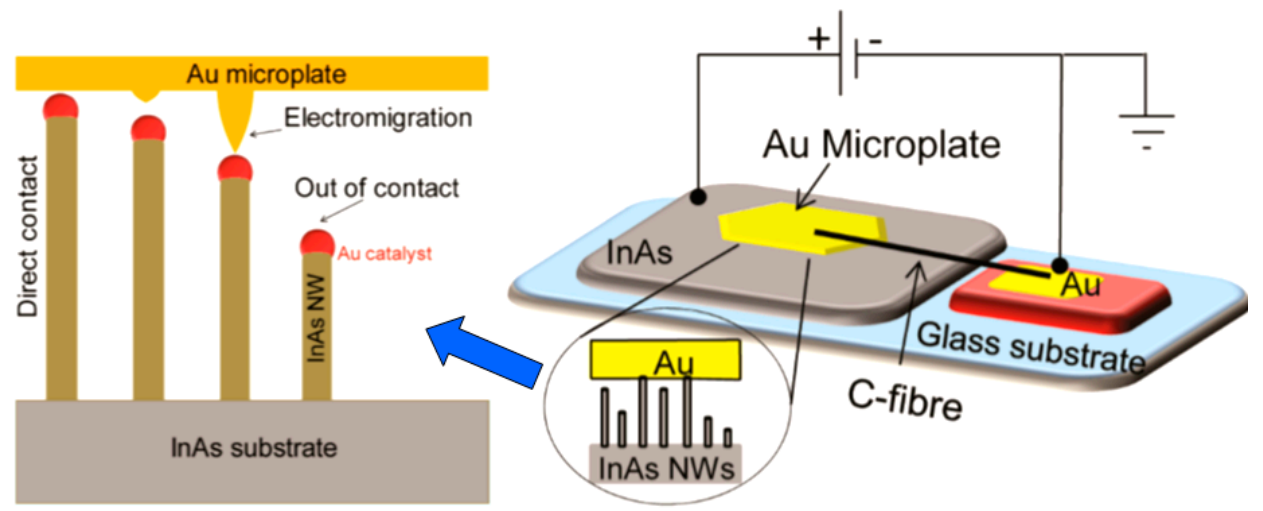

Figure 29. Schematic showing the device configuration of Au microplate/InAs NWs sandwich. Reproduced with permission from Radha et al. [310]. Copyright 2012: American Chemical Society.

The approach proposed by Choi et al. [134] and Ahn et al. [311,312] was also of interest for the gas and vapor sensor design (see Figure 24). Figure 30b,d shows side- and top-view scanning electron microscope (SEM) images of $\mathrm{ZnO}$ nanowires grown on patterned electrodes. $\mathrm{ZnO}$ nanowires, grown only on the patterned electrodes, have many nanowire/nanowire junctions as seen in Figure 30c. These junctions act as an electrical conducting path for electrons. The device structure is very simple and efficient for gas sensitive elements forming, because the electrical contacts to nanowires are 
self-assembled during the synthesis of nanowires. In addition, growing nanomaterials directly onto the sensor chips simplifies the manufacture of sensors. Ahn et al. [311,312] asserted that this method of on-chip fabrication of nanowire-based gas sensors is scalable and reproducible. Furthermore, it integrates stable nanomaterials onto the electrode surface without using any binders for fixing nanomaterials onto the electrodes. A more detailed description of the sensors based on vertically oriented nanomaterials can be found in [220]. It is important to note that this method of manufacturing sensors does not require any manipulation of nanomaterials, and therefore, in their manufacture, one can use the technological modes that allow growing nanowires of a small diameter. This means that sensors manufactured in this way can have very high sensitivity, which was experimentally confirmed [130,219,220,313]. For example, Figure 31 shows the results reported by Yuon et al. [313]. It is seen that sensors really show very high sensitivity. High sensitivity appears to be due to the small area of inter-nanowires contacts. With a sufficiently large diameter of NWs, only the presence of the adsorbate-modulated Schottky barriers [108], formed between individual nanowires, can explain high sensitivity.
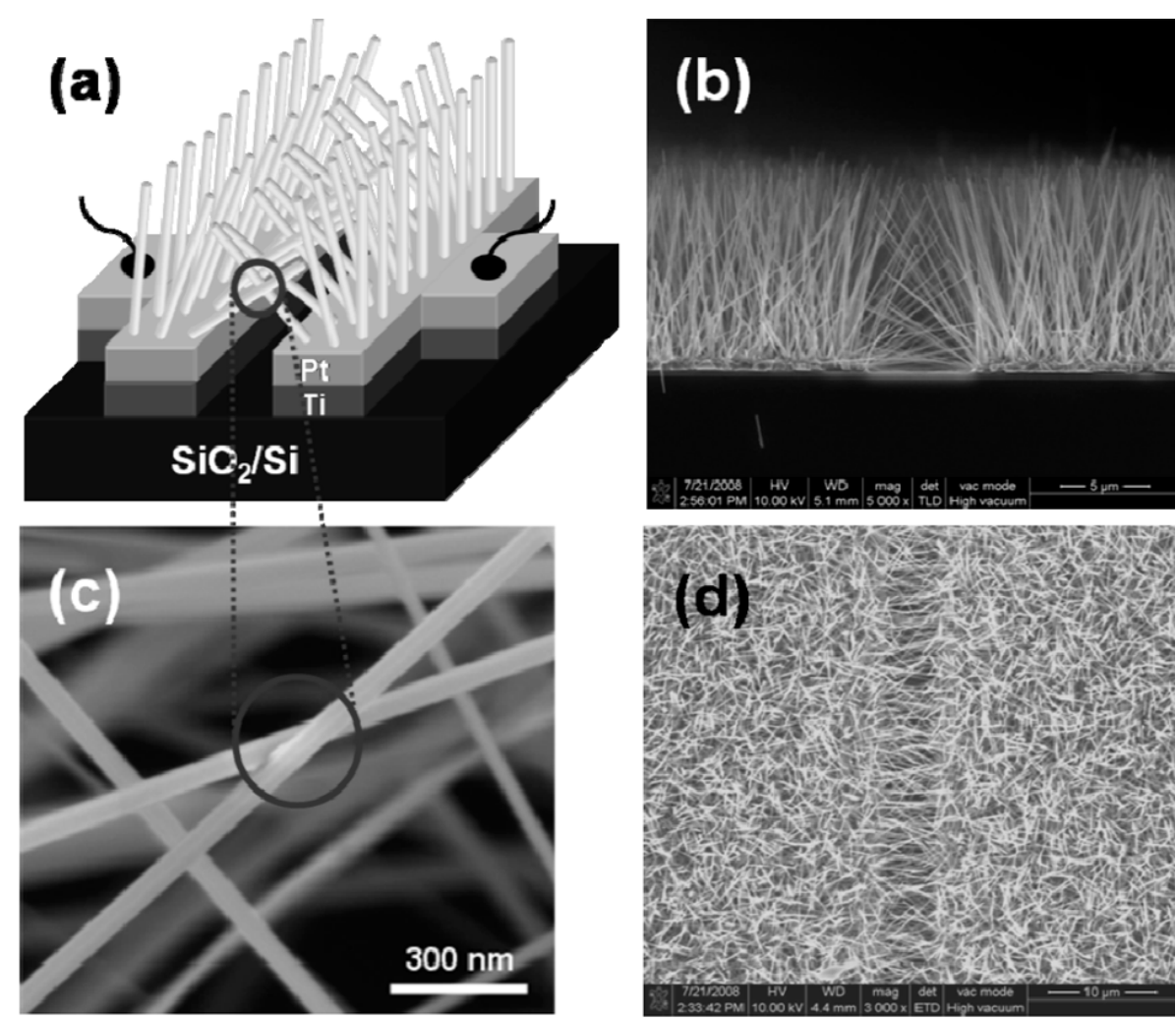

Figure 30. (a) Schematic illustration of $\mathrm{ZnO}$-nanowire air bridges over the $\mathrm{SiO}_{2} / \mathrm{Si}$ substrate. (b) Sideand (d) top-view SEM images clearly show the selective growth of $\mathrm{ZnO}$ nanowires on the Ti/Pt electrode. (c) The junction between $\mathrm{ZnO}$ nanowires, grown on both electrodes. Reproduced with permission from Ahn et al. [312]. Copyright 2009: Elsevier.

However, despite the general progress in on-chip fabrication of metal oxide-based nanomaterials, few of them can be directly grown on substrates/electrodes. In this regard, $\mathrm{ZnO}$ is the best material for these purposes. It should also be taken into account that NWs in such structures can form inter-nanowires contacts without sintering. This means that with any vibration of the sensor, the area and the number of such contacts can change, leading to a change in the basic sensor characteristics. According to McAleer et al. [314], a significant reduction in the number of contacts in the NWs networks, involved in the percolation-dependent transport, compared with polycrystalline metal 
oxides, inevitably should worsen also the stability (thermal, mechanical, and chemical), as well as the overall performance of the devices, fabricated using the indicated approach [108].
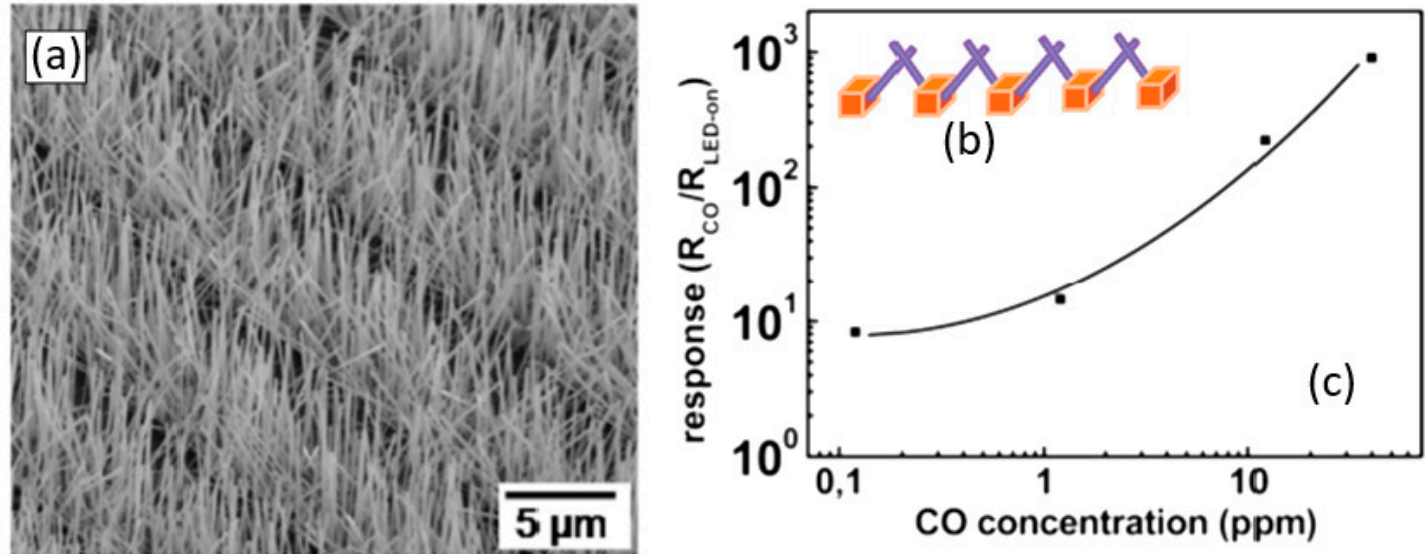

Figure 31. (a) SEM images of $\mathrm{ZnO}$ NWs grown on substrates with the Au electrodes (electrode line width $\times$ gap distance $=3 \times 5 \mu \mathrm{m}$ ); (b) schematic representation of the nanobridge junctions formed and (c) sensor response to the CO gas. Reproduced with permission from Yuon et al. [313]. Copyright 2010: American Chemical Society.

\subsubsection{Sensors with Horizontally Oriented Nanomaterials}

The experiment showed that from the point of view of the stability of sensors parameters, a more reliable configuration is the structure shown in Figure 32, when the nanowires grow and form a bridge between the electrodes, fabricated on the substrate $[163,219,315]$. However, to implement this configuration, NWs should be sufficiently long to create a connection between the two electrodes. Therefore, the distance between the electrodes should be extremely small. This will facilitate both the formation of the bridge and will allow the formation of such bridges using nanowires of a smaller diameter, which is necessary to achieve high sensitivity. Another important step for the NWs growth is the deposition of a catalytic film on the sidewall of electrodes. This step allows the NWs to grow first on the catalytic film and then pass through the trench to the opposite side of the electrode. Unfortunately, it is difficult to control this process, which introduces an element of randomness and uncertainty in the properties of sensors manufactured using this technology.

Additionally, noteworthy is the approach proposed by Kim and Son [316]. They adapted a step edge decoration (SED) method [317], as a bottom-up technique to fabricate a lateral nanowire array (see Figure 33). Using this technique, high quality $\mathrm{ZnO}$ nanowires with a diameter of about $20 \mathrm{~nm}$ and a regular interval of about $80 \mathrm{~nm}$ were fabricated on a sapphire substrate. Gas sensors based on these structures demonstrated a high response to ethanol $\left(S=R_{g} / R_{a} \sim 170\right.$ for $\left.200 \mathrm{ppm}\right)$. Despite the possibility of creating gas sensors based on individual nanowires without using any operations related to their separation and manipulation, this technology is still too expensive for large-scale use.

In this regard, the methods described in [318-320] are more suitable for forming a lateral nanowire array. These methods are based on creating conditions for the growth of nanostructures along the surface of the substrate. For example, the crystallographic property of the substrate should be suitable for the orientation growth of growing NWs along the substrate surface. Using this approach, Nikoobakht et al. [318,319] successfully fabricated horizontally aligned ZnO NWs on an $\alpha$-plane

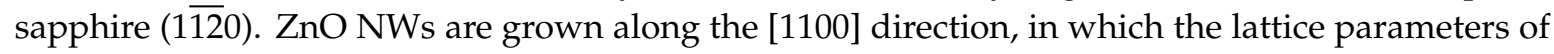
c-plane $\mathrm{ZnO}$ NWs and $\alpha$-plane sapphire are similar. In this architecture, NWs can be grown on the places where the nanodevices could be subsequently manufactured. In this case there is no need to transfer NWs to a different surface or align them. With the use of only three photolithographic steps, this technique allows the industrial-scale production of nanodevices (see Figure 34). First, an $\alpha$-plane sapphire surface is patterned with gold nanodroplets. Next, small-diameter zinc oxide NWs are 
grown selectively on the predefined gold sites. A growth direction of the NWs is controlled using the anisotropic crystal match between zinc oxide and the underlying substrate. Unfortunately, it is very rarely possible to fulfill the condition for horizontal growth, because substrates should exhibit a good lattice mismatch with the growing NWs. This significantly limits the applicability of this method. In addition, the reality is not so good. The method suggested by Qin et al. [321] allows circumventing this limitation. Qin et al. [321] showed that by applying the combined effect of a $\mathrm{ZnO}$ seed layer and a catalytically inactive layer ( $\mathrm{Cr}$ or $\mathrm{Sn}$ ), one can fabricate horizontally aligned $\mathrm{ZnO}$ NWs on various organic and inorganic substrates with single crystal, polycrystalline, and amorphous structures. Wang et al. [322], when this method was employed, fabricated the aligned $\mathrm{SnO}_{2} \mathrm{NWs}$ and showed that gas sensors based on these structures can have a high sensitivity to $\mathrm{NO}_{2}$.
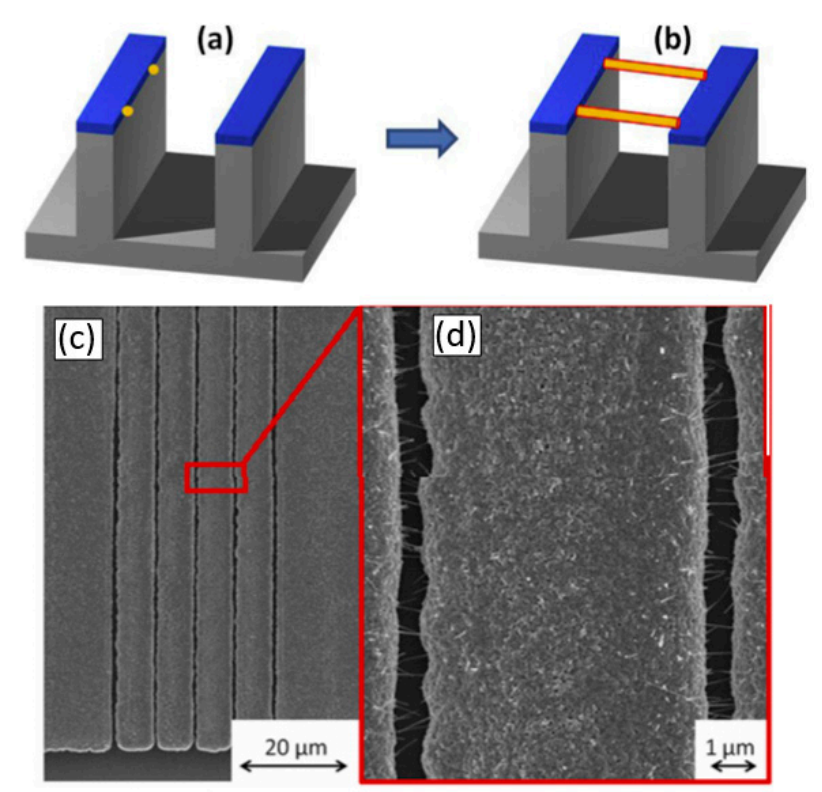

Figure 32. (a,b) Schematic of the bridging NW growth. Reproduced with permission from Huang et al. [219]. Published by Elsevier as open access; (c,d) SEM images of the fabricated CuO NWs-based gas sensor: (c) Low magnification; (d) high magnification. Reproduced with permission from Steinhauer et al. [163]. Copyright 2013: Elsevier.

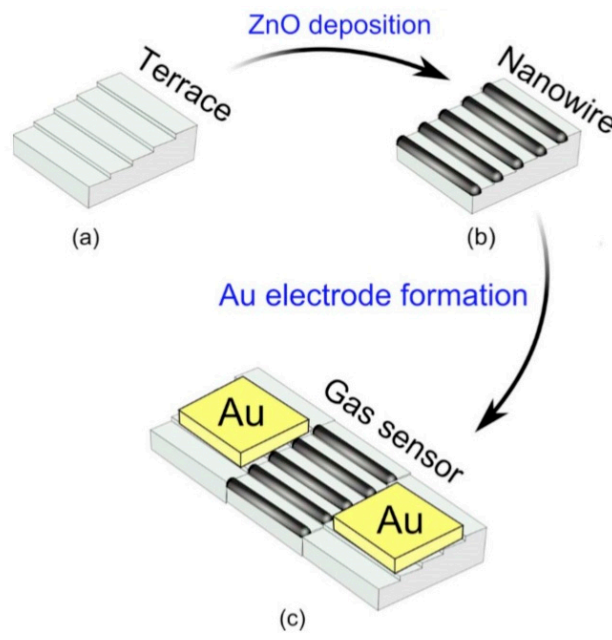

Figure 33. Diagram of the gas sensor fabrication process: (a) Uniform terraces formed on the (0001) sapphire substrate, (b) nanowires growth on the terrace using the laser pulsed layer deposition method, (c) nanowire-based gas sensor on the terrace. Reproduced with permission from Kim and Son [316]. Copyright 2009: Institute of Physics. 

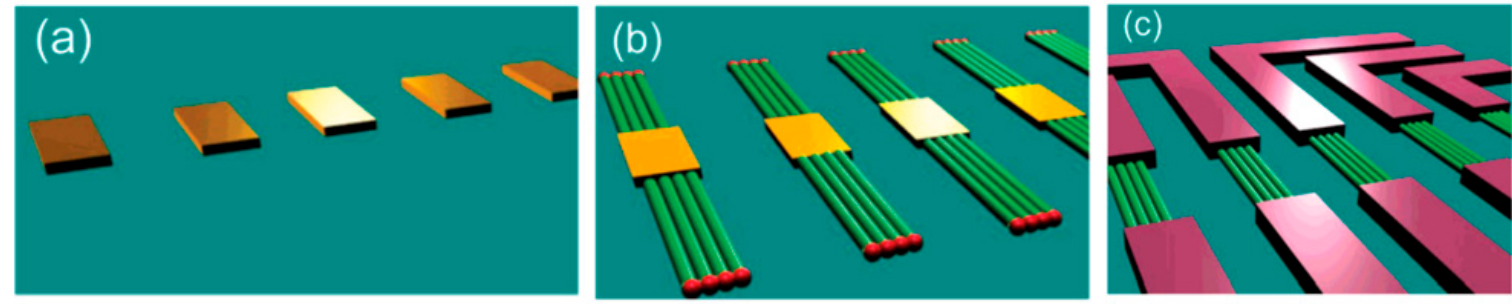

Figure 34. Schematic of the photolithography process for a scalable fabrication of nanowire devices. (a) Gold pads and fiducial marks are deposited on the surface. (b) NWs are grown selectively from the two sides of the gold pads. (c) Metal electrodes and bonding pads are placed exactly on NWs by the alignment of fiducial marks. Reproduced with permission from Nikoobakht [319]. Copyright 2007: American Chemical Society.

\subsubsection{Large-Scale Fabrication of Nanowire Networks-Based Gas Sensors}

As we can see, quite a lot of different methods of direct growth of NWs have been developed to date, allowing the production of 1D nanostructure-based gas sensors. However, to date, a reliable technological route for the production of large-scale gas sensors based on the NW networks for commercial purposes has not yet been developed. Hwang et al. [153] suggested a facile route to fabricate single crystalline $\mathrm{SnO}_{2} \mathrm{NW}$ networks-based gas sensors on a large scale. The $\mathrm{SnO} 2 \mathrm{NW}$ networks were grown on 16 different sensor elements via a single step vapor phase reaction using laser-scribed $\mathrm{Al}_{2} \mathrm{O}_{3}$ substrates with patterned $\mathrm{Au}$ catalyst layers, $\mathrm{Au}$ electrodes, and Pt heaters (Figure 35). NWs were several tens of micrometers long and 30-100 nm thick. Hwang et al. [153] showed that fabricated sensors had high sensitivity and selectivity to $\mathrm{NO}_{2}$ and $\mathrm{C}_{2} \mathrm{H}_{5} \mathrm{OH}$ (see Figure 36). At the same time, they did not show how identical the parameters of all these 16 sensors were. Without this, one cannot talk about a large-scale production. It should be noted that the nanowire networks shown in Figure 35c looks like a loose structure in which the position of the nanowires relative to each other is not fixed. In this situation, doubts arise about the stability of this structure and its electrophysical and gas sensing properties when exposed to an external vibration.
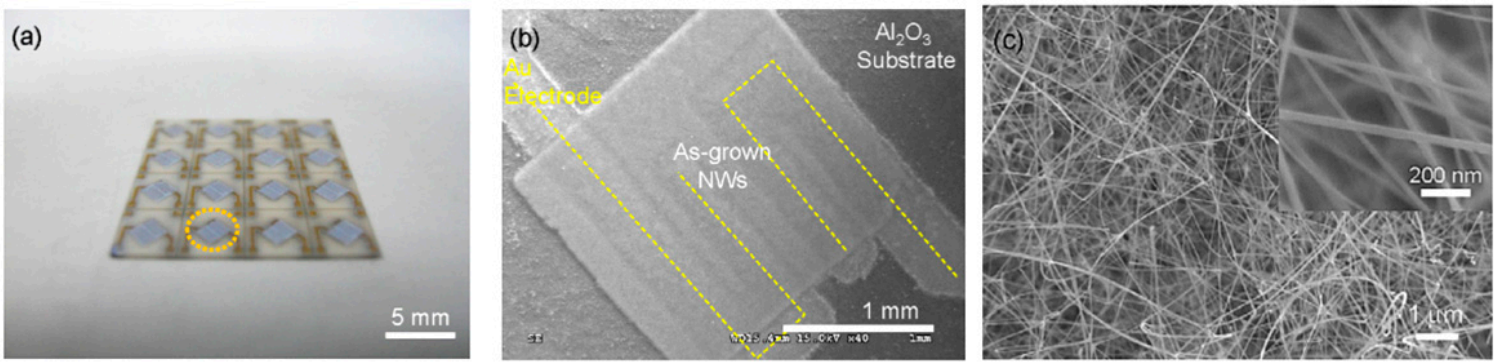

Figure 35. The sensor elements: (a) 16 sensor elements prepared by the one-pot growth of $\mathrm{SnO}_{2}$ nanowire

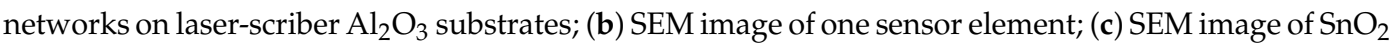
nanowire networks. Reproduced with permission from Hwang et al. [153]. Copyright 2012: Elsevier. 
A

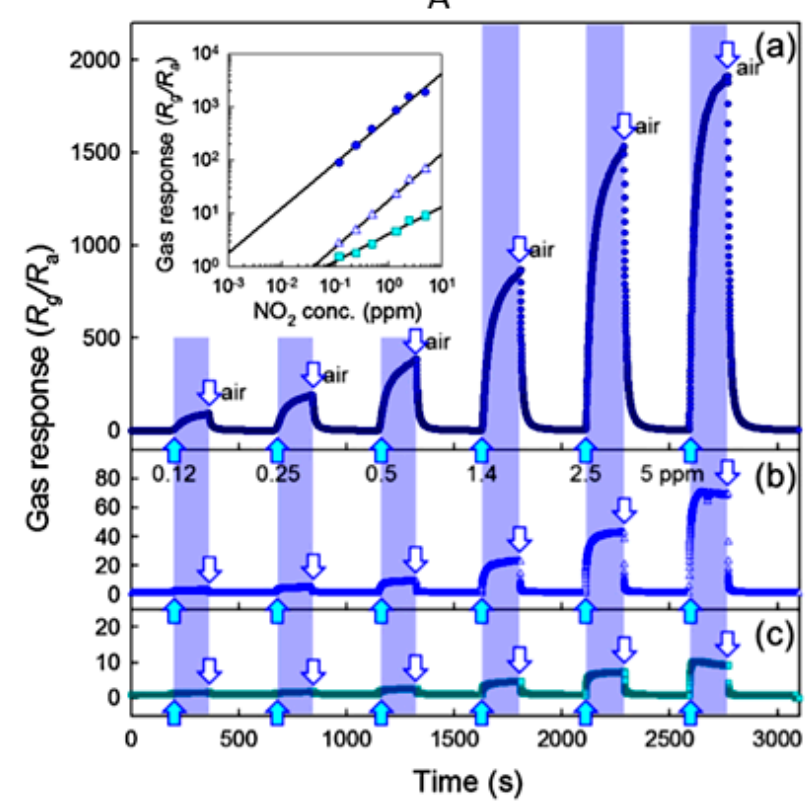

B
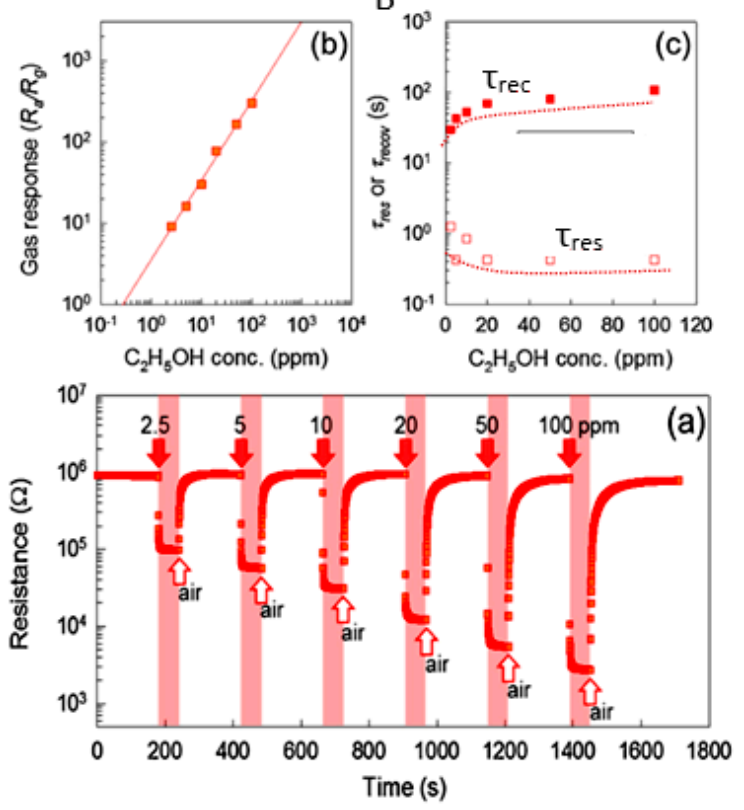

Figure 36. (A) Dynamic sensing transients to $0.12-5$ ppm $\mathrm{NO}_{2}$ at (a) 141 , (b) 190 , and (c) $240{ }^{\circ} \mathrm{C}$ and the corresponding sensor response as a function of $\mathrm{NO}_{2}$ concentration (insert); (B) (a) dynamic sensing transients to 2.5-100 ppm $\mathrm{C}_{2} \mathrm{H}_{5} \mathrm{OH}$, (b) gas responses as a function of the $\mathrm{C}_{2} \mathrm{H}_{5} \mathrm{OH}$ concentration, and (c) the $90 \%$ response times $\left(\tau_{\text {res }}\right)$ and $90 \%$ recovery times $\left(\tau_{\text {rec }}\right)$. Reproduced with permission from Hwang et al. [153]. Copyright 2012: Elsevier.

\section{2D Nanomaterials}

\subsection{Introduction}

The use of 2D nanomaterials is another promising area in the development of gas sensors. 2D nanomaterials are objects that in one direction have a size in the range of up to $100 \mathrm{~nm}$. The most famous 2D nanomaterials are graphene [8,323], black phosphorus or phosphorene [324], silicene, borophene, boron nitride [325], and transition metal dichalcogenides (TMDs) [326], which have a layered structure and allow the formation of atomically thin 2D nanomaterials of a large area. 2D materials are characterized by a high degree of anisotropy and chemical functionality. All these nanomaterials differ in their mechanical, chemical, electrophysical, surface properties, as well as in size, shape, biocompatibility, and stability to the influence of external factors. However, their low-dimension nanostructure gives them some common characteristics. 2D nanomaterials are the thinnest materials known, which means that they have the highest specific surface areas among all known materials. As a result, they can adsorb large numbers of gas and drug molecules and provide excellent control over the kinetics of surface reactions. In addition, the thinness of these nanomaterials allows them to respond rapidly to external signals such as light or chemical and biological agents. This characteristic makes these materials invaluable for applications requiring high levels of surface interactions on a small scale. An experiment showed that these properties make 2D nanomaterials suitable for a wide range of applications, such as drug delivery, energy conversion and storage, electronics, optoelectronics, biosensing, various biomedical applications, and design of chemical sensors, including gas sensors, etc. [327-333].

\subsection{Advantages of 2D Nanomaterials for Gas Sensor Design}

The main advantages of 2D nanomaterials for use in gas sensors include:

1. 2D layered nanomaterials, as well as $1 \mathrm{D}$ nanomaterials, possess a large surface area and high surface-to-volume ratio (see Figure 37), allowing more atoms to interact with the atmosphere. 
This is especially important for gas sensors, since such a structure of a gas sensitive material facilitates surface reactions, such as adsorption, chemisorption, and heterogeneous catalysis, controlling gas sensitive effects [324,334].

2. Unique structures of 2D nanomaterials can provide these materials with properties that cannot be achieved with conventional bulk structures.

3. The 2D layered structure has an increased mechanical stability, which is very important when developing sensors on flexible substrates [336,337].

4. Bandgap engineering is another advantage of $2 \mathrm{D}$ nanomaterials for gas sensor applications. It is assumed that bandgap engineering via a thickness control at the atomic level will make it possible to control the electronic and adsorption/desorption properties of gas sensing materials [324].

5. Due to their relatively larger lateral size, 2D nanostructured materials offer a better conformal contact with the electrodes in comparison with 1D nanomaterials.

6. The possibility of assembly into three-dimensional (3D) architectures can also be attributed to the advantages of 2D nanomaterials [338].

7. In addition, it should be borne in mind that in 2D nanomaterials only one crystallographic plane is involved in gas-sensitive effects. This, as well as in the case of 1D nanostructures, significantly simplifies the modeling of processes, occurring on this surface, and contributes to a better understanding of the nature of gas-sensitive effects [339]. Moreover, when the crystallographic structure of 2D nanomaterials is correctly selected, then this factor can contribute to improved sensor selectivity.

8. Different composite materials based on two-dimensional materials is another opportunity for creating gas-sensitive materials with unique properties that are not accessible in a 2D material or 3D structures based on one oxide material [340,341]. The experiment showed that, in addition to metals, polymers, and metal oxides, other 2D nanomaterials can be used to form 2D-based composites. Layered combinations of different 2D materials are generally called van der Waals heterostructures or hybrid two-dimensional materials. Hybrid two-dimensional materials are considered to be advanced multifunctional materials that have outstanding physical and chemical properties important for various applications [342,343]. In particular, Shanmugasundaram et al. [344] and Yang et al. [345] believed that gas sensors based on such heterostructures can overcome the disadvantages inherent in gas sensors based on simple materials such as low selectivity. Some approaches that can be used in the formation of 2D-based heterostructures are described in [346].

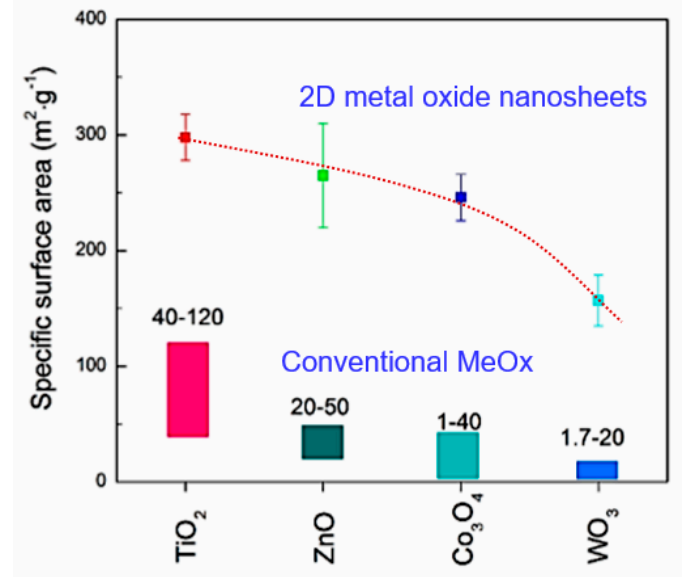

Figure 37. Typical specific surface areas of conventional metal oxide nanoparticles and 2D metal oxide nanosheets. Reproduced from Sun et al. [335]. Published by Nature Research as open access. 
Currently, based on these 2D nanomaterials, a large number of prototypes of gas sensors have been made, which have increased sensitivity to various gases. An analysis of these results can be found in numerous reviews devoted to the consideration of these materials [323,326,334,345,347-354].

\subsection{Features of $2 D$ Nanomaterials Synthesis}

Studies have shown that in addition to traditional layered 2D nanomaterials such as graphene, black phosphorus or phosphorene, silicene, borophene, boron nitride, and transition metal dichalcogenides (TMDs), metal oxides may also have 2D structures [351,355]. It was established that some metal oxides such as $\mathrm{Ga}_{2} \mathrm{O}_{3}$ and metal trioxides with a general formula of $\mathrm{MO}_{3}(\mathrm{M}=\mathrm{Mo}, \mathrm{Ta}$, $\mathrm{W}$, etc.) have a layered structure in hydrate or anhydrate phases [356]. For example, $\mathrm{MoO}_{3}$ has a layered structure in which each layer is predominantly composed of a distorted $\mathrm{MoO}_{6}$ octahedra in an orthorhombic crystal (space group $\mathrm{P}_{\mathrm{cmn}}$ ) [357]. The $\alpha-\mathrm{V}_{2} \mathrm{O}_{5}$, the most stable phase in the vanadium oxide family due to its highest oxidation state of vanadium, also has a layered structure and crystallizes with an orthorhombic unit cell structure (space group: $P_{m m n}$ ). Each layer is composed of a distorted trigonal bipyramidal polyhedral where $\mathrm{O}$ atoms locate around the $\mathrm{V}$ atoms [358]. To form 2D nanomaterials based on such layered metal oxides, one can use methods commonly used in the formation of graphene, phosphorene, and transition metal dichalcogenides (TMDs) [324,348,359]. Thus, Ji et al. [360] combined grinding and sonication to exfoliate bulk $\alpha-\mathrm{MoO}_{3}$ crystals into singleand few-layer nanosheets. A surfactant was used to stabilize them. It is important that nanosheets of the aforementioned oxides with oxygen terminated basal surfaces are stable both in air and in water.

Perovskites are another large family of layered 2D metal oxides [361]. Layered perovskites consist of $\mathrm{ABO}_{3}$ layers interleaved by thin sheets of motifs with $\mathrm{A}$ and $\mathrm{B}$ cations of possibly different sizes. Three main layered perovskites are the Aurivillius (AU), Dion-Jacobson (DJ), and Ruddlesden-Popper (RP) phases [362]. The general formula of the AU phases is $\left[\mathrm{Bi}_{2} \mathrm{O}_{2}\right]-\left[\mathrm{A}_{(\mathrm{n}-1)} \mathrm{B}_{\mathrm{n}} \mathrm{O}_{3 n+1}\right] . \mathrm{Bi}_{2} \mathrm{WO}_{6}$ and $\mathrm{SrBi}_{2} \mathrm{Ta}_{2} \mathrm{O}_{9}$ are examples of such oxides. The general formula of the DJ phases is $\mathrm{MA}_{(n-1)} \mathrm{B}_{n} \mathrm{O}_{(3 n+1)}$. Metal oxides $\mathrm{LaNb}_{2} \mathrm{O}_{7},(\mathrm{Ca}, \mathrm{Sr})_{2} \mathrm{Nb}_{3} \mathrm{O}_{10}$, and $\mathrm{La}_{2} \mathrm{Ti}_{2} \mathrm{NbO}_{10}$ have such a formula. The $\mathrm{RP}$ phases include compounds such as $\mathrm{SrLaTi}_{2} \mathrm{TaO}_{10}$ and $\mathrm{Ca}_{2} \mathrm{Ta}_{2} \mathrm{TiO}_{10}$. They can be directly synthesized into a $2 \mathrm{D}$ form using layer-by-layer deposition techniques with possible stabilization steps. If the perovskites bulk crystals are stratified, similar to graphene or TMDs, 2D perovskites can be directly exfoliated from their naturally stratified phases. However, indicated perovskites were not used in the development of gas sensors. Many of the parent layered perovskites are highly polarizable and form the basis of dielectric and ferroelectric materials [362].

As for the traditional metal oxides used in the development of gas sensors, such as $\mathrm{SnO}_{2}$, $\mathrm{ZnO}, \mathrm{In}_{2} \mathrm{O}_{3}$, etc., they do not have a natural layered crystal phase. Therefore, for the formation of $2 \mathrm{D}$ nanostructures of these metal oxides, one has to use other approaches based on the development of special synthesis modes. Using this approach, 2D nanomaterials based on oxides such as $\mathrm{ZnO}[200,363-365]$, $\mathrm{SnO}_{2}$ [366,367], $\mathrm{WO}_{3}$ [368], $\mathrm{CuO}$ [369], $\mathrm{Co}_{3} \mathrm{O}_{4}$ [370,371], $\mathrm{In}_{2} \mathrm{O}_{3}$ [372], and $\mathrm{V}_{2} \mathrm{O}_{5}$ [373] were formed. It was established that for these purposes it can be used as either the hydrothermal or solvothermal synthesis [200,363-368], as well as precipitation [374], layer-by layer deposition, and sonochemical processes [375]. The appearance of such structures is shown in Figure 1c,e. Typically, these structures are quasi-single crystalline structures.

\subsection{Gas Sensors Based on 2D Nanomaterials and Their Limitations}

\subsubsection{Sensors Performances}

The parameters of gas sensors developed on the basis of 2D metal oxides are shown in Table 4 . As one can see, sensors based on 2D nanomaterials have the characteristics typical of metal oxide-based gas sensors. The maximum sensor response, depending on the material used, its structural parameters, and the nature of the detected gas, is observed in the temperature range from $\mathrm{RT}$ to $400{ }^{\circ} \mathrm{C}$. The best samples are also fast-acting and exhibit increased sensitivity. 
It should be noted that both in the formation of sensitive layers, and in the fabrication of sensors based on 2D nanomaterials, in order to optimize their parameters, all approaches, developed previously for conventional metal oxides and other 2D nanomaterials, can be used [376]. They are bulk doping or surface modification with noble metals [377] and metal oxides [378-380]. As with conventional metal oxides [115,123], these approaches provide a significant improvement in sensor parameters such as sensitivity, selectivity, and the time of sensor response and recovery (see Figure 38). For example, Yin et al. [379] showed that the response of the $\mathrm{WO}_{3}$ nanosheet-based sensors coated with $\mathrm{SnO}_{2}$ nanoparticles to a $50 \mathrm{ppm}$ acetone vapor was 10 times higher than that of the pristine $\mathrm{WO}_{3}$ nanosheet gas sensor. However, it must be borne in mind that despite the progress made, the efficient integration of 2D functional layers with a three-dimensional sensor platform remains a significant challenge, limiting device performance and circuit design [381].

Table 4. Parameters of gas sensors based on 2D metal oxide structures.

\begin{tabular}{|c|c|c|c|c|c|c|c|}
\hline $\begin{array}{l}\text { Nanosheets } \\
\text { (Technology) }\end{array}$ & $\begin{array}{l}\text { DT, } \\
\text { nm }\end{array}$ & Response $^{\text {a),b) }}$ & $\mathrm{DL}, \mathrm{ppm}$ & $\begin{array}{c}\text { Target } \\
\text { Gas }\end{array}$ & $\begin{array}{c}\tau_{\text {res }} / \tau_{\text {rec }} \\
\mathrm{s}\end{array}$ & $\begin{array}{l}\mathrm{T}_{\text {oper, }} \\
{ }^{\circ} \mathrm{C}\end{array}$ & Ref. \\
\hline $\mathrm{ZnO}(\mathrm{ST})$ & 30 & 11 ${ }^{\mathrm{a})} @ 100$ ppm & 5.0 & $\mathrm{CO}$ & $25 / 36$ & 300 & {$[63]$} \\
\hline $\mathrm{P} \mathrm{ZnO}(\mathrm{HT})$ & $\sim 100$ & 84 $4^{\mathrm{a})} 50$ ppm & 1.0 & $\mathrm{C}_{2} \mathrm{H}_{5} \mathrm{OH}$ & $15 / 12$ & 330 & [200] \\
\hline $\mathrm{MP} \mathrm{ZnO}(\mathrm{HT})$ & $\sim 18$ & $101^{\mathrm{a})} @ 100$ ppm & 1.0 & $\mathrm{C}_{2} \mathrm{H}_{2}$ & $11 / 5$ & 400 & [364] \\
\hline $\mathrm{ZnO}(\mathrm{FP})$ & $\sim 20$ & 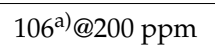 & $<1.0$ & $\mathrm{CH}_{3} \mathrm{COCH}_{3}$ & $19 / 14$ & 300 & [374] \\
\hline $\mathrm{ZnO}(\mathrm{SC})$ & $10-60$ & 75\%b)@1 ppm & 0.05 & $\begin{array}{c}\mathrm{HCHO}, \\
\mathrm{CH}_{3} \mathrm{CHO}\end{array}$ & $10 / 62$ & 220 & [375] \\
\hline $\mathrm{ZnO}: S n-\mathrm{Rh}(\mathrm{HT})$ & - & $15^{\mathrm{a})} 100$ ppm & 5.0 & $\mathrm{C}_{2} \mathrm{H}_{5} \mathrm{OH}$ & $3 / 10$ & 300 & [378] \\
\hline $\mathrm{SnO}_{2}(\mathrm{HT})$ & $\sim 15$ & 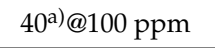 & 5.0 & $\mathrm{C}_{2} \mathrm{H}_{5} \mathrm{OH}$ & $1 / 9$ & 300 & [366] \\
\hline $\mathrm{SnO}_{2}(\mathrm{HT})$ & $\sim 20$ & 70a)@100 ppm & 100 & $\mathrm{CO}$ & $9 / 18$ & 300 & [367] \\
\hline \multirow{2}{*}{$\mathrm{SnO}_{2}(\mathrm{HT})$} & \multirow{2}{*}{$\sim 10$} & 70a)@100 ppm & $<5.0$ & $\mathrm{C}_{2} \mathrm{H}_{5} \mathrm{OH}$ & - & 250 & \multirow{2}{*}{ [382] } \\
\hline & & 10a)@500 ppm & $<50$ & $\mathrm{CO}$ & $1 / 3$ & 300 & \\
\hline $\mathrm{WO}_{3}(\mathrm{HT})$ & $\sim 10$ & $\sim 6^{\mathrm{a})} @ 50 \mathrm{ppb}$ & 0.05 & $\mathrm{NO}_{2}$ & $140 / 75$ & 140 & [368] \\
\hline $\mathrm{WO}_{3}$ (HTA) & $10-50$ & $80 \%$ b)@ppm & 600 & $\mathrm{H}_{2}$ & $120 / 235$ & 250 & [383] \\
\hline $\mathrm{WO}_{3} / \mathrm{SnO}_{2}(\mathrm{HT})$ & $30-90$ & 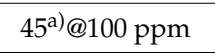 & $\sim 1.0$ & $\mathrm{C}_{3} \mathrm{H}_{6} \mathrm{O}$ & $2 / 30-60$ & 260 & [379] \\
\hline $\mathrm{CuO}$ (FHT) & $\sim 19$ & 9a)@100 ppm & 10 & $\mathrm{C}_{2} \mathrm{H}_{5} \mathrm{OH}$ & $15 / 11$ & 370 & [369] \\
\hline $\mathrm{CuO}(\mathrm{FHT})$ & $\sim 63$ & 10a)@100 ppb & $<0.01$ & $\mathrm{H}_{2} \mathrm{~S}$ & $234 / 76$ & RT & [384] \\
\hline $\mathrm{PNiO}(\mathrm{HT})$ & $\sim 14$ & $13^{\mathrm{a})} @ 10 \mathrm{ppm}$ & 0.001 & $\mathrm{H}_{2} \mathrm{~S}$ & $100 / 79$ & 92 & [385] \\
\hline $\mathrm{NiO}(\mathrm{ACD})$ & $\sim 100$ & 650\% ${ }^{\mathrm{b})} @ 8$ ppm & 0.008 & $\mathrm{HCHO}$ & $120 / 120$ & 150 & [386] \\
\hline $\mathrm{Co}_{3} \mathrm{O}_{4}(\mathrm{FHT})$ & $20-50$ & 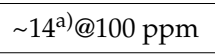 & 10 & $\mathrm{C}_{2} \mathrm{H}_{5} \mathrm{OH}$ & N/A & 160 & [387] \\
\hline $\mathrm{Co}_{3} \mathrm{O}_{4}(\mathrm{FHT})$ & $\sim 40$ & 9a)@100 ppm & 0.2 & $\mathrm{NH}_{3}$ & $9 / 134$ & RT & [371] \\
\hline $\mathrm{In}_{2} \mathrm{O}_{3}$ (FTSS) & $\sim 3.5$ & 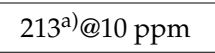 & 0.01 & $\mathrm{NO}_{\mathrm{x}}$ & $4 / 9$ & 120 & [372] \\
\hline $\mathrm{In}_{2} \mathrm{O}_{3 /} \mathrm{WO}_{3}(4 \mathrm{wt} \%)(\mathrm{IM})$ & $\sim 2.5$ & 25 & 0.1 & $\mathrm{HCHO}$ & $1 / 67$ & 170 & [380] \\
\hline $\mathrm{V}_{2} \mathrm{O}_{5} \cdot 0.76 \mathrm{H}_{2} \mathrm{O}(\mathrm{MOA})$ & $1.5-2.6$ & 2\%b)@10 ppm & 10 & $\mathrm{H}_{2}$ & - & 250 & [373] \\
\hline $\mathrm{RuO}_{2}$ (LPE) & $\sim 1.3$ & $1.1 \% \mathrm{~b}) @ 20$ ppm & 5 & $\mathrm{NO}_{2}$ & - & 80 & [388] \\
\hline
\end{tabular}

ACD—aqueous chemical deposition process; DL—detection limit; DT—thickness; FP_facile precipitation method; FHT_facile hydrothermal process; HTA—-high temperature anodization; FTSS — facile two-step synthetic method; HTS - hydrothermal synthesis; IM-impregnating method; MOA-molecular-level oriented attachment method; $\mathrm{MP}$-mesoporous; LPE-liquid phase exfoliation technique; $\mathrm{P}$-porous; Response: a) $\mathrm{R}_{\text {air }} / \mathrm{R}_{\text {gas }}$; $\left.{ }^{b}\right) \Delta \mathrm{R} / \mathrm{R}_{0}(\%)$; $\mathrm{RT}$-room temperature; SC-sonochemical method; ST-solvothermal process; $\mathrm{T}_{\text {oper }}$-operation temperature; $\tau_{\text {rec }}$-recovery time; $\tau_{\text {res }}$-response time.

Bag and Lee [389] showed that the parameters of 2D structure-based gas sensors can also be improved through the formation of various types of heterostructures, such as $2 \mathrm{D}-0 \mathrm{D}$, 2D-1D, 2D-2D, and 2D-3D heterostructures. However, they also recognize that despite their many advantages, the development and manufacture of 2D nanostructured material-based gas sensors using heterostructures still face problems. Too many technological difficulties arise in the preparation 
of gas-sensitive materials based on such heterostructures. At that point, the formation of 2D-2D heterostructures is of particular difficulty, since in this case it is necessary to layer one 2D nanomaterial onto another with the formation of a close contact between them. A description of possible approaches to the formation of such structures can be found in [346].

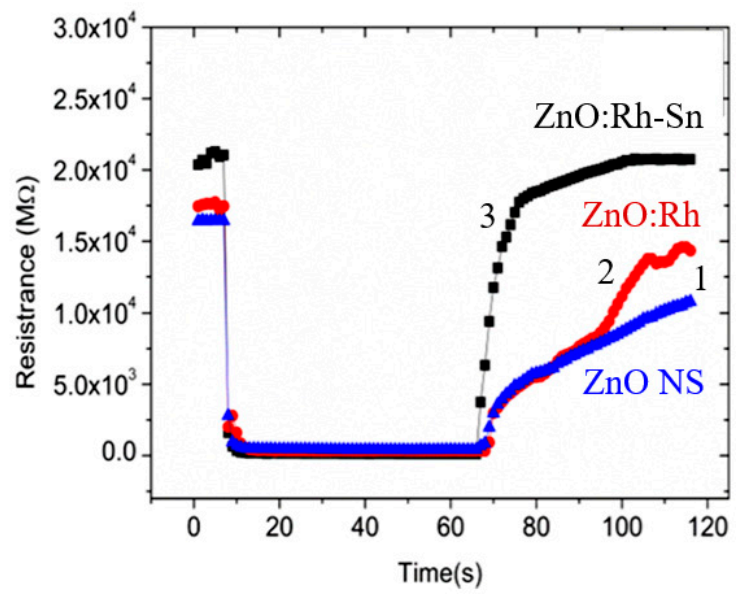

Figure 38. The response and recovery curves of different sensors to $100 \mathrm{ppm}$ ethanol at an optimum working temperature $\left(300{ }^{\circ} \mathrm{C}\right)$ : $1-\mathrm{ZnO}$ nanosheets; $2-\mathrm{ZnO}: \mathrm{Rh} ; 3-\mathrm{ZnO}: \mathrm{Rh}-\mathrm{Sn}$. Reproduced from Sun et al. [335]. Published by Nature Research as open access.

At the beginning of this section, we noted that one crystallographic plane is involved in gas sensitive effects in 2D nanomaterials, which makes it possible to determine the crystallographic planes most suitable for constructing gas sensors with improved parameters. Unfortunately, due to the difficulties in forming nanosheets with the required crystallographic orientation, research in this direction is almost not carried out. Only Xu et al. [200] in their work have compared the gas-sensitive characteristics of $\mathrm{ZnO}$ nanosheets (NSs) with (0001) и (1010) planes and established that the ZnO NS (0001) sensor shows a better performance than the NS (1010)-based sensors (see Figure 39). This means that the 2D ZnO structures faceted by the (0001) plane are preferred when developing gas sensors.

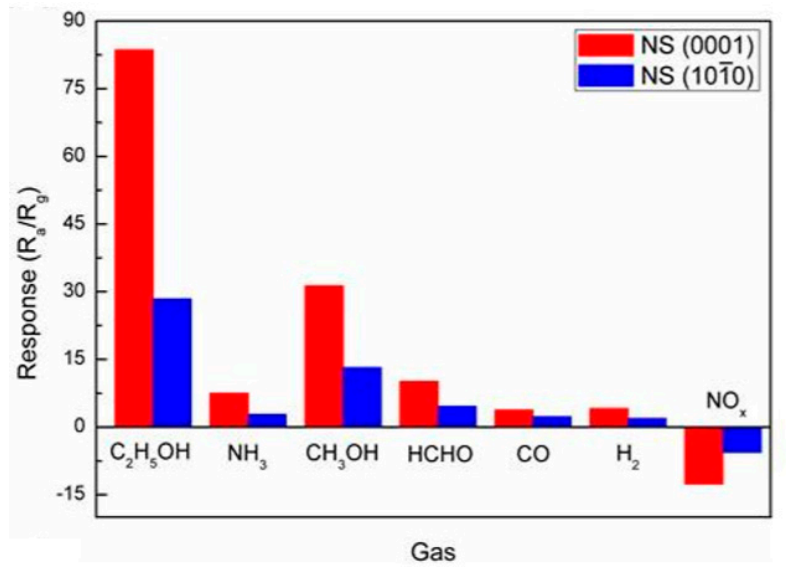

Figure 39. Response of $\mathrm{ZnO}$ nanosheets-based sensors to different gases. $\mathrm{ZnO}$ nanosheets in these sensors are faceted by different crystallographic planes, (0001) and $\pm(01 \overline{1} 0)$, respectively. Reproduced with permission from Xu et al. [200]. Copyright 2017: Elsevier.

\subsubsection{Technologies of Sensor Fabrications and Their Limitations}

Despite the progress made in the development of sensors based on 2D metal oxides, it must be recognized that these sensors are still inferior in parameters to many conventional metal oxide 
nanocrystallite-based gas sensors. Some studies [360,366] point to the significant superiority of 2D nanomaterial-based sensors over conventional polycrystalline gas sensors. However, as a rule, in these articles, the conventional polycrystalline gas sensors that are used for comparison do not have the optimal structure of the gas-sensitive layer. For example, Lou et al. [366] compared sensors based on $2 \mathrm{D} \mathrm{SnO}_{2}$ nanosheets with a thickness of $\sim 15 \mathrm{~nm}$ with sensors, fabricated using agglomerated $\mathrm{SnO}_{2}$ powders with a crystallite size of more than $20 \mathrm{~nm}$.

From our point of view, the advantages of conventional gas sensors based on polycrystalline material in comparison with 2D nanomaterial-based devices are due to the following reasons:

Firstly, there are technological difficulties in the fabrication of gas sensors based on 2D nanomaterials [360,390-392]. For example, if 2D nanomaterials are in the form of a large nanosheet, then in the case of a thick-film technology used for forming a gas-sensitive layer, there is a threat of the formation of the layer, consisting of strongly agglomerated 2D nanosheets. This makes it difficult for the gas to penetrate the inter-nanosheet space. Additionally, this further reduces the sensitivity and significantly increases the response and recovery times. Wherein, unlike the conventional material, i.e., polycrystalline metal oxides, we cannot use the mechanical milling of agglomerated materials, since milling will be accompanied by crushing of 2D nanomaterials.

Secondly, it is very difficult to grow 2D nanomaterials, which are large but small in thickness, using traditional approaches to the synthesis of metal oxides. When nanosheets become large in size, then their thickness becomes more than 10-50 nm, which does not contribute to achieving high sensitivity of the sensors. If during the synthesis of 2D nanomaterials we try to limit the thickness of the plates, then in the end we get a material that is slightly different from ordinary nanocrystallites used in conventional gas sensors.

Some problems associated with the excess thickness of nanosheets have been resolved on the basis of new technological approaches [348,393]. It was shown that with an appropriate optimization of the process, thin nanosheets can be synthesized using a wide variety of techniques such as hydro/solvothermal synthesis [335], the interface-mediated synthesis method [394], 2D-oriented attachment method [395], 2D-templated synthesis [396], self-assembly of nanocrystals [395,397], and the on-surface synthesis method [398]. Using this strategy, large $2 \mathrm{D}$ structures of $\mathrm{TiO}_{2}, \mathrm{ZnO}_{,} \mathrm{Co}_{3} \mathrm{O}_{4}$, $\mathrm{WO}_{3}, \mathrm{Fe}_{3} \mathrm{O}_{4}, \mathrm{~V}_{2} \mathrm{O}_{5} \cdot 0.76 \mathrm{H}_{2} \mathrm{O}$, and $\mathrm{MnO}_{2}$ with a thickness ranging from 1.6 to $5.2 \mathrm{~nm}$ (corresponding to 2-7 stacking monolayers) have been synthesized [355,373]. It is important to note that metal oxides with such a thickness should have unique properties in terms of gas sensitive effects. For example, five-atomic-layer-thick $\mathrm{SnO}_{2}$ sheets $(0.66 \mathrm{~nm})$ have a $40 \%$ surface occupancy by highly reactive $\mathrm{Sn}$ and $\mathrm{O}$ atoms with low coordination numbers [399]. These surface atoms could serve as centers to efficiently adsorb gaseous molecules, and/or as catalytically active sites, favoring the surface reactions with participation of adsorbed species.

It should be noted, however, that the proposed technologies very often do not agree well with the large-scale production of gas sensors. For example, in $[371,379,385], \mathrm{NiO}, \mathrm{Co}_{3} \mathrm{O}_{4}$, and $\mathrm{CuO}$ nanosheets were synthesized directly on an $\mathrm{Al}_{2} \mathrm{O}_{3}$ tube, into which a heater was subsequently mounted inside, and in [363,388], $\mathrm{ZnO}$ and $\mathrm{NiO}$ nanosheets were synthesized directly on a substrate with already formed contacts (see Figure 40a). Li et al. [371] believed that sensors with nano-sheets grown directly on substrates should have excellent performance, since during the process of synthesis the nanosheets form a network porous nanoscale system that promotes fast diffusion and efficient adsorption of gas over the entire sensor surface, which should significantly improve its sensitivity and reduce the response time. SEM images shown in Figure 40b,c demonstrate that the structure of the gas sensitive layer formed in this way really compares favorably with the structure of the gas sensitive layer formed using conventional thick film technology [364,366]. SEM images on nanosheets used for fabrication of gas sensing layers using thick-film technology are shown in Figure 41. 2D nanomaterials aggregated into three-dimensional (3D) architectures are indeed characterized by a significantly greater porosity and better gas permeability. Therefore, in most of the studies, using 2D nanosheets as active sensing elements, these 2D nanomaterials are aggregated in various porous 3D architectures [363,400]. 
The nanosheets may self-assemble spontaneously or can grow on pre-existing cores. The 2D nanosheets in $3 \mathrm{D}$ assemblies generally require a thickness of several $\mathrm{nm}$ or more in order to have sufficient mechanical strength to sustain an open architecture under dry conditions [400]. However, in this article we will not analyze gas sensors developed on the basis of such porous 3D assemblies. A special article (the second part of our review) will be devoted to the consideration of such 3D nanomaterials, mesoporous-macroporous, and hierarchical structures.
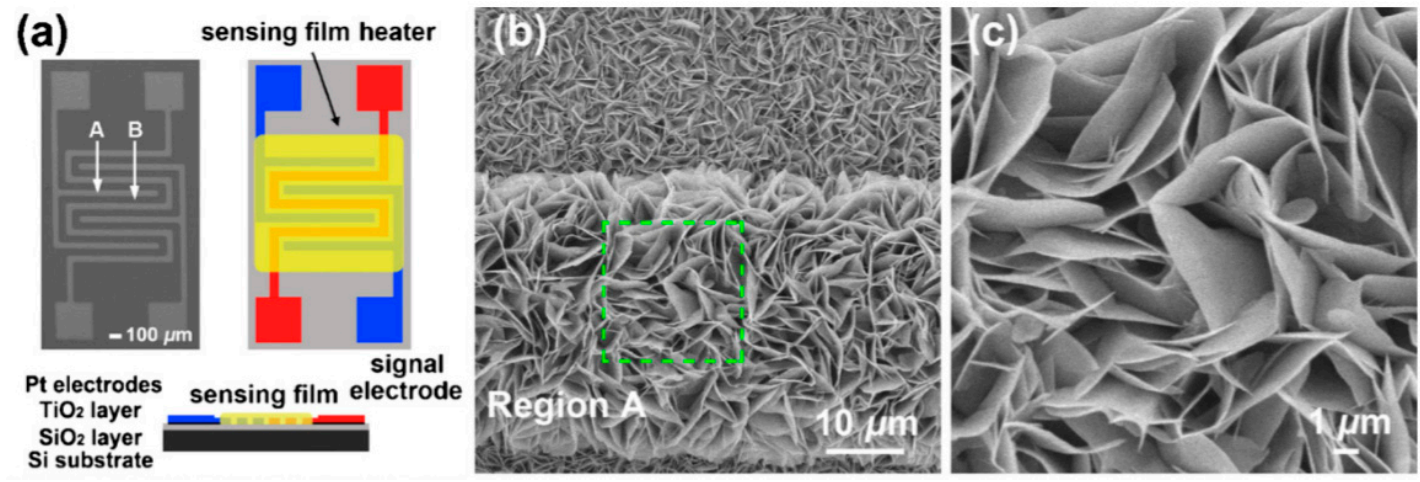

Figure 40. (a) Schematic diagrams of the different views for the microstructure sensor. Morphologies and crystal structures of $\mathrm{ZnO}$ nanosheets (NSs): (b,c) FESEM images of ZnO NSs taken from different regions in the microstructure sensor. Reproduced with permission from Zeng et al. [363]. Copyright 2012: Elsevier.
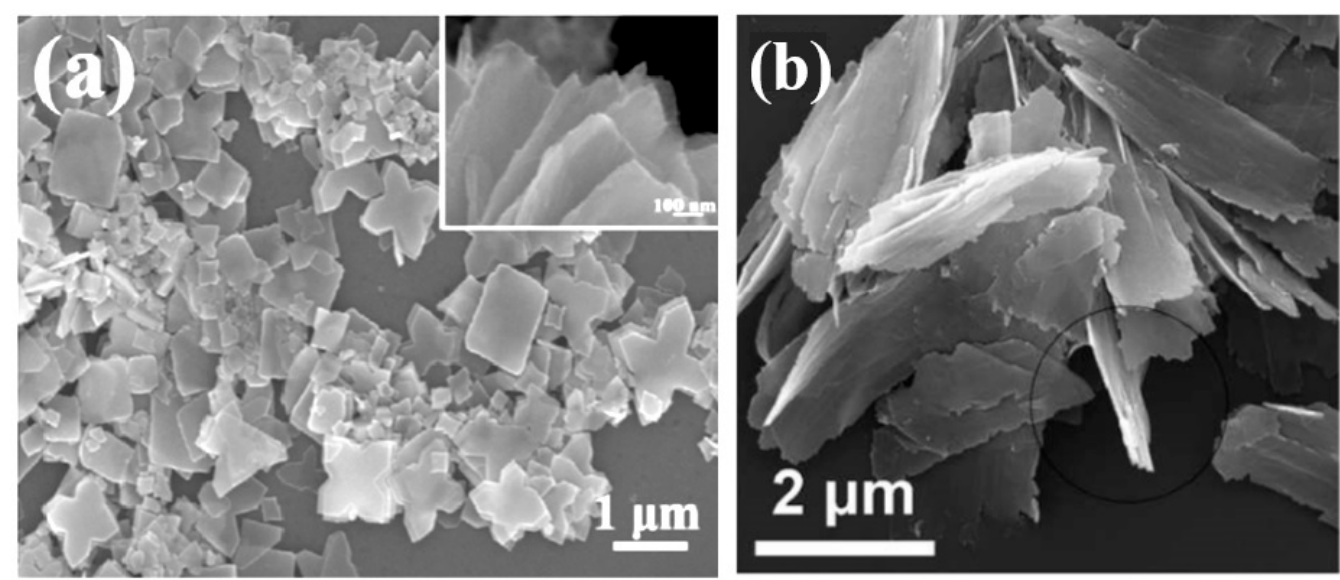

Figure 41. Low and high magnification (inset) FESEM images of $\mathrm{WO}_{3}(\mathbf{a})$ and $\mathrm{Co}_{3} \mathrm{O}_{4}$ nanosheets (b). Nanosheets were synthesized via a hydrothermal method. The thickness of nanosheets was from 20 to $30 \mathrm{~nm}$ for $\mathrm{WO}_{3}$ and from 20 to $50 \mathrm{~nm}$ for $\mathrm{Co}_{3} \mathrm{O}_{4}$ nanosheets. (a) Reproduced with permission from Wang et al. [368]. Copyright 2017: Elsevier; (b) reproduced with permission from Wang et al. [387]. Copyright 2015: Royal Society of Chemistry.

As for the porosity or gas permeability of 2D-based nanomaterials used in the formation of a gas-sensitive layer by the methods of thick-film technology, several approaches have been proposed to solve this problem. In particular, Cao et al. [384] for this purpose used surface decoration of $\mathrm{In}_{2} \mathrm{O}_{3}$ nanosheets (NSs) by $\mathrm{WO}_{3}$ nanoparticles. As a result, both an increase in sensitivity and an improvement in the rate of sensor response were achieved. It can be assumed that $\mathrm{WO}_{3}$ nanoparticles provide the necessary gap between $\mathrm{In}_{2} \mathrm{O}_{3}$ nanosheets. Choi et al. [388] used another approach. For the effective penetration of gas molecules into the sensing layers, sub- $5 \mathrm{~nm}$-scale pores were generated on the Ru oxide NSs by an ultrafast optical sintering technique. Wang et al. [372] showed that nanopores with a diameter of $\sim 3 \mathrm{~nm}$ in ultrathin $\mathrm{In}_{2} \mathrm{O}_{3}$ nanosheets with a thickness of $3.5 \mathrm{~nm}$ can also be formed in the process of their synthesis. Wang et al. [372] suggested that the formation of mesopores in $\operatorname{In}_{2} \mathrm{O}_{3}$ 
nanosheets should be attributed to the removal of glycerol ligands during the hydrolysis process. Huang et al. [401] showed that $\mathrm{ZnO}$ nanosheets, fabricated by an annealing monodisperse basic zinc nitrate $(\mathrm{BZN})$ nanosheets at $300{ }^{\circ} \mathrm{C}$ for $2 \mathrm{~h}$ in air, are also highly porous (see Figure 42 ).

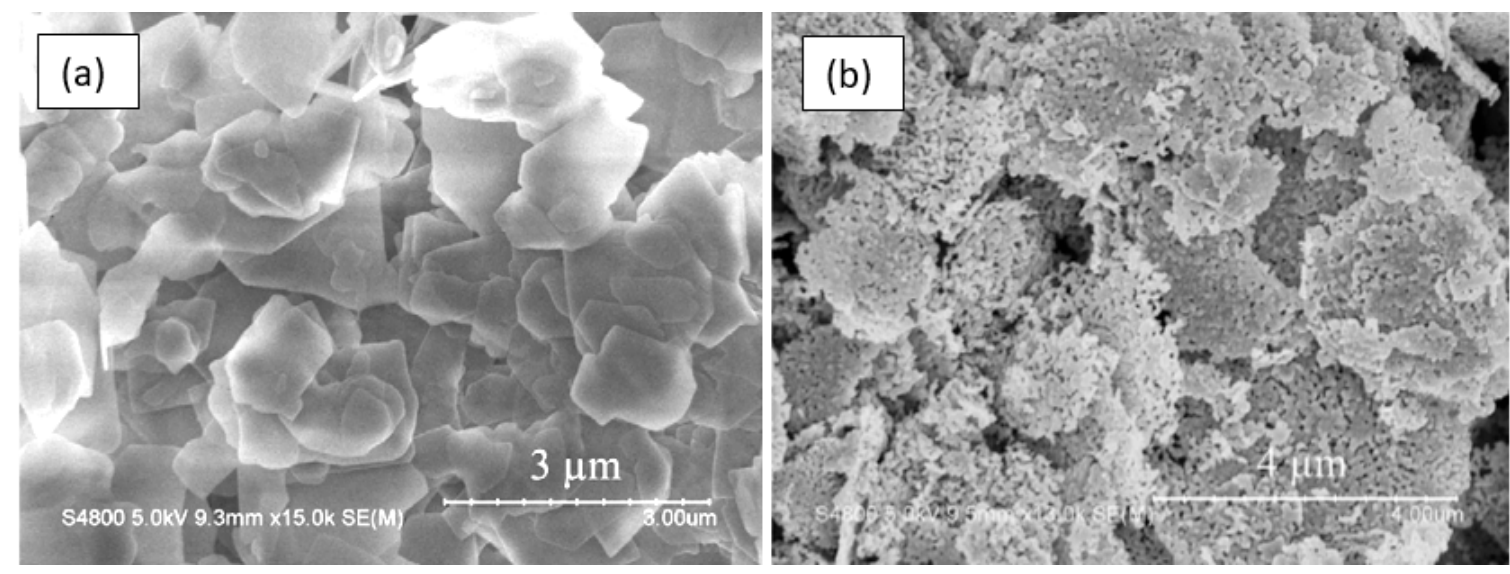

Figure 42. SEM images of (a) the as-synthesized BZN nanosheets, and (b) porous ZnO nanosheets after BZN nanosheets annealing at $300{ }^{\circ} \mathrm{C}$. The thickness of nanosheets before annealing was in the range of 12-20 nm, and < $15 \mathrm{~nm}$ after annealing. Reproduced with permission from Huang et al. [401]. Copyright 2011: Elsevier.

In addition, in many works devoted to the development of gas sensors based on 2D nanomaterials, the temperatures above $200{ }^{\circ} \mathrm{C}$ were not used [372,374,380]. Moreover, in some works [373,379,387] an additional heat treatment was not used at all. As a rule, this decision was due to the fact that the heat treatment at an elevated temperature led to a drop in the sensor response (see Figure 43). This suggests that one of the reasons for the increased response of gas sensors based on 2D nanomaterials may be the small contact area between the nanosheets, due to the feature of the gas-sensitive layer structure (see Figure 44). The absence of high temperature treatments suggests that we do not have any sintering between nanosheets, and, therefore, usual mechanical contacts are formed between nanosheets. The last one also means that the adhesion of the formed layers to the substrate and the stability of inter-nanosheets contacts may not be good enough for a long-term operation in various conditions. As a rule, only 2D nanomaterials-based layers formed by methods of thick-film technology were subjected to heat treatments at a temperature of $350-600{ }^{\circ} \mathrm{C}[200,369,375,378,388]$.

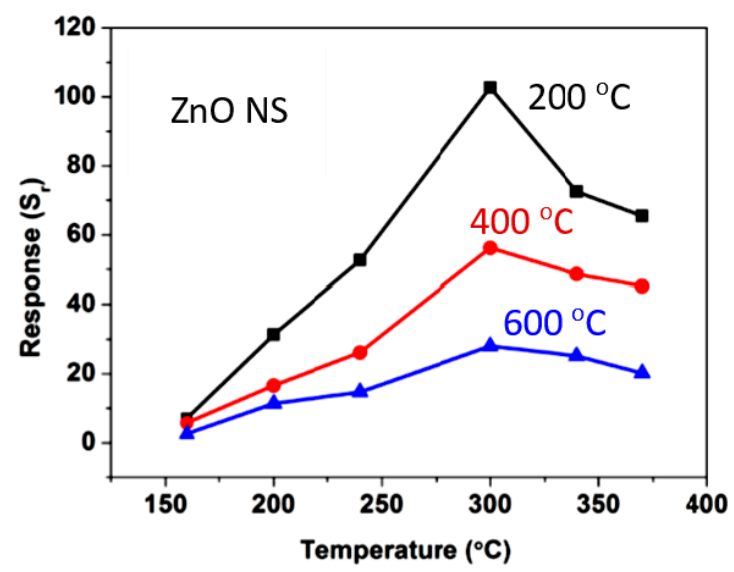

Figure 43. The operating temperature influence on the conductivity response to acetone vapor (200 ppm) of gas sensors based on $\mathrm{ZnO}$ nanosheets calcinated at 200, 400, and $600{ }^{\circ} \mathrm{C}$. Reproduced with permission from Li et al. [374]. Copyright 2017: Elsevier. 
We must not forget the fact that the smaller the thickness of nanosheets, the worse their stability. Wang et al. [368] drew attention to this in their research. Studying the synthesis of $2 \mathrm{D} \mathrm{WO}_{3}$ nanosheets with a wall thickness of $\sim 10 \mathrm{~nm}$ and analyzing the parameters of gas sensors, they found that the stability of much thinner $\mathrm{WO}_{3}$ nanosheets is poorer. In this case, the removal of templates P123 (polyethylene oxide-polypropylene oxide-polyethilene oxide) resulted in the formation of large agglomerates, accompanied by a decrease in the sensor response. Zhang et al. [375] also pointed to the importance of this process. They noted that gas sensors with highly agglomerated $\mathrm{ZnO}$ nanosheets had significantly worse parameters. This is natural, since the existence of channels and gaps between the nanosheets is a necessary condition for providing good gas permeability of the sensitive layer required to achieve a high sensitivity and fast response of gas sensors [74].

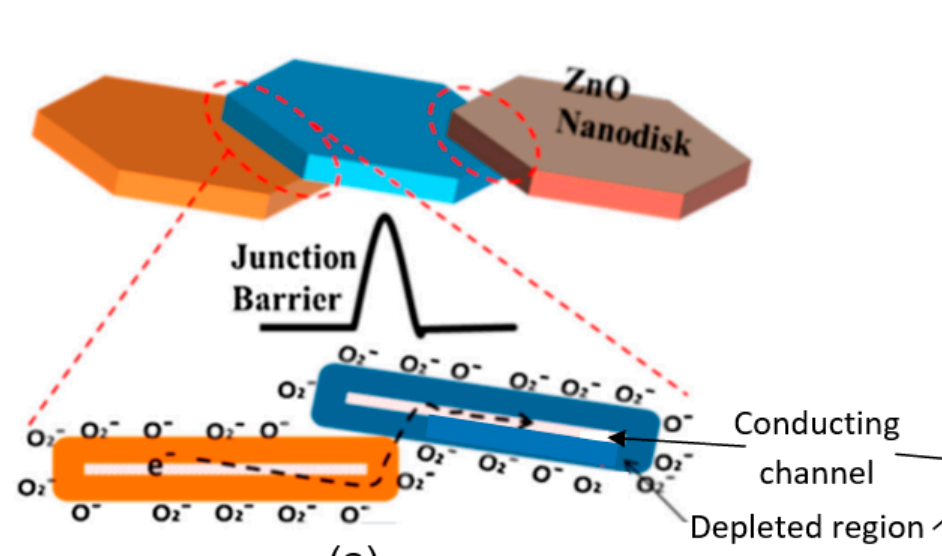

(a)

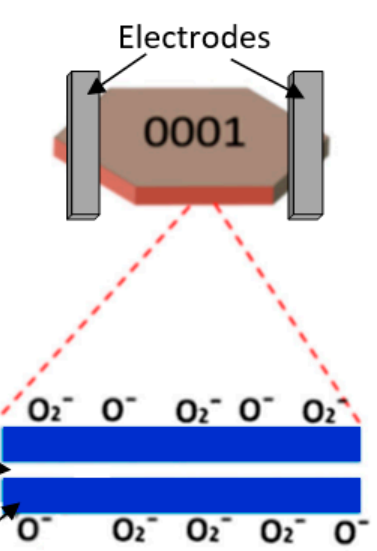

(b)

Figure 44. Schematic representation of the sensing mechanism in $\mathrm{ZnO}$ gas sensors fabricated using (a) a stack of $\mathrm{ZnO}$ nanodisks and (b) an individual nanodisk. Reproduced with permission from Alenezi et al. [402]. Copyright 2014: American Chemical Society.

\subsubsection{Sensors on Individual 2D Nanomaterials}

It seems that many of the problems described earlier can be solved through the manufacture of sensors based on individual 2D nanomaterials, since with this approach it is possible to fully realize the advantages of 2D nanomaterials. However, the experience of using 1D nanomaterials shows that in this way there are many technological difficulties. Unfortunately, individual nanosheets or nanoflakes, as it was observed earlier with the 1D nanomaterials, are difficult to handle. Therefore, for the transfer of individual nanosheets, it is necessary to develop special technologies and instruments that are poorly compatible with the technologies intended for the mass production of gas sensors [403]. Usually for the transfer of layered 2D materials onto different substrates at a desired location it is necessary to use a long working distance optical inspection system in combination with an XYZ $\theta$ direction micro-manipulator for an accurate placement, and a certain polymer layer as a transfer medium. The PMMA/sacrifice layer, PDMS, thermoplastic polymer, and hybrid stamp composed of PDMS/PPC or (PC, PMMA)/hBN are usually used as polymer carriers [403]. The comparison of the methods designed for the 2D materials transfer is given in Table 5. The transfer process involves several steps (see Figure 45). At the first stage, the polymer carrier is spin-coated onto a $\mathrm{Si} / \mathrm{SiO} 2$ substrate or a glass slide and then thin flakes of 2D nanostructures are mechanically exfoliated onto the carrier. In the second stage: The substrate with a polymer layer and 2D nanomaterial is attached on the micro-manipulator and transferred to the desired location. At the final stage, the substrate-carrier rises slowly and the residual polymer in the acetone solution is removed. For the transfer media, such as a thermoplastic polymer and a hybrid stamp, additional heating of the substrates is required to release the stacking. Given the complexity and labor input of this process, atomically thin nanoflakes and nanosheets, were mostly employed for sensing in a suspended form to detect solutes [400]. 
Table 5. Comparison between the different deterministic placement methods. Qualitative comparison in terms of cleanness, easiness, and speed between the different deterministic placement methods described in the text. Comments about their main drawbacks are also included in the table.

\begin{tabular}{|c|c|c|c|c|}
\hline Method & Cleanness & Easiness & Speed & Notes \\
\hline PMMA carrier layer & $* * *$ & $* * *$ & $* * *$ & $\begin{array}{l}\text { Spin-coating is needed, direct contact with the } \\
\text { polymer, it can transfer large-area flakes. }\end{array}$ \\
\hline Elvacite sacrificial layer & * & $* * *$ & $* * *$ & $\begin{array}{l}\text { Capillary forces, spin-coating is needed, direct } \\
\text { contact with the polymer. }\end{array}$ \\
\hline Wedging & $*$ & $* *$ & $* * *$ & $\begin{array}{l}\text { Capillary forces, dip-coating is needed, difficult } \\
\text { alignment, direct contact with the polymer, } \\
\text { transfer over curved or uneven surfaces } \\
\text { is possible. }\end{array}$ \\
\hline PDMS dry transfer & $* * *$ & $* * * * *$ & $* * * * *$ & Direct contact with the polymer. \\
\hline Van der Waals pick-up & $* * * * *$ & * & $* *$ & $\begin{array}{l}\text { Spin-coating is needed, several steps involved, } \\
\text { only works to transfer heterostructures, direct } \\
\text { contact with the polymer only for the } \\
\text { topmost layer. }\end{array}$ \\
\hline
\end{tabular}

Source. Reproduced with permission from Frisenda et al. [403]. Copyright 2018: Royal Society of Chemistry.

It should be recognized, however, that there are works aimed at the formation of 2D metal oxide thin films, as close as possible to the monolayer. In particular, a few studies focused on the formation of a monolayer film of 2D metal oxides were conducted by Sasaki's team [404,405]. They successfully fabricated a closely packed monolayer film of 2D titania nanosheet by the electrostatic self-assembly method [404] and Langmuir-Blodgett technique [405]. Titania nanosheets, used in the last experiments, were $10-30 \mu \mathrm{m}$ in lateral size and $1.2-1.3 \mathrm{~nm}$ in thickness. A cross-sectional TEM image of the 10-layer film of $\mathrm{Ti}_{0.87} \mathrm{O}_{2}$ nanosheets deposited on the atomically flat substrate of $\mathrm{SrRuO}_{3}$ revealed that the substrate surface is uniformly covered with the ultrathin film (Figure 46). However, this study was not focused on the application of monolayer films of 2D nanosheets in gas sensors. Therefore, the studies performed by [406] can be considered as a first paper devoted to the fabrication of chemiresistive gas sensors with a monolayer film of 2D nanomaterial. For these purposes Miao et al. [406] used copper(II) oxide nanosheets, synthesized using the hydrothermal method (Figure 47a). Nanosheets had a length and width ranging from 300 to $1000 \mathrm{~nm}$, and the thickness was around 30 to $50 \mathrm{~nm}$ (Figure 47b). A monolayer film of copper(II) oxide nanosheets (Figure 47c) was prepared by the self-assembly method at the air-water interface (see Figure 48). After the formation of a monolayer at the air-water interface, the lab jack was raised up at a rate of $5 \mathrm{~mm} / \mathrm{min}$ until the glass holder was above water level to transfer the monolayer onto the substrates. Then, films were dried at room temperature for $30 \mathrm{~min}$. The as-prepared monolayer with contacts was annealed in a furnace at $400^{\circ} \mathrm{C}$ for $6 \mathrm{~h}$ before testing of gas sensing characteristics. Miao et al. [406] showed that relying on this method and using the layer-by layer deposition approach, one can also form a multilayer film, based on different 2D nanomaterials.

Miao et al. [406] stated that this method provides a facile, versatile, and highly reproducible manufacturing of chemiresistive gas sensors with the sensing layer based on a monolayer film of 2D nanomaterials. However, this method of manufacturing chemiresistive gas sensors is not a method intended for large-scale production. The main result of the research conducted by Miao et al. [406], is a conclusion that an increase in the number of nanosheets in gas sensitive layers, as previously predicted, is accompanied by a decrease in sensitivity (see Figure 49a) and an increase in the response time. The negative effect of the thickness of the sensing film is explained by the effect of dilution of the analyzed gas and impeded gas diffusion (Figure 49b), which increase with an increasing thickness of a sensing layer. 
(a)

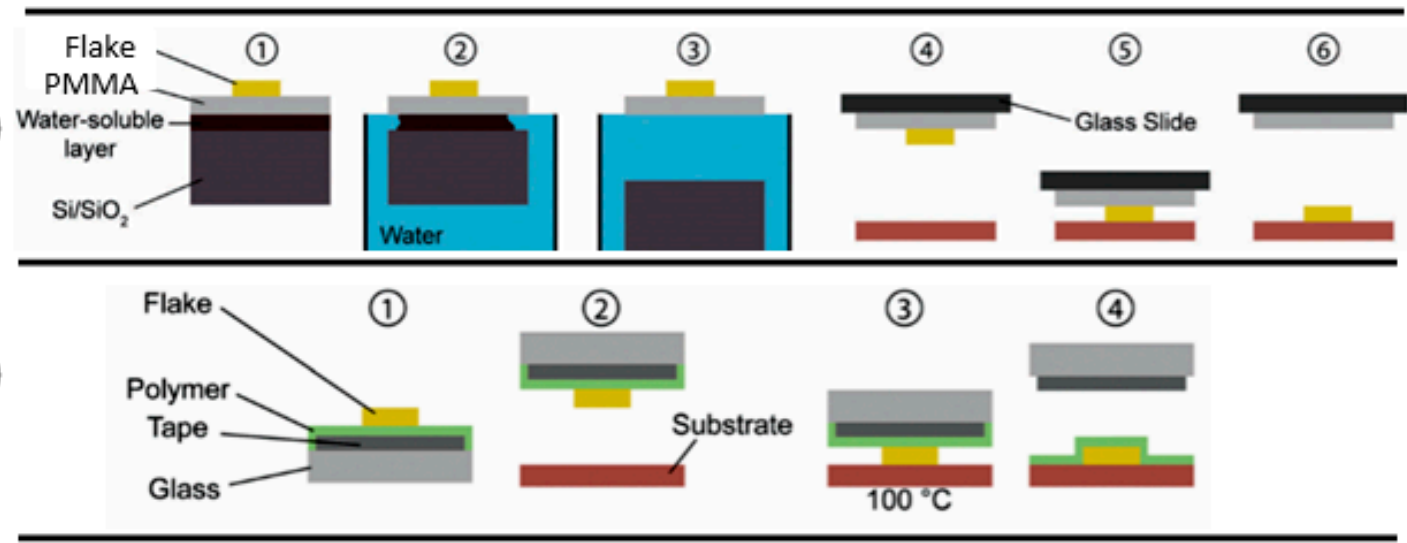

(c)

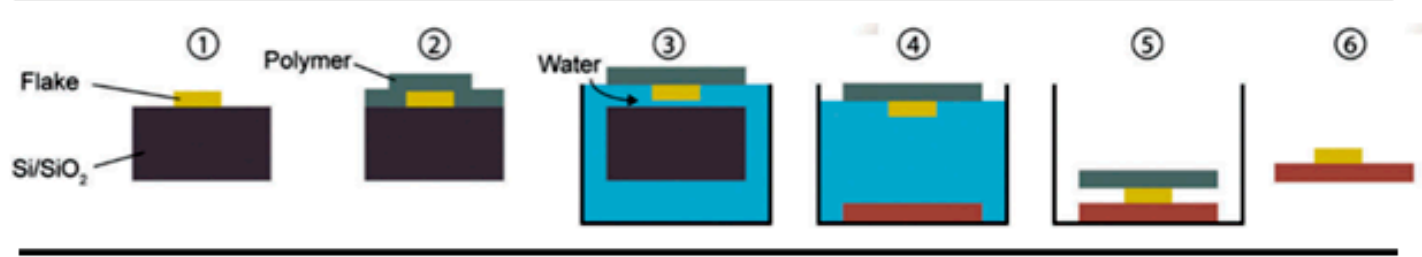

(1)

(d)

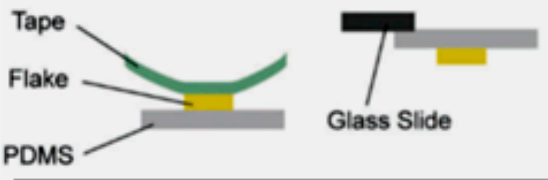

(3)

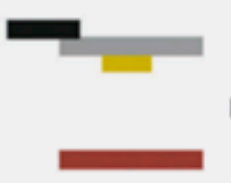

(5)

(6)

Figure 45. Illustration of transfer methods: (a) The PMMA carrying layer transfer method. The designated flake to be transferred is exfoliated onto a $\mathrm{Si} / \mathrm{SiO}_{2}$ substrate which has been coated with a water-soluble polymer layer and PMMA (1). The stack is then immersed in water (2) where the water-soluble layer can dissolve leaving the PMMA layer carrying the flake floating on the water surface (3). The PMMA is then attached to a glass slide connected to a micromanipulator with the flake facing down (4). With the help of a microscope the flake is aligned with the target substrate and is then brought in contact (5). By gently separating the PMMA from the final substrate the flake gets transferred. (b) The Elvacite sacrificial layer transfer method. The target flake is exfoliated onto a layer of Evalcite deposited onto an adhesive tape attached to a glass slide (1). The stack is then positioned onto a target substrate and the flake is aligned with pre-existing features of the substrate (2). The substrate is heated up at $100{ }^{\circ} \mathrm{C}$ and the stack can then be brought in contact with the hot substrate (3) which melts the Evalcite layer leaving the capped flake on the final substrate (4). (c) The wedging transfer method. The flake to be transferred is exfoliated onto a hydrophilic substrate such as $\mathrm{Si} / \mathrm{SiO}_{2}(1)$ and then covered by a layer of hydrophobic polymer (2). The stack is then immersed in water where the water molecules can intercalate between the $\mathrm{SiO}_{2}$ and the polymer carrying the flake (3). The polymer film carrying the flake remains floating on the water surface where it can be aligned with the help of a needle to the final substrate (4). By pumping down the water the two can be brought in contact (5). Then, the polymer can be dissolved leaving the flake transferred onto the final substrate (6). (d) The PDMS dry transfer method. The flake to be transferred is exfoliated onto a PDMS stamp (1) and the stamp is then attached to a glass slide connected to a micromanipulator (2). Using a microscope, the flake can be aligned with the final substrate (3) and brought in contact (4). By slowly peeling the PDMS stamp (5) the flake can be deposited on the substrate (6). Reproduced with permission from Frisenda et al. [403]. Copyright 2018: Royal Society of Chemistry. 
(a)

(b)

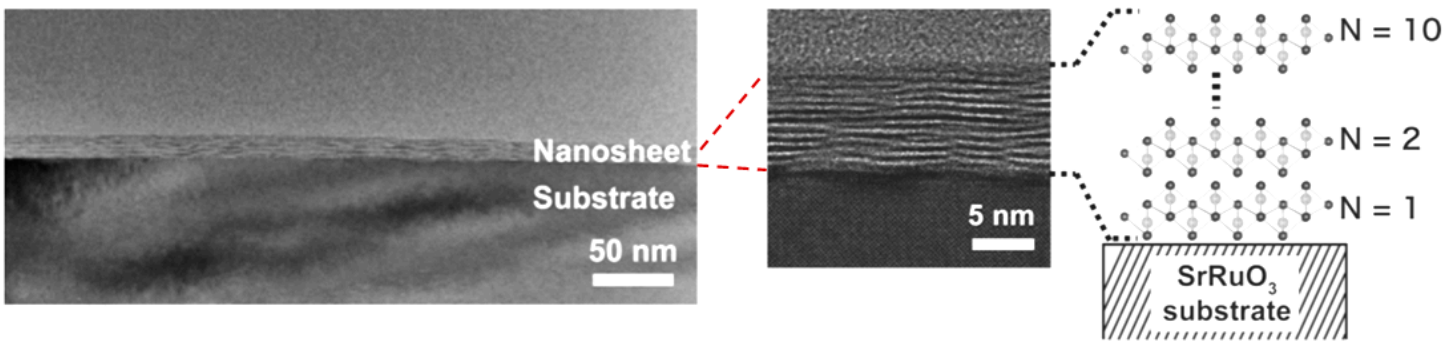

Figure 46. Cross-sectional TEM images of the 10-layer film of $\mathrm{Ti}_{0.87} \mathrm{O}_{2}$ nanosheets formed using the LB deposition technique: (a) Wide view; (b) magnified image. Reproduced with permission from Akatsuka et al. [405]. Copyright 2009: American Chemical Society.
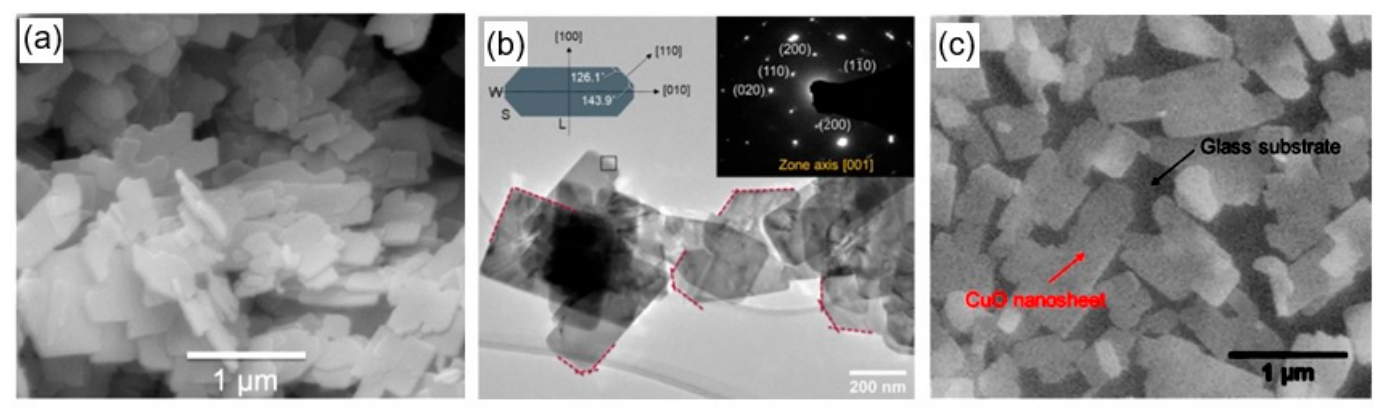

Figure 47. (a) SEM images of as-synthesized CuO nanosheets; (b) low-magnification TEM image of $\mathrm{CuO}$ nanosheets and the SAED pattern and a sketch of the crystal orientation in the real space as inset; (c) top surface SEM image of the $\mathrm{CuO}$ nanosheet monolayer on the glass substrate. Reproduced from Miao et al. [406]. Published by ACS as open access.

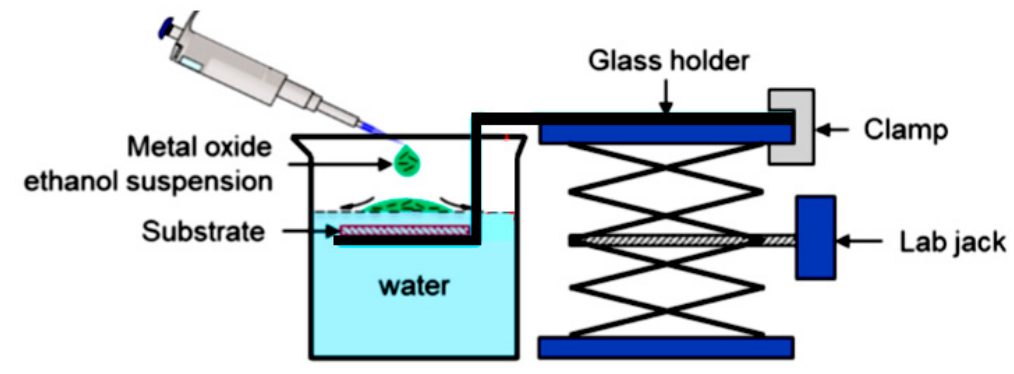

Figure 48. Illustration of the monolayer film formation process using the home-built coater. The red box illustrates that the $\mathrm{CuO}$ nanosheets float on the water surface due to the formation of a negative meniscus at the edges and self-assembly due to the attraction force of the same type of meniscus. Reproduced from Miao et al. [406]. Published by ACS as open access.

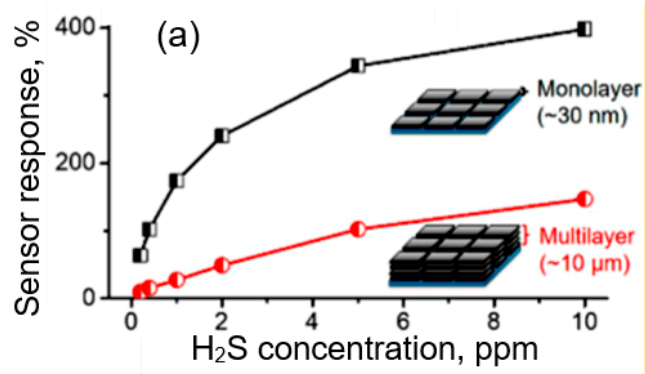

(b)

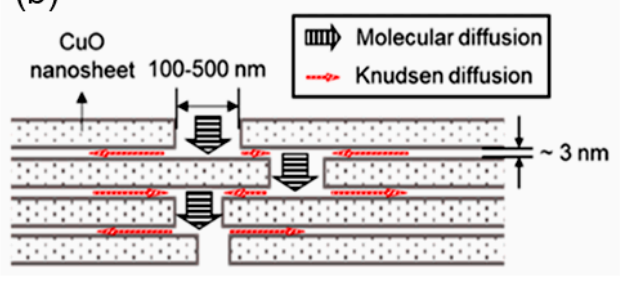

Figure 49. (a) Sensor response of monolayer- and multilayer-based sensors to $\mathrm{H}_{2} \mathrm{~S}$; (b) model of a multilayer film with lamellar structure. Reproduced from Miao et al. [406]. Published by ACS as open access. 


\section{Summary}

As is known, for the large-scale implementation of new materials and technologies, it is necessary that devices based on them are much cheaper and have significantly better parameters compared to the samples, existing on the market. Unfortunately, the materials that were considered in this article do not provide a significant improvement in the parameters of gas sensors. Despite the stated advantages of 1D and 2D nanomaterials for application in gas sensors, these sensors are far from perfect. Moreover, the technologies used in the manufacture of gas sensors based on these nanomaterials are more expensive than those used in the fabrication of conventional metal oxide-based gas sensors. In addition, many of these technologies are hard-compatible with the processes used in large-scale production of gas sensors.

Of course, over the past decade, various fabrication and characterization strategies have been developed with the aim to accomplish electrical measurements of individual 1D and 2D metal oxide structures free of parasitic effects, and to develop gas sensors that are competitive in parameters with conventional devices. For instance, low-current measurement protocols were proposed that allowed devices based on 1D nanomaterials to operate for a long time without degradation of their performance $[158,159,235]$. Thus, it can be expected that the development of new technologies adapted to nanomaterials can lead to complete and well-controlled characterization of devices based on 1D and 2D structures, which were previously unattainable [5]. However, despite the significant successes achieved in the development of new 1D and 2D nanomaterials, the improvement of their synthesis technologies, and the manufacture of gas sensors based on them, do not expect the appearance on the sensor market of gas sensors based on individual 1D and 2D nanomaterials. This means that with traditional gas sensors developed based on the nanocrystalline metal oxides using conventional well-developed thin-film and thick-film technology, a long time will dominate the sensor market $[24,29,74,97]$.

Regarding 1D nanostructures arrays and 2D nanostructures assembled into three-dimensional (3D) architectures such as nanoflowers, hollow spheres, etc., we must state that these nanostructures have much more prospects for appearance in devices developed for the sensor market. After appropriate optimization of the technology of 1D and 2D nanomaterials synthesis, which will allow both to form nanostructures with controlled and reproducible parameters, and to improve the sensors performances, sensors based on 1D nanostructures arrays and assembled 2D nanomaterials may well compete with gas sensors based on conventional metal oxides. A detailed discussion of assembled 1D and 2D nanomaterials and gas sensors, developed on their basis, will be presented in the second part of this article.

Author Contributions: G.K. - conceptualization, methodology, data analysis, visualization, writing—original draft preparation and editing. All authors have read and agreed to the published version of the manuscript.

Funding: This research was funded by the State Program of the Republic of Moldova project 20.80009.5007.02.

Conflicts of Interest: The author declare no conflict of interest.

\section{References}

1. Comini, E. Metal oxide nano-crystals for gas sensing. Anal. Chim. Acta 2006, 568, 28-40. [CrossRef] [PubMed]

2. Franke, M.E.; Koplin, T.J.; Simon, U. Metal and metal oxide nanoparticles in chemiresistors: Does the nanoscale matter. Small 2006, 2, 36-50. [CrossRef]

3. Lu, J.G.; Chang, P.C.; Fan, Z.Y. Quasi-one-dimensional metal oxide materials-Synthesis, properties and applications. Mater. Sci. Eng. R. 2006, 52, 49-91. [CrossRef]

4. Kauffman, D.R.; Star, A. Carbon nanotube gas and vapor sensors. Angew. Chem. Int. Ed. 2008, 47, 6550-6570. [CrossRef] [PubMed]

5. Comini, E.; Baratto, C.; Faglia, G.; Ferroni, M.; Vomiero, A.; Sberveglieri, G. Quasi-one dimensional metal oxide semiconductors: Preparation, characterization and application as chemical sensors. Prog. Mater. Sci. 2009, 54, 1-67. [CrossRef] 
6. Comini, E.; Baratto, C.; Concina, I.; Faglia, G.; Falasconi, M.; Ferroni, M.; Galstyan, V.; Gobbi, E.; Ponzoni, A.; Vomiero, A.; et al. Metal oxide nanoscience and nanotechnology for chemical sensors. Sens. Actuators B 2013, 179, 3-20. [CrossRef]

7. Comini, E.; Baratto, C.; Faglia, G.; Ferroni, M.; Ponzoni, A.; Zappa, D.; Sberveglieri, G. Metal oxide nanowire chemical and biochemical sensors. J. Mater. Res. 2013, 28, 2911-2931. [CrossRef]

8. Geim, A.K. Graphene: Status and prospects. Science 2009, 324, 1530-1534. [CrossRef]

9. Lee, J.-H. Gas sensors using hierarchical and hollow oxide nanostructures: Overview. Sens. Actuators B 2009, 140, 319-336. [CrossRef]

10. Zhai, T.; Fang, X.; Liao, M.; Xu, X.; Zeng, H.; Yoshio, B.; Golberg, D. A comprehensive review of one-dimensional metal-oxide nanostructure photodetectors. Sensors 2009, 9, 6504-6529. [CrossRef]

11. Chaudhuri, R.G.; Paria, S. Core/shell nanoparticles: Classes, properties, synthesis mechanisms, characterization, and applications. Chem. Rev. 2012, 112, 2373-2433. [CrossRef] [PubMed]

12. Khin, M.M.; Nair, A.S.; Babu, V.J.; Murugan, R.; Ramakrishna, S. A review on nanomaterials for environmental remediation. Energy Environ. Sci. 2012, 5, 8075-8109. [CrossRef]

13. Lai, X.; Halpert, J.E.; Wang, D. Recent advances in micro-nano-structured hollow spheres for energy applications: From simple to complex systems. Energy Environ. Sci. 2012, 5, 5604-5618. [CrossRef]

14. Tiwari, J.N.; Tiwari, R.N.; Kim, K.S. Zero-dimensional, one-dimensional, two-dimensional and three-dimensional nanostructured materials for advanced electrochemical energy devices. Prog. Mater. Sci. 2012, 57, 724-803. [CrossRef]

15. Mirzaei, A.; Leonardi, S.G.; Neri, G. Detection of hazardous volatile organic compounds (VOCs) by metal oxide nanostructures-based gas sensors: A review. Ceram. Intern. 2016, 42, 15119-15141. [CrossRef]

16. Muller, K.; Bugnicourt, E.; Latorre, M.; Jorda, M.; Sanz, Y.E.; Lagaron, J.M.; Miesbauer, O.; Bianchin, A.; Hankin, S.; Bölz, U.; et al. Review on the processing and properties of polymer nanocomposites and nanocoatings and their applications in the packaging, automotive and solar energy fields. Nanomaterials 2014, 7, 74. [CrossRef]

17. Jeevanandam, J.; Barhoum, A.; Chan, Y.S.; Dufresne, A.; Danquah, M.K. Review on nanoparticles and nanostructured materials: History, sources, toxicity and regulations. Beilstein J. Nanotechnol. 2018, 9, 1050-1074. [CrossRef]

18. Samyn, P.; Barhoum, A.; Öhlund, T.; Dufresne, A. Review: Nanoparticles and nanostructured materials in papermaking. J. Mater. Sci. 2018, 53, 146-184. [CrossRef]

19. Dai, Z.; Liang, T.; Lee, J.-H. Gas sensors using ordered macroporous oxide nanostructures. Nanoscale Adv. 2019, 1, 1626-1639. [CrossRef]

20. Kolahalam, L.A.; Kasi Viswanath, I.V.; Diwakar, B.S.; Govindh, B.; Reddy, V.; Murthy, Y.L.N. Review on nanomaterials: Synthesis and applications. Nanomater. Proc. 2019, 18, 2182-2190. [CrossRef]

21. Nasiri, N.; Clarke, C. Nanostructured gas sensors for medical and health applications: Low to high dimensional materials. Biosensors 2019, 9, 43. [CrossRef]

22. Sberveglieri, G. Gas Sensors; Kluwer Academic Publishing: Berlin, Germany, 1992.

23. Comini, E.; Faglia, G.; Sberveglieri, G. Solid State Gas Sensing; Springer Science \& Business Media: New York, NY, USA, 2008.

24. Korotcenkov, G.; Sysoev, V. Conductometric metal oxide gas sensors. In Chemical Sensors. Comprehensive Sensor Technologies Volume 4: Solid State Devices; Korotcenkov, G., Ed.; Momentum Press: New York, NY, USA, 2011; pp. 39-186.

25. Carpenter, M.A.; Mathur, S.; Kolmakov, A. Metal Oxide Nanomaterials for Chemical Sensors; Springer Science \& Business Media: Berlin, Germany, 2012; p. 548.

26. Jaaniso, R.; Tan, O. Semiconductor Gas Sensors; Woodhead Publisher: Cambridge, MA, USA, 2013.

27. Barsan, N.; Schierbaum, K. Gas Sensors Based on Conducting Metal Oxides; Korotcenkov, G., Ed.; Elsevier: Cambridge, MA, USA, 2018.

28. Korotcenkov, G. Handbook of Humidity Measurement: Methods, Materials and Technologies, Volume 2: Electronic and Electrical Humidity Sensors; CRC Press: Boca Raton, FL, USA, 2019.

29. Ihokura, K.; Watson, J. The Stannic Oxide Gas Sensor: Principles and Applications; CRC Press: Boca Raton, FL, USA, 1994. 
30. Yamazoe, N.; Shimanoe, K. New perspectives of gas sensor technology. Sens. Actuators B 2009, 138, $100-107$. [CrossRef]

31. Korotcenkov, G. Chemical Sensors: Comprehensive Sensor Technologies. Volume 6: Sensors Applications; Momentum Press: New York, NY, USA, 2011.

32. Fleischer, M.; Lehmann, M. Solid State Gas Sensors_Industrial Application; Springer: New York, NY, USA, 2012.

33. Korotcenkov, G. Handbook of Humidity Measurement: Methods, Materials and Technologies, Volume 1: Spectroscopic Methods of Humidity Measurement; CRC Press: Boca Raton, FL, USA, 2018.

34. Barsan, N.; Weimar, U. Conduction model of metal oxide gas sensors. J. Electroceram. 2001, 7, $143-167$. [CrossRef]

35. Kohl, D. Surface processes in the detection of reducing gases with $\mathrm{SnO}_{2}$-based devices. Sens. Actuators 1989, 18,71-113. [CrossRef]

36. Wolkenstein, T. Electronic Processes on Semiconductor Surfaces during Chemisorption; Springer: New York, NY, USA, 1991.

37. Barsan, N.; Schweizer-Berberich, M.; Gopel, W. Fundamental and practical aspects in the design of nanoscaled $\mathrm{SnO}_{2}$ gas sensors. A status report. Fresen. J. Anal. Chem. 1999, 365, 287-304. [CrossRef]

38. Barsan, N.; Koziej, D.; Weimar, U. Metal oxide-based gas sensor research: How to? Sens. Actuators B 2007, 121, 18-35. [CrossRef]

39. Barsan, N.; Simion, C.; Heine, T.; Pokhrel, S.; Weimar, U. Modeling of sensing and transduction for p-type semiconducting metal oxide based gas sensors. J. Electroceram. 2010, 25, 11-19. [CrossRef]

40. Brynzari, V.; Korotchenkov, G.; Dmitriev, S. Theoretical study of semiconductor thin film gas sensitivity: Attempt to consistent approach. J. Electron. Technol. 2000, 33, 225-235.

41. Hahn, S.H.; Barsan, N.; Weimar, U.; Ejakov, S.G.; Visser, J.H.; Soltis, R.E. CO sensing with $\mathrm{SnO}_{2}$ thick film sensors: Role of oxygen and water vapour. Thin Solid Films 2003, 436, 17-24. [CrossRef]

42. Yamazoe, N.; Sakai, G.; Shimanoe, K. Oxide semiconductor gas sensors. Catal. Surv. Asia 2003, 7, 63-75. [CrossRef]

43. Yamazoe, N.; Shimanoe, K. Theory of power laws for semiconductor gas sensors. Sens. Actuators B 2008, 128, 566-573. [CrossRef]

44. Yamazoe, N.; Shimanoe, K. Receptor function and response of semiconductor gas sensor. J. Sens. 2009, 2009, 875704. [CrossRef]

45. Koziej, D.; Barsan, N.; Weimar, U.; Szuber, J.; Shimanoe, K.; Yamazoe, N. Water-oxygen interplay on tin dioxide surface: Implication on gas sensing. Chem. Phys. Lett. 2005, 410, 321-323. [CrossRef]

46. Batzill, M. Surface science studies of gas sensing materials: $\mathrm{SnO}_{2}$. Sensors 2006, 6, 1345-1366. [CrossRef]

47. Gurlo, A. Interplay between $\mathrm{O}_{2}$ and $\mathrm{SnO}_{2}$ : Oxygen ionosorption and spectroscopic evidence for adsorbed oxygen. ChemPhysChem 2006, 7, 2041-2052. [CrossRef]

48. Gurlo, A.; Riedel, R. In situ and operando spectroscopy for assessing mechanisms of gas sensing. Angew. Chem. Int. Ed. 2007, 46, 3826-3848. [CrossRef] [PubMed]

49. Yamazoe, N.; Shimanoe, K. Basic approach to the transducer function of oxide semiconductor gas sensors. Sens. Actuators B 2011, 160, 1352-1362. [CrossRef]

50. Gurlo, A. Nanosensors: Towards morphological control of gas sensing activity. $\mathrm{SnO}_{2}, \mathrm{In}_{2} \mathrm{O}_{3}, \mathrm{ZnO}$ and $\mathrm{WO}_{3}$ case studies. Nanoscale 2011, 3, 154-165. [CrossRef]

51. Prades, J.D.; Cirera, A.; Korotcenkov, G.; Cho, B.K. Microstructural and surface modeling of $\mathrm{SnO}_{2}$ using DFT calculations. In Chemical Sensors: Simulation and Modeling. Volume 1: Microstructural Characterization and Modeling of Metal Oxides; Korotcenkov, G., Ed.; Momentum Press: New York, NY, USA, 2012; pp. 81-162.

52. Setkus, A. Numerical simulation of electrical responses to gases in advanced structures. In Chemical Sensors: Simulation and Modeling. Volume 2: Conductometric Gas Sensors; Korotcenkov, G., Ed.; Momentum Press: New York, NY, USA, 2012; pp. 1-50.

53. Spencer, J.S. Density functional theory modeling of $\mathrm{ZnO}$ for gas sensor applications. In Chemical Sensors: Simulation and Modeling. Volume 1: Microstructural Characterization and Modeling of Metal Oxides; Korotcenkov, G., Ed.; Momentum Press: New York, NY, USA, 2012; pp. 163-216.

54. Valasco-Velez, J.-J. Co-adsorption on processes and quantum mechanical modeling of gas-sensing effects. In Chemical Sensors: Simulation and Modeling. Volume 2: Conductometric Gas Sensors; Korotcenkov, G., Ed.; Momentum Press: New York, NY, USA, 2012; pp. 51-96. 
55. Gurlo, A. Insights into the mechanism of gas sensor operation. In Metal Oxide Nanomaterials for Chemical Sensors; Carpenter, M., Mathur, S., Kolmakov, A., Eds.; Integrated Analytical Systems; Springer: New York, NY, USA, 2013; pp. 3-34.

56. Kim, H.J.; Lee, J.-H. Highly sensitive and selective gas sensors using p-type oxide semiconductors: Overview. Sens. Actuators B 2014, 192, 607-627. [CrossRef]

57. Korotcenkov, G. Chemical Sensors: Simulation and Modeling. Volume 2: Conductometric Gas Sensors; Momentum Press: New York, NY, USA, 2012.

58. Korotcenkov, G.; Brinzari, V.; Cho, B.K. $\mathrm{In}_{2} \mathrm{O}_{3}$ and $\mathrm{SnO}_{2}$ based ozone sensors: Fundamentals. J. Sens. 2016, 2016, 3816094. [CrossRef]

59. Al-Hashem, A.M.; Akbar, S.; Morris, P. Role of oxygen vacancies in nanostructured metal-oxide gas sensors: A review. Sens. Actuators B 2019, 301, 126845. [CrossRef]

60. Deng, Y. Semiconducting Metal Oxides for Gas Sensors; Springer: Singapore, 2019.

61. Gaskov, A.; Rumyantseva, M.; Marikutsa, A. Tin oxide nanomaterials: Active centers and gas sensor properties. In Tin Oxides Materials; Ornaghi Orlandi, M., Korotcenkov, G., Eds.; Elsevier: Cambridge, MA, USA, 2019; pp. 163-220.

62. Xu, C.N.; Tamaki, J.; Miura, N.; Yamazoe, N. Grain-size effects on gas sensitivity of porous $\mathrm{SnO}_{2}$-based elements. Sens. Actuators B 1991, 3, 147-155. [CrossRef]

63. Yamazoe, N.; Shimanoe, K. Roles of shape and size of component crystals in semiconductor gas sensors I. Response to oxygen. J. Electrochem. Soc. 2008, 155, j85-j92. [CrossRef]

64. Korotcenkov, G.; Han, S.D.; Cho, B.K.; Brinzari, V. Grain size effects in sensor response of nanostructured $\mathrm{SnO}_{2}$ - and $\mathrm{In}_{2} \mathrm{O}_{3}$-based conductometric gas sensor. Crit. Rev. Sol. St. Mater. Sci. 2009, 34, 1-17. [CrossRef]

65. Korotcenkov, G. Metal oxides for solid state gas sensors. What determines our choice? Mater. Sci. Eng. B 2007, 139, 1-23. [CrossRef]

66. Korotcenkov, G. Chemical Sensors, Volumes 1-3: Fundamentals of Sensing Materials; Momentum Press: New York, NY, USA, 2011; pp. 2010-2011.

67. Korotcenkov, G. Handbook of Gas Sensor Materials, Volume 1: Conventional Approaches; Springer: New York, NY, USA, 2013.

68. Govardhan, K.; Grace, A.N. Metal/metal oxide doped semiconductor based metal oxide gas sensors-A review. Sens. Lett. 2016, 14, 741-750. [CrossRef]

69. Gerasimov, G.N.; Gromov, V.F.; Belysheva, T.V.; Ikim, M.; Trakhtenberg, L.I. Effect of the composition and structure of metal oxide nanocomposites on the sensor process when detecting reducing gases. Rus. J. Phys. Chem. 2017, 91, 1609-1620. [CrossRef]

70. Balamurugan, C.; Song, S.-J.; Kim, H.-S. Enhancing gas response characteristics of mixed metal oxides gas sensors. J. Korean Ceram. Soc. 2018, 55, 1-20. [CrossRef]

71. Mounasamy, V.; Kumar Mani, G.; Madanagurusamy, S. Vanadium oxide nanostructures for chemiresistive gas and vapour sensing: A review on state of the art. Microchim. Acta 2020, 187, 253. [CrossRef]

72. Korotcenkov, G.; Cho, B.K. Ozone measuring: What can limit the application of $\mathrm{SnO}_{2}$-based gas sensors? Sens. Actuators B 2012, 161, 28-44. [CrossRef]

73. Korotcenkov, G.; Brinzari, V.; Ham, M.-H. Materials acceptable for gas sensor design: Advantages and limitations. Key Eng. Mater. 2018, 780, 80-89. [CrossRef]

74. Korotcenkov, G. The role of morphology and crystallographic structure of metal oxides in response of conductometric-type gas sensors. Mater. Sci. Eng. R. 2008, 61, 1-39. [CrossRef]

75. Potyrailo, R.A. Combinational concepts for development of sensing materials. In Chemical Sensors: Fundamentals of Sensing Materials. Volume 1: General Approaches; Korotcenkov, G., Ed.; Momentum Press: New York, NY, USA, 2010; pp. 159-214.

76. Korotcenkov, G. Sensor materials: Selection guide. In Chemical Sensors: Fundamentals of Sensing Materials. Volume 3: Polymers and Other Materials; Korotcenkov, G., Ed.; Momentum Press: New York, NY, USA, 2011; pp. 351-374.

77. Li, Z.J.; Li, H.J.; Chen, X.L.; Li, L.; Xu, Y.P.; Li, K.Z. $\beta-\mathrm{Ga}_{2} \mathrm{O}_{3}$ nanowires on unpatterned and patterned $\mathrm{MgO}$ single crystal substrates. J. Alloys Comp. 2002, 345, 275-279. [CrossRef]

78. Malik, R.; Tomer, V.K.; Kumar Mishra, Y.; Lin, L. Functional gas sensing nanomaterials: A panoramic view. Appl. Phys. Rev. 2020, 7, 021301. [CrossRef] 
79. Varghese, O.K.; Gong, D.; Paulose, M.; Grimes, C.A.; Dickey, E.C. Crystallization and high-temperature structural stability of titanium oxide nanotube arrays. J. Mater. Res. 2003, 18, 156-165. [CrossRef]

80. Varghese, O.K.; Gong, D.; Paulose, M.; Ong, K.G.; Grimes, C.A. Hydrogen sensing using titania nanotubes. Sens. Actuators B 2003, 93, 338-344. [CrossRef]

81. Kam, K.C.; Deepak, F.L.; Cheetham, A.K.; Rao, C.N.R. $\operatorname{In}_{2} \mathrm{O}_{3}$ nanowires, nanobouquets and nanotrees. Chem. Phys. Lett. 2004, 397, 329-334. [CrossRef]

82. Guha, P.; Chakrabarti, S.; Chaudhuri, S. Synthesis of $\beta-\mathrm{Ga}_{2} \mathrm{O}_{3}$ nanowire from elemental Ga metal and its photoluminescence study. Phys. E 2004, 23, 81-85. [CrossRef]

83. Kuchibhatla, S.V.N.T.; Karakoti, A.S.; Bera, D.; Seal, S. One dimensional nanostructured materials. Prog. Mater. Sci. 2007, 52, 699-913. [CrossRef]

84. Barth, S.; Hernandez-Ramirez, F.; Holmes, J.D.; Romano-Rodriguez, A. Synthesis and applications of one-dimensional semiconductors. Prog. Mater. Sci. 2010, 55, 563-627. [CrossRef]

85. Gyger, F.; Hübner, M.; Feldmann, C.; Barsan, N.; Weimar, U. Nanoscale $\mathrm{SnO}_{2}$ hollow spheres and their application as a gas-sensing material. Chem. Mater. 2010, 22, 4821-4827. [CrossRef]

86. Soldano, C.; Comini, E.; Baratto, C.; Ferroni, M.; Faglia, G.; Sberveglieri, G. Metal oxides mono-dimensional nanostructures for gas sensing and light emission. J. Am. Ceram. Soc. 2012, 95, 831-850. [CrossRef]

87. Lu, F.; Cai, W.; Zhang, Y. ZnO hierarchical micro/nanoarchitectures: Solvothermal synthesis and structurally enhanced photocatalytic performance. Adv. Func. Mater. 2008, 18, 1047-1056. [CrossRef]

88. Li, L.; Fang, X.; Chew, H.G.; Zheng, F.; Liew, T.H.; Xu, X.; Zhang, Y.; Pan, S.; Li, G.; Zhang, L. Crystallinity-controlled germanium nanowire arrays: Potential field emitters. Adv. Funct. Mater. 2008, 18, 1080-1088. [CrossRef]

89. Xu, L.; Chen, Q.; Xu, D. Hierarchical ZnO nanostructures obtained by electrodeposition. J. Phys. Chem. C 2007, 111, 11560-11565. [CrossRef]

90. Sepulveda-Guzman, S.; Reeja-Jayan, B.; De la Rosa, E.; Torres-Castro, A.; Gonzalez-Gonzalez, V.; Jose-Yacaman, M. Synthesis of assembled $\mathrm{ZnO}$ structures by precipitation method in aqueous media. Mater. Chem. Phys. 2009, 115, 172-178. [CrossRef]

91. Krunks, M.; Dedova, T.; Açik, I.O. Spray pyrolysis deposition of zinc oxide nanostructured layers. Thin Solid Films 2006, 515, 1157-1160. [CrossRef]

92. Orel, Z.C.; Anzlovar, A.; Drazic, G.; Zigon, M. Cuprous oxide nanowires prepared by an additive-free polyol process. Cryst. Growth Des. 2007, 7, 453-458. [CrossRef]

93. Dev, A.; Kar, S.; Chakrabarti, S.; Chaudhuri, S. Optical and field emission properties of ZnO nanorod arrays synthesized on zinc foils by the solvothermal route. Nanotechnology 2006, 17, 1533-1540. [CrossRef]

94. Korotcenkov, G. Handbook of Gas Sensor Materials, Volume 2: New Trends and Technologies; Springer: New York, NY, USA, 2014.

95. Tiemann, M. Porous metal oxides as gas sensors. Chemistry 2007, 13, 8376-8388. [CrossRef]

96. Korotcenkov, G.; Cho, B.K. The role of grain size on the thermal stability of nanostructured metal oxides used in gas sensor applications and approaches for grain-size stabilization. Prog. Cryst. Growth 2012, 58, 167-208. [CrossRef]

97. Korotcenkov, G. Handbook of Humidity Measurement: Methods, Materials and Technologies, Volume 3: Sensing Materials and Technologies; CRC Press: Boca Raton, FL, USA, 2020.

98. Korotcenkov, G.; Rusu, E. How to improve performance of porous silicon based gas and vapour sensors. Approaches and achievements. Phys. Status Solidi (a) 2019, 216, 1900348. [CrossRef]

99. Rumyantseva, M.N.; Gas'kov, A.M. Chemical modification of nanocrystalline metal oxides: Effect of the real structure and surface chemistry on the sensor properties. Russ. Chem. Bull. 2008, 57, 1106-1125. [CrossRef]

100. Korotcenkov, G.; Cho, B.K. Instability of metal oxide-based conductometric gas sensors and approaches to stability improvement. Sens. Actuators B 2011, 156, 527-538. [CrossRef]

101. Korotcenkov, G.; Cho, B.K. Engineering approaches to improvement operating characteristics of conductometric gas sensors. Part 1: Improvement of sensor sensitivity and selectivity. Sens. Actuators B 2013, 188, 709-728. [CrossRef]

102. Korotcenkov, G.; Cho, B.K. Engineering approaches to improvement operating characteristics of conductometric gas sensors. Part 2: Decrease of dissipated (consumable) power and improvement stability and reliability. Sens. Actuators B 2014, 198, 316-341. [CrossRef] 
103. Korotcenkov, G.; Cho, B.K. Material and structural engineering of metal oxides aimed for gas sensor applications. Adv. Mater. Res. 2014, 974, 76-85. [CrossRef]

104. Krivetskiy, V.V.; Rumyantseva, M.N.; Gaskov, A. Chemical modification of polycrystalline tin dioxide for selective gas sensors. Russ. Chem. Rev. 2013, 82,917-941. [CrossRef]

105. Korotcenkov, G.; Brinzari, V.; Cho, B.K. $\mathrm{In}_{2} \mathrm{O}_{3}$ and $\mathrm{SnO}_{2}$-based ozone sensors: Design and characterization. Crit. Rev. Sol. St. Mater. Sci. 2018, 43, 83-132. [CrossRef]

106. Kolmakov, A.; Moskovits, M. Chemical sensing and catalysis by one-dimensional metal oxide nanostructures. Annu. Rev. Mater. Res. 2004, 34, 151-180. [CrossRef]

107. Kolmakov, A.; Klenov, D.O.; Lilach, Y.; Stemmer, S.; Moskovits, M. Enhanced gas sensing by individual $\mathrm{SnO}_{2}$ nanowires and nanobelts functionalized with Pd catalyst particles. Nano Lett. 2005, 5, 667-673. [CrossRef] [PubMed]

108. Kolmakov, A. Some recent trends in the fabrication, functionalisation and characterisation of metal oxide nanowire gas sensors. Int. J. Nanotechnol. 2008, 5, 450-474. [CrossRef]

109. Zhang, Y.; Kolmakov, A.; Lilach, Y.; Moskovits, M. Electronic control of chemistry and catalysis at the surface of an individual tin oxide nanowire. J. Phys. Chem. B 2005, 109, 1923-1929. [CrossRef]

110. Kolmakov, A.; Chen, X.; Moskovits, M. Functionalizing nanowires with catalytic nanoparticles for gas sensing applications. J. Nanosci. Nanotechnol. 2008, 8, 111-121. [CrossRef]

111. Rai, P.; Majhi, S.M.; Yu, Y.T.; Lee, J.-H. Noble metal@ metal oxide semiconductor core@ shell nano-architectures as a new platform for gas sensor applications. RSC Adv. 2015, 5, 76229-76248. [CrossRef]

112. Woo, H.S.; Na, C.W.; Lee, J.-H. Design of highly selective gas sensors via physicochemical modification of oxide nanowires: Overview. Sensors 2016, 16, 1531. [CrossRef] [PubMed]

113. Morrison, S.R. Selectivity in semiconductor gas sensor. Sens. Actuators 1987, 12, 425-440. [CrossRef]

114. Kohl, D. The role of noble-metals in the chemistry of solid-state gas sensors. Sens. Actuators B 1990, 1, 158-165. [CrossRef]

115. Korotcenkov, G. Gas response control through structural and chemical modification of metal oxides: State of the art and approaches. Sens. Actuators B 2005, 107, 209-232. [CrossRef]

116. Korotcenkov, G. Practical aspects in design of one-electrode semiconductor gas sensors: Status report. Sens. Actuators B 2007, 121, 664-678. [CrossRef]

117. Rumyantseva, M.N.; Kovalenko, V.V.; Gas'kov, A.M.; Pagnier, T. Metal-oxide based nanocomposites as materials for gas sensors. Russ. J. Gen. Chem. 2008, 78, 1081. [CrossRef]

118. Ryzhikov, A.; Labeau, M.; Gaskov, A. Selectivity improvement of semiconductor gas sensors by filters. In Sensors for Environment, Health and Security; Baraton, M.-I., Ed.; Springer: New York, NY, USA, 2009; pp. 141-157.

119. Trakhtenberg, L.I.; Gerasimov, G.N.; Gromov, V.F.; Kozhushner, M.A.; Ilegbusi, O.J. Experimental investigation and modeling of gas-sensing effects in mixed metal oxide nanocomposites. In Chemical Sensors: Simulation and Modeling. Volume 2: Conductometric Gas Sensors; Korotcenkov, G., Ed.; Momentum Press: New York, NY, USA, 2012; pp. 261-296.

120. Jeong, H.M.; Kim, J.H.; Jeong, S.Y.; Kwak, C.H.; Lee, J.-H. $\mathrm{Co}_{3} \mathrm{O}_{4}-\mathrm{SnO}_{2}$ hollow heteronanostructures: Facile control of gas selectivity by compositional tuning of sensing materials via galvanic replacement. ACS Appl. Mater. Interfaces 2016, 8, 7877-7883. [CrossRef] [PubMed]

121. Korotcenkov, G.; Brinzari, V.; Cho, B.K. Conductometric gas sensors based on metal oxide modified with gold nanoparticles: A review. MicroChim. Acta 2016, 18, 1033-1054. [CrossRef]

122. Xu, F.; Ho, H.P. Light-activated metal oxide gas sensors: A review. Micromachines 2017, 8, 333. [CrossRef]

123. Korotcenkov, G.; Cho, B.K. Metal oxide based composites in conductometric gas sensors: Achievements and challenges. Sens. Actuators B 2017, 244, 182-210. [CrossRef]

124. Dai, Z.R.; Gole, J.L.; Stout, J.D.; Wang, Z.L. Tin oxide nanowires, nanoribbons, and nanotubes. Phys. Chem. $B$ 2002, 106, 1274-1279. [CrossRef]

125. Hu, J.Q.; Ma, X.L.; Shang, N.G.; Xie, Z.Y.; Wong, N.B.; Lee, C.S.; Lee, S.T. Large-scale rapid oxidation synthesis of $\mathrm{SnO}_{2}$ nanoribbons. J. Phys. Chem. B 2002, 106, 3823-3826. [CrossRef]

126. Li, C.; Zhang, D.; Han, S.; Liu, X.; Tang, T.; Zhou, C. Diameter-controlled growth of single-crystalline $\mathrm{In}_{2} \mathrm{O}_{3}$ nanowires and their electronic properties. Adv. Mater. 2003, 15, 143-146. [CrossRef] 
127. Zhang, Y.; Ago, H.; Liu, J.; Yumura, M.; Uchida, K.; Ohshima, S.; Iijima, S.; Zhu, J.; Zhang, X. The synthesis of In, $\mathrm{In}_{2} \mathrm{O}_{3}$ nanowires and $\mathrm{In}_{2} \mathrm{O}_{3}$ nanoparticles with shape-controlled. J. Cryst. Growth 2004, 264, 363-368. [CrossRef]

128. Comini, E.; Faglia, G.; Sberveglieri, G.; Pan, X.; Wang, Z.L. Stable and highly sensitive gas sensors based on semiconducting oxide nanobelts. Appl. Phys. Lett. 2002, 81, 1869-1871. [CrossRef]

129. Sysoev, V.V.; Schneider, T.; Goschnick, J.; Kiselev, I.; Habicht, W.; Hahn, H.; Strelcov, E.; Kolmakov, A. Percolating $\mathrm{SnO}_{2}$ nanowire network as a stable gas sensor: Direct comparison of long-term performance versus $\mathrm{SnO}_{2}$ nanoparticle films. Sens. Actuators B 2009, 139, 699-703. [CrossRef]

130. Ramgir, N.; Datta, N.; Kaur, M.; Kailasaganapathi, S.; Debnath, A.K.; Aswal, D.K.; Gupta, S.K. Metal oxide nanowires for chemiresistive gas sensors: Issues, challenges and prospects. Colloids Surf. A 2013, 439, 101-116. [CrossRef]

131. Haghiri-Gosnet, A.M.; Vieu, C.; Simon, G.; Mej1as, M.; Carcenac, F.; Launois, H. Nanofabrication at a $10 \mathrm{~nm}$ length scale: Limits of lift-off and electroplating transfer processes. J. Phys. IV 1999, 9, 133-141. [CrossRef]

132. Marrian, C.R.K.; Tennant, D.M. Nanofabrication. J. Vac. Sci. Technol. A 2003, 21, S207-S215. [CrossRef]

133. Candeloro, P.; Comini, E.; Baratto, C.; Faglia, G.; Sberveglieri, G.; Kumar, $\mathrm{R}$. $\mathrm{SnO}_{2}$ lithographic processing for nanopatterned gas sensors. J. Vac. Sci. Technol. B 2005, 23, 2784-2788. [CrossRef]

134. Choi, Y.-J.; Hwang, I.-S.; Park, J.-G.; Choi, K.J.; Park, J.-H.; Lee, J.-H. Novel fabrication of an $\mathrm{SnO}_{2}$ nanowire gas sensor with high sensitivity. Nanotechnology 2008, 19, 095508. [CrossRef]

135. Lee, S.H.; Jo, G.; Park, W.; Lee, S.; Kim, Y.-S.; Cho, B.K.; Lee, T.; Kim, W.B. Diameter-engineered $\mathrm{SnO}_{2}$ nanowires over contact-printed gold nanodots using size-controlled carbon nanopost array stamps. ACS Nano 2010, 4, 1829-1836. [CrossRef]

136. Wagner, R.S.; Ellis, W.C. Vapor-liquid-solid mechanism of single crystal growth. Appl. Phys. Lett. 1964, 4, 89-90. [CrossRef]

137. Givargizov, E. Fundamental aspects of VLS growth. J. Cryst. Growth 1975, 31, 20-30. [CrossRef]

138. Devan, R.S.; Patil, R.; Lin, J.H.; Ma, Y.-R. One-dimensional metal-oxide nanostructures: Recent developments in synthesis, characterization, and applications. Adv. Funct. Mater. 2012, 22, 3326-3370. [CrossRef]

139. Jiang, X.C.; Wang, Y.L.; Herricks, T.; Xia, Y.N. Ethylene glycol-mediated synthesis of metal oxide nanowires. J. Mater. Chem. 2004, 14, 695-703. [CrossRef]

140. Miao, J.J.; Wang, H.; Li, Y.R.; Zhu, J.M.; Zhu, J.J. Ultrasonic-induced synthesis of $\mathrm{CeO}_{2}$ nanotubes. J. Cryst. Growth 2005, 281, 525-529. [CrossRef]

141. Zou, G.; Li, H.; Zhang, Y.; Xiong, K.; Qian, Y. Solvothermal/hydrothermal route to semiconductor nanowires. Nanotechnology 2006, 17, S313-S320. [CrossRef]

142. Mathur, S.; Ganesan, R.; Grobelsek, I.; Shen, H.; Ruegamer, T.; Barth, S. Plasma-assisted modulation of morphology and composition in tin oxide nanostructures for sensing applications. Adv. Eng. Mater. 2007, 9, 658-663. [CrossRef]

143. Huang, X.-J.; Choi, Y.-K. Chemical sensors based on nanostructured materials. Sens. Actuators B 2007, 122, 659-671. [CrossRef]

144. Choi, K.J.; Jang, H.W. One-dimensional oxide nanostructures as gas-sensing materials: Review and issues. Sensors 2010, 10, 4083-4099. [CrossRef]

145. Li, D.; Chang, P.; Lu, J.G. Quasi one-dimensional metal oxide structures: Synthesis, characterization and application as chemical sensors. In Chemical Sensors: Fundamental of Sensing Materials. Volume 2: Nanostructured Materials; Korotcenkov, G., Ed.; Momentum Press: New York, NY, USA, 2010; pp. $29-86$.

146. Guo, T.; Yao, M.-S.; Lin, Y.-H.; Nan, C.-W. A comprehensive review on synthesis methods for transition-metal oxide nanostructures. CrystEngComm 2015, 17, 3551-3585. [CrossRef]

147. Wang, Z.L. Zinc oxide nanostructures: Growth, properties and applications. J. Phys. Condens. Matter 2004, 16, R829-R858. [CrossRef]

148. Fields, L.L.; Zheng, J.P.; Cheng, Y.; Xiong, P. Room temperature low-power hydrogen sensor based on a single tin dioxide nanobelt. Appl. Phys. Lett. 2006, 88, 263102. [CrossRef]

149. Hernandez-Ramirez, F.; Prades, J.D.; Jimenez-Diaz, R.; Fischer, T.; Romano-Rodriguez, A.; Mathur, S.; Morante, J.R. On the role of individual metal oxide nanowires in the scaling down of chemical sensors. Phys. Chem. Chem. Phys. 2009, 11, 7105-7110. [CrossRef]

150. Law, M.; Goldberger, J.; Yang, P. Semiconductor nanowires and nanotubes. Annu. Rev. Mater. Res. 2004, 34, 83-122. [CrossRef] 
151. Korotcenkov, G.; Golovanov, V.; Cornet, A.; Brinzari, V.; Morante, J.; Ivanov, M. Distinguishing feature of metal oxide films' structural engineering for gas sensor application. J. Phys. Confer. Series IOP 2005, 15, 256-261. [CrossRef]

152. Prades, J.D.; Jimenez-Diaz, R.; Hernandez-Ramirez, F.; Barth, S.; Cirera, A.; Romano-Rodriguez, A.; Mathur, S.; Morante, J.R. Equivalence between thermal and room temperature UV light-modulated responses of gas sensors based on individual SnO2 nanowires. Sens. Actuators B 2009, 140, 337-342. [CrossRef]

153. Hwang, I.-S.; Kim, S.-J.; Choi, J.-K.; Jung, J.-J.; Yoo, D.J.; Dong, K.-Y.; Ju, B.-K.; Lee, J.-H. Large-scale fabrication of highly sensitive $\mathrm{SnO}_{2}$ nanowire network gas sensors by single step vapor phase growth. Sens. Actuators $B$ 2012, 165, 97-103. [CrossRef]

154. Li, C.; Zhang, D.H.; Liu, X.L.; Han, S.; Tang, T.; Han, J.; Zhou, C.W. $\operatorname{~}_{2} \mathrm{O}_{3}$ nanowires as chemical sensors. Appl. Phys. Lett. 2003, 82, 1613-1615. [CrossRef]

155. Zhang, D.H.; Liu, Z.Q.; Li, C.; Tang, T.; Liu, X.L.; Han, S.; Lei, B.; Zhou, C.W. Detection of $\mathrm{NO}_{2}$ down to ppb levels using individual and multiple $\mathrm{In}_{2} \mathrm{O}_{3}$ nanowire devices. Nano Lett. 2004, 4, 1919-1924. [CrossRef]

156. Ying, Z.; Wan, Q.; Song, Z.T. $\mathrm{SnO}_{2}$ nanowhiskers and their ethanol sensing characteristics. Nanotechnology 2004, 15, 1682-1684. [CrossRef]

157. Qian, L.H.; Wang, K.; Li, Y.; Fang, H.T.; Lu, Q.H.; Ma, X.L. CO sensor based on Au-decorated $\mathrm{SnO}_{2}$ nanobelt. Mater. Chem. Phys. 2006, 10, 82-84. [CrossRef]

158. Hernandez-Ramirez, F.; Prades, J.D.; Tarancon, A.; Barth, S.; Casals, O.; Jimenez-Diaz, R.; Pellicer, E.; Rodriguez, J.; Juli, M.A.; Romano-Rodriguez, A.; et al. Portable microsensors based on individual $\mathrm{SnO}_{2}$ nanowires. Nanotechnology 2007, 18, 495-501. [CrossRef]

159. Hernandez-Ramírez, F.; Tarancón, A.; Casals, O.; Arbiol, A.J.; Rodríguez, R.; Morante, J.R. High response and stability in $\mathrm{CO}$ and humidity measures using a single $\mathrm{SnO}_{2}$ nanowire. Sens. Actuators B 2007, 121, 3-17. [CrossRef]

160. Choi, S.W.; Kim, S.S. Room temperature CO sensing of selectively grown networked ZnO nanowires by $\mathrm{Pd}$ nanodot functionalization. Sens. Actuators B 2012, 168, 1688-1713. [CrossRef]

161. Kumar, V.; Sen, S.; Muthe, K.P.; Gaur, N.K.; Gupta, S.K.; Yakhmi, J.V. Copper doped $\mathrm{SnO}_{2}$ nanowires as highly sensitive $\mathrm{H}_{2} \mathrm{~S}$ gas sensor. Sens. Actuators $B$ 2009, 138, 587-590. [CrossRef]

162. Zeng, Z.M.; Wang, K.; Zhang, Z.X.; Chen, J.J.; Zhou, W.L. The detection of $\mathrm{H}_{2} \mathrm{~S}$ at room by using individual indium oxide nanowire transistors. Nanotechnology 2009, 20, 045503. [CrossRef] [PubMed]

163. Steinhauer, S.; Brunet, E.; Maier, T.; Mutinati, G.C.; Köck, A. Suspended CuO nanowires for ppb level $\mathrm{H}_{2} \mathrm{~S}$ sensing in dry and humid atmosphere. Sens. Actuators B 2013, 186, 550-556. [CrossRef]

164. Chen, Y.; Xu, P.; Xu, T.; Zheng, D.; Li, X. ZnO-nanowire size effect induced ultra-high sensing response to ppb-level $\mathrm{H}_{2}$ S. Sens. Actuators B 2017, 240, 264-272. [CrossRef]

165. Kwak, C.H.; Woo, H.-S.; Abdel-Hady, F.; Wazzan, A.A.; Lee, J.-H. Vapor-phase growth of urchin-like $\mathrm{Mg}$-doped $\mathrm{ZnO}$ nanowire networks and their application to highly sensitive and selective detection of ethanol. Sens. Actuators B 2016, 223, 527-534. [CrossRef]

166. Zhao, Y.M.; Zhu, Y.Q. Room temperature ammonia sensing properties of $\mathrm{W}_{18} \mathrm{O}_{49}$ nanowires. Sens. Actuators $B$ 2009, 137, 27-31. [CrossRef]

167. Meier, D.C.; Semancik, S.; Button, B.; Strelcov, E.; Kolmakov, A. Coupling nanowire chemiresistors with MEMS microhotplate gas sensing platforms. Appl. Phys. Lett. 2007, 91, 63118-63120. [CrossRef]

168. Strelcov, E.; Sysoev, V.V.; Dmitriev, S.; Cothren, J.; Kolmakov, A. Self-heated nanowire sensors: Opportunities, optimization and limitations. AIP Conf. Pros. 2009, 1137, 9-11.

169. Prades, J.D.; Jimenez-Diaz, R.; Hernandez-Ramirez, F.; Barth, S.; Cirera, A.; Romano-Rodriguez, A.; Mathur, S.; Morante, J.R. Ultralow power consumption gas sensors based on self-heated individual nanowires. Appl. Phys. Lett. 2008, 93, 123110. [CrossRef]

170. Salehi, A. A highly sensitive self-heated $\mathrm{SnO}_{2}$ carbon monoxide sensor. Sens. Actuators B 2003, 96, 88-93. [CrossRef]

171. Ke, M.-T.; Lee, M.-T.; Lee, C.-Y.; Fu, L.-M. A MEMS-based benzene gas sensor with a self-heating $\mathrm{WO}_{3}$ sensing layer. Sensors 2009, 9, 2895-2906. [CrossRef] [PubMed]

172. Prades,J.D.; Jimenez-Diaz, R.; Hernandez-Ramirez, F.; Pan, J.; Romano-Rodriguez, A.; Mathur, S.; Morante, J.R. Direct observation of the gas-surface interaction kinetics in nanowires through pulsed self-heating assisted conductometric measurements. Appl. Phys. Lett. 2009, 95, 053101. [CrossRef] 
173. Prades, J.D.; Hernández-Ramírez, F.; Fischer, T.; Hoffmann, M.; Müller, R.; López, N.; Mathur, S.; Morante, J.R. Simultaneous $\mathrm{CO}$ and humidity quantification with self-heated nanowires in pulsed mode. Procedia Eng. 2011, 25, 1485-1488. [CrossRef]

174. Henrich, V.E.; Cox, P.A. The Surface Science of Metal. Oxides; Cambridge University Press: Cambridge, UK, 1994.

175. Lucas, E.; Decker, S.; Khaleel, A.; Seitz, A.; Fultz, S.; Ponce, A.; Li, W.; Carnes, C.; Klabunde, K. Nanocrystalline metal oxides as unique chemical reagent/sorbents. Chem. Eur. J. 2001, 7, 2505-2510. [CrossRef]

176. Brinzari, V.; Korotcenkov, G.; Golovanov, V. Factors influencing the gas sensing characteristics of tin dioxide films deposited by spray pyrolysis: Understanding and possibilities for control. Thin Solid Films 2001, 391, 167-175. [CrossRef]

177. Brinzari, V.; Korotcenkov, G.; Schwank, J.; Lantto, V.; Saukko, S.; Golovanov, V. Morphological rank of nano-scale tin dioxide films deposited by spray pyrolysis from $\mathrm{SnCl}_{4} \cdot 5 \mathrm{H}_{2} \mathrm{O}$ water solution. Thin Solid Films 2002, 408, 51-58. [CrossRef]

178. Golovanov, V.; Maki-Jaskari, M.A.; Rantala, T.T.; Korotcenkov, G.; Brinzari, V.; Cornet, A.; Morante, J. Experimental and theoretical studies of the indium oxide-based gas sensors deposited by spray pyrolysis. Sens. Actuators B 2005, 106, 563-571.

179. Golovanov, V.; Pekna, T.; Kiv, A.; Litovchenko, V.; Korotcenkov, G.; Brinzari, V.; Cornet, A.; Morante, J. The influence of structural factors on sensitivity of $\mathrm{SnO}_{2}$-based gas sensors to $\mathrm{CO}$ in humid atmosphere. Ukr. Phys. J. 2005, 50, 374-380.

180. Batzill, M.; Katsiev, K.; Burst, L.M.; Diebold, U.; Chaka, A.M.; Delley, B. Gas-phase-dependent properties of $\mathrm{SnO}_{2}$ (110), (100), and (101) single-crystal surfaces: Structure, composition, and electronic properties. Phys. Rev. B 2005, 72, 165414. [CrossRef]

181. Korotcenkov, G.; Blinov, I.; Stetter, J.R. Kinetics of indium oxide-based thin film gas sensor response: The role of "redox" and adsorption/desorption processes in gas sensing effects. Thin Solid Films 2007, 515, 3987-3996. [CrossRef]

182. Gurlo, A. Nanosensors: Does crystal shape matter? Small 2010, 6, 2077-20729. [CrossRef] [PubMed]

183. Gao, X.; Zhang, T. An overview: Facet-dependent metal oxide semiconductor gas sensors. Sens. Actuators $B$ 2018, 227, 604-633. [CrossRef]

184. Liang, C.; Meng, G.; Lei, Y.; Phillip, F.; Zhang, L. Catalytic growth of semiconducting $\operatorname{In}_{2} \mathrm{O}_{3}$ nanofibers. Adv. Mater. 2001, 13, 1330-1333. [CrossRef]

185. Dai, Z.R.; Pan, Z.W.; Wang, Z.L. Novel nanostructures of functional oxides synthesized by thermal evaporation. Adv. Funct. Mater. 2003, 13, 9-24. [CrossRef]

186. Kong, Y.Y.; Wang, Z.L. Structures of indium oxide nanobelts. Sol. State Commun. 2003, 128, 1-4. [CrossRef]

187. Hernandez-Ramirez, F.; Prades, J.D.; Cirera, A. Nanosensors: A platform to model the sensing mechanisms in metal oxides. In Chemical Sensors: Simulation and Modeling. Volume 2: Conductometric Gas Sensors; Korotcenkov, G., Ed.; Momentum Press: New York, NY, USA, 2012; pp. 97-126.

188. Morante, J.R. Chemical to electrical transduction mechanisms from single metal oxide nanowire measurements: Response time constant analysis. Nanotechnology 2013, 24, 444004. [CrossRef]

189. Li, J.Y.; Qiao, Z.Y.; Chen, X.L.; Chen, L.; Cao, Y.G.; He, M.; Li, H.; Cao, Z.M.; Zhang, Z. Synthesis of $\beta-\mathrm{Ga}_{2} \mathrm{O}_{3}$ nanorods. J. Alloys Compd. 2000, 306, 300-302. [CrossRef]

190. Pan, Z.W.; Dai, Z.R.; Wang, Z.L. Nanobelts of semiconducting oxides. Science 2001, 291, 1947-1949. [CrossRef]

191. Lee, J.S.; Park, K.; Nahm, S.; Kim, S.W.; Kim, S. $\mathrm{Ga}_{2} \mathrm{O}_{3}$ nanomaterials synthesized from ball-milled GaN powders. Cryst. Growth 2002, 244, 287-295. [CrossRef]

192. Kong, X.Y.; Wang, Z.L. Spontaneous polarization-induced nanohelixes, nanosprings, and nanorings of piezoelectric nanobelts. Nano Lett. 2003, 3, 1625-1631. [CrossRef]

193. Kong, X.H.; Sun, X.M.; Li, Y.D. Synthesis of ZnO nanobelts by carbothermal reduction and their photoluminescence properties. Chem. Lett. 2003, 32, 546-547. [CrossRef]

194. Jiang, C.; Han, Y.; Liu, S.; Zhang, Z. A general approach to functional metal oxide nanobelts: Thermal decomposition of precursors and interface diffusion growth mechanism. CrystEngComm. 2014, 16, 952-958. [CrossRef]

195. Liu, Y.; Zheng, C.; Wang, W.; Zhan, Y.; Wang, G. Production of $\mathrm{SnO}_{2}$ nanorods by redox reaction. Cryst. Growth 2001, 33, 8-12. [CrossRef] 
196. Wang, W.; Xu, C.; Wang, X.; Liu, Y.; Zhan, Y.; Zheng, C.; Song, F.; Wang, G. Preparation of $S_{2 n O}$ nanorods by annealing $\mathrm{SnO}_{2}$ powder in $\mathrm{NaCl}$ flux. J. Mater. Chem. 2002, 12, 1922-1925. [CrossRef]

197. Xu, C.; Xu, G.; Liu, Y.; Zhao, X.; Guanghou, W.G. Preparation and characterization of $\mathrm{SnO}_{2}$ nanorods by thermal decomposition of $\mathrm{SnC}_{2} \mathrm{O}_{4}$ precursor. Scr. Mater. 2002, 46, 789-794. [CrossRef]

198. Spencer, M.J.S. Gas sensing applications of 1D-nanostructured zinc oxide: Insights from density functional theory calculations. Prog. Mater. Sci. 2012, 57, 437-486. [CrossRef]

199. Xu, G.; Zhang, L.; He, C.; Ma, D.; Lu, Z. Adsorption and oxidation of $\mathrm{NO}$ on various $\mathrm{SnO}_{2}(110)$ surfaces: A density functional theory study. Sens. Actuators B 2015, 221, 717-722. [CrossRef]

200. Xu, J.; Xue, Z.; Qin, N.; Cheng, Z.; Xiang, Q. The crystal facet-dependent gas sensing properties of ZnO nanosheets: Experimental and computational study. Sens. Actuators B 2017, 242, 148-157. [CrossRef]

201. Dai, Z.R.; Pan, Z.W.; Wang, Z.L. Ultra-long single crystalline nanoribbons of tin oxide. Sol. St. Commun. 2001, 118, 351-354. [CrossRef]

202. Ma, X.L.; Li, Y.; Zhu, Y.L. Growth mode of the $\mathrm{SnO}_{2}$ nanobelts synthesized by rapid oxidation. Chem. Phys. Lett. 2003, 376, 794-798. [CrossRef]

203. Huang, L.; Pu, L.; Shi, Y.; Zhang, R.; Gu, B.; Du, Y.; Wright, S. Controlled growth of well-faceted zigzag tin oxide mesostructures. Appl. Phys. Let. 2005, 87, 163124. [CrossRef]

204. Fan, Z.; Lu, J.G. Gate-refreshable nanowire chemical sensors. Appl. Phys. Lett. 2005, 86, 123510. [CrossRef]

205. Zhu, L.; Zeng, W. Room-temperature gas sensing of ZnO-based gas sensor: A review. Sens. Actuators A 2017, 267, 242-261. [CrossRef]

206. Hsueh, H.T.; Hsueh, T.J.; Chang, S.J.; Hung, F.Y.; Hsu, C.L.; Dai, B.T.; Lam, K.T.; Wen, K.H. A flexible ZnO nanowire-based humidity sensor. IEEE Trans. Nanotechnol. 2012, 11, 520-525. [CrossRef]

207. Comini, E. Metal oxide nanowire sensors innovation and quality of life. Mater. Today 2016, 19, 559-567. [CrossRef]

208. Courbat, J.; Briand, D.; Oprea, A.; Bârsan, N.; Weimar, U.; De Rooij, N.F. Multi sensor platform on plastic foil for environmental monitoring. Procedia Chem. 2009, 1, 597-600. [CrossRef]

209. Oprea, A.; Courbat, J.; Briand, D.; Bârsan, N.; Weimar, U.; De Rooij, N.F. Environmental monitoring with a multisensor platform on polyimide foil. Sens. Actuators B 2012, 171, 190-197. [CrossRef]

210. Sysoev, V.V.; Button, B.K.; Wepsiec, K.; Dmitriev, S.; Kolmakov, A. Toward the nanoscopic 'electronic nose': Hydrogen vs carbon monoxide discrimination with an array of individual metal oxide nano- and mesowire sensors. Nano Lett. 2006, 6, 1584-1588. [CrossRef]

211. Goschnick, J. An electronic nose for intelligent consumer products based on a gas analytical gradient microarray. Microelectron. Eng. 2001, 57-58, 693-704. [CrossRef]

212. Sysoev, V.V.; Kiselev, I.; Frietsch, M.; Goschnick, J. Temperature gradient effect on gas discrimination power of a metal-oxide thin-film sensor microarray. Sensors 2004, 4, 37-46. [CrossRef]

213. Sysoev, V.; Goschnick, J.; Schneider, T.; Strelcov, E.E.; Kolmakov, A. A gradient microarray electronic nose based on percolating $\mathrm{SnO}_{2}$ nanowire sensing elements. Nano Lett. 2007, 7, 3182-3188. [CrossRef] [PubMed]

214. Zhang, F.; Barrowcliff, R.; Hsu, S.T. Thermal stability of $\mathrm{IrO} 2$ nanowires. In Proceedings of the International Conference on MEMS, NANO and Smart Systems (ICMENS'05), Banff, AB, Canada, 24-27 July 2005; IEEE Computer Soc.: Washington, DC, USA, 2005; pp. 418-420.

215. Kuang, Q.; Lao, C.; Zhong, L.W.; Xie, Z.; Zheng, L. High-sensitivity humidity sensor based on a single $\mathrm{SnO}_{2}$ nanowire. J. Am. Chem. Soc. 2007, 129, 6070-6071. [CrossRef] [PubMed]

216. Tonezzer, M.; Hieu, N.V. Size-dependent response of single-nanowire gas sensors. Sens. Actuators B 2012, 163, 146-152. [CrossRef]

217. Huang, J.; Wan, Q. Gas sensors based on semiconducting metal oxide one-dimensional nanostructures. Sensors 2009, 9, 9903-9924. [CrossRef]

218. Arafat, M.M.; Dinan, B.; Akbar, S.A.; Haseeb, A.S.M.A. Gas sensors based on one dimensional nanostructured metal-oxides: A review. Sensors 2012, 12, 7207-7258. [CrossRef]

219. Huang, C.M.; Thanh, D.T.; Hieu, L.V. On-chip growth of semiconductor metal oxide nano-wires for gas sensors: A review. J. Sci. Adv. Mater. Devices 2017, 2, 263-285. [CrossRef]

220. Ahmad, R.; Majhi, S.M.; Zhang, X.; Swager, T.M.; Salama, K.N. Recent progress and perspectives of gas sensors based on vertically oriented ZnO nanomaterials. Adv. Colloid Interface Sci. 2019, 270, 1-27. [CrossRef] [PubMed] 
221. Karnati, P.; Akbar, S.; Morris, P.A. Conduction mechanisms in one dimensional core-shell nanostructures for gas sensing: A review. Sens. Actuators B 2019, 295, 127-143. [CrossRef]

222. Mirzaei, A.; Lee, J.-H.; Majhi, S.M.; Weber, M.; Bechelany, M.; Kim, H.W.; Kim, S.S. Resistive gas sensors based on metal-oxide nanowires. J. Appl. Phys. 2019, 126, 241102. [CrossRef]

223. Zhang, A.; Gao, P.-X. Metal oxide nanoarrays for chemical sensing: A review of fabrication methods, sensing modes, and their inter-correlations. Front. Mater. 2019, 6, 55. [CrossRef]

224. Jian, Y.; Hu, W.; Zhao, Z.; Cheng, P.; Haick, H.; Yao, M.; Wu, W. Gas sensors based on chemi-resistive hybrid functional nanomaterials. Nano-Micro Lett. 2020, 12, 71. [CrossRef]

225. Ren, Q.; Cao, Y.-Q.; Arulraj, D.; Liu, C.; Wu, D.; Li, W.-M.; Liz, A.-D. Review-Resistive-type hydrogen sensors based on zinc oxide nanostructures. J. Electrochem. Soc. 2020, 167, 067528. [CrossRef]

226. Yoshida, T.; Shinohara, K.; Itohara, D.; Fujita, Y. Effects of thermal pressing on ZnO nanoparticle layers deposited by drop casting. e-J. Surf. Sci. Nanotechnol. 2016, 14, 175-178. [CrossRef]

227. Ko, Y.H.; Kim, S.; Yu, J.S. Drop-cast and dye-sensitized ZnO nanorod-based visible-light photodetectors. Phys. Status Solidi Rapid. Res. Lett. 2013, 7, 659-663. [CrossRef]

228. Freer, E.M.; Grachev, O.; Duan, X.; Martin, S.; Stumbo, D.P. High-yield self-limiting single-nanowire assembly with dielectrophoresis. Nat. Nanotechnol. 2010, 5, 525-530. [CrossRef]

229. Raychaudhuri, S.; Dayeh, S.A.; Wang, D.; Yu, E.T. Precise semiconductor nanowire placement through dielectrophoresis. Nano Lett. 2009, 9, 2260-2266. [CrossRef]

230. Hernandez-Ramírez, F.; Tarancon, A.; Casals, O.; Rodríguez, J.; Romano-Rodríguez, A.; Morante, J.R.; Barth, S.; Mathur, S.; Choi, T.Y.; Poulikakos, D.; et al. Fabrication and electrical characterization of circuits based on individual tin oxide nanowires. Nanotechnology 2006, 17, 5577-5583. [CrossRef]

231. Li, Q.; Koo, S.-M.; Richter, C.A.; Edelstein, M.D.; Bonevich, J.E.; Kopanski, J.J.; Suehle, J.S.; Vogel, E.M. Precise alignment of single nanowires and fabrication of nanoelectromechanical switch and other test structures. IEEE Trans. Nanotechnol. 2007, 6, 256-262. [CrossRef]

232. Jimenez-Diaz, R.; Prades, J.D.; Casals, O.; Andreu, T.; Morante, J.R.; Mathur, S.; Morante, J.R.; Prades, J.D.; Romano-Rodriguez, A.; Santander, J.; et al. From the fabrication strategy to the device integration of gas nanosensors based on individual nanowires. Nanotechnology 2011, 2, 204-207.

233. Kolmakov, A. The effect of morphology and surface doping on sensitization of quasi-1D metal oxide nanowire gas sensors. SPIE Proc. 2006, 6370, 73700X.

234. Nagahara, L.A.; Amlani, I.; Lewenstein, J.; Tsui, R.K. Directed placement of suspended carbon nanotubes for nanometer-scale assembly. Appl. Phys. Lett. 2002, 80, 3826. [CrossRef]

235. Volkert, C.A.; Mino, A.M. Focused ion beam microscopy and micromachining. MRS Bul. 2007, 32, 389-399. [CrossRef]

236. Zhou, Y.X.; Johnson, A.T., Jr.; Hone, J.; Smith, W.F. Simple fabrication of molecular circuits by shadow mask evaporation. Nano Lett. 2003, 3, 1371-1474. [CrossRef]

237. Gierak, J. Focused ion beam technology and ultimate applications. Semicond. Sci. Technol. 2009, $24,043001$. [CrossRef]

238. Melngailis, J. Focused ion beam technology and applications. J. Vac. Sci. Technol. B 1987, 5, 469-495. [CrossRef]

239. Tseng, A.A. Recent developments in nanofabrication using focused ion beams. Small 2005, 1, 924-939. [CrossRef]

240. FEI. Focused Ion Beam Technology, Capabilities and Applications; FEI Company: Hillsboro, OR, USA, 2004.

241. Gamo, K. Focused ion beam technology. Semicond. Sci. Technol. 1993, 8, 1118-1123. [CrossRef]

242. Melngailis, J. Applications of ion microbeam lithography and direct processing. In Handbook of VLSI Lithography, 2nd ed.; Helbert, J.N., Ed.; Noyes: Park Ridge, NJ, USA, 2001; pp. 791-855.

243. Ebbesen, T.W.; Lezec, H.J.; Hiura, H.; Bennett, J.W.; Gaemi, H.F.; Thio, T. Electrical conductivity of individual carbon nanotubes. Nature 1996, 382, 54-56. [CrossRef]

244. Nam, C.Y.; Tham, D.; Fischer, J.E. Disorder effects in focused-ion-beam-deposited Pt contacts on GaN nanowires. Nano Lett. 2005, 5, 2029-2033. [CrossRef]

245. Griffith, S.; Mondol, M.; Kong, D.S.; Jacobson, J.M. Nanostructure fabrication by direct electron beam writing of nanoparticles. J. Vac. Sci. Technol. B 2002, 20, 2768-2772. [CrossRef] 
246. Rotkina, L.; Lin, J.-F.; Bird, J.P. Nonlinear current-voltage characteristics of Pt nanowires and nanowire transistors fabricated by electron-beam deposition. Appl. Phys. Let. 2003, 83, 4426. [CrossRef]

247. Donarelli, M.; Ferroni, M.; Ponzoni, A.; Rigoni, F.; Zappa, D.; Baratto, C.; Faglia, G.; Comini, E.; Sberveglieri, G. Single metal oxide nanowire devices for ammonia and other gases detection in humid atmosphere. Procedia Eng. 2016, 168, 1052-1055. [CrossRef]

248. Gopal, V.; Radmilovic, V.R.; Daraio, C.; Jin, S.; Yang, P.; Stach, E.A. Rapid prototyping of site-specific nanocontacts by electron and ion beam assisted direct-write nanolithography. Nano Lett. 2004, 4, 2059-2063. [CrossRef]

249. Wang, D.; Zhu, R.; Zhaoying, Z.; Ye, X. Controlled assembly of zinc oxide nanowires using dielectrophoresis. Appl. Phys. Lett. 2007, 90, 103110. [CrossRef]

250. Kumar, P. Directed self-assembly: Expectations and achievements. Nanoscale Res. Lett. 2010, 5, 1367-1376. [CrossRef] [PubMed]

251. Chang, Y.-K.; Hong, F.C.-N. The fabrication of ZnO nanowire field-effect transistors by roll-transfer printing. Nanotechnology 2009, 20, 195302. [CrossRef] [PubMed]

252. Van Osch, T.H.J.; Perelaer, J.; De Laat, A.W.M. Inkjet printing of narrow conductive tracks on untreated polymeric substrates. Adv. Mater. 2008, 20, 343-345. [CrossRef]

253. Cui, Z. (Ed.) Printed Electronics. Materials, Technologies and Applications; Wiley: Singapore, 2016.

254. Mårtensson, T.; Carlberg, P.; Borgstrom, M.; Montelius, L.; Seifert, W.; Samuelson, L. Nanowire arrays defined by nanoimprinting lithography. Nano Lett. 2004, 4, 699-702. [CrossRef]

255. Maury, P.; Peter, M.; Mahalingam, V.; Reinhoudt, D.N.; Huskens, J. Patterned self-assembled monolayers on silicon oxide prepared by nanoimprint lithography and their applications in nanofabrication. Adv. Funct. Mater. 2005, 15, 451-457. [CrossRef]

256. Kim, Y.-K.; Kim, G.T.; Ha, J.S. Simple patterning via adhesion between a buffered-oxide etchant-treated PDMS stamp and a $\mathrm{SiO}_{2}$ substrate. Adv. Funct. Mater. 2007, 17, 2125-2132. [CrossRef]

257. Vomiero, A.; Ponzoni, A.; Comini, E.; Ferroni, M.; Faglia, G.; Sberveglieri, G. Direct integration of metal oxide nanowires into an effective gas sensing device. Nanotechnology 2010, 21, 145502. [CrossRef] [PubMed]

258. Nikoobakht, B.; Wang, X.; Herzing, A.; Shi, J. Scalable synthesis and device integration of self-registered one-dimensional zinc oxide nanostructures and related materials. Chem. Soc. Rev. 2013, 42, 342-365. [CrossRef] [PubMed]

259. Hong, L.Y.; Lin, H.N. NO gas sensing at room temperature using single titanium oxide nanodot sensors created by atomic force microscopy nanolithography. Beilstein J. Nanotechnol. 2016, 7, 1044-1051. [CrossRef] [PubMed]

260. Morag, A.; Jelinek, R. “Bottom-up" transparent electrodes. J. Colloid Interface Sci. 2016, 482, $267-289$. [CrossRef] [PubMed]

261. Ma, P.; Xu, Z.; Wang, M.; Lu, L.; Yin, M.; Chen, X.; Li, D.; Ren, W. Fast fabrication of $\mathrm{TiO}_{2}$ hard stamps for nanoimprint lithograph. Mater. Res. Bull. 2017, 90, 253-259. [CrossRef]

262. Xia, Y.N.; Yang, P.D.; Sun, Y.G.; Wu, Y.Y.; Mayers, B. One-dimensional nanostructures: Synthesis, characterization, and applications. Adv. Mater. 2003, 15, 353-389. [CrossRef]

263. Whang, D.; Jin, S.; Wu, Y.; Lieber, C.M. Large-scale hierarchical organization of nanowire arrays for integrated nanosystems. Nano Lett. 2003, 3, 1255-1259. [CrossRef]

264. Lieber, C.M. Nanoscale science and technology: Building a big future from small things. MRS Bull. 2003, 28, 486-491. [CrossRef]

265. Qi, P.; Vermesh, O.; Grecu, M.; Javey, A.; Wang, Q.; Dai, H. Toward large arrays of multiplex functionalized carbon nanotube sensors for highly sensitive and selective molecular detection. Nano Lett. 2003, 3, 347-351. [CrossRef]

266. Assad, O.; Leshansky, A.M.; Wang, B.; Stelzner, T.; Christiansen, S.; Haick, H. Spray coating route for highly aligned and large-scale arrays of nanowires. ACS Nano 2012, 6, 4702-4712. [CrossRef] [PubMed]

267. Liu, X.; Long, Y.-Z.; Liao, L.; Duan, X.; Fan, Z. Large-scale integration of semiconductor nanowires for high-performance flexible electronics. ACS Nano 2012, 6, 1888-1900. [CrossRef] [PubMed]

268. Long, Y.Z.; Yu, M.; Sun, B.; Gu, C.Z.; Fan, Z. Recent advances in large-scale assembly of semiconducting inorganic nanowires and nanofibers for electronics, sensors and photovoltaics. Chem. Soc. Rev. 2012, 12, 4560-4580. [CrossRef] [PubMed] 
269. Hu, H.; Wang, S.; Feng, X.; Pauly, M.; Decher, G.; Long, Y. In-plane aligned assemblies of 1D-nanoobjects: Recent approaches and applications. Chem. Soc. Rev. 2020, 49, 509-553. [CrossRef] [PubMed]

270. Huang, Y.; Duan, X.; Wei, Q.; Lieber, C.M. Direct assembly of one-dimensional nanostructures into functional networks. Science 2001, 291, 630-633. [CrossRef] [PubMed]

271. Javey, A.; Nam, S.M.; Friedman, R.S.; Yan, H.; Lieber, C.M. Layer-by-Layer assembly of nanowires for three-dimensional, multifunctional electronics. Nano Lett. 2007, 7, 773-777. [CrossRef]

272. Ruda, H.E.; Shik, A. Principles of nanowire alignment in an electric field. J. Appl. Phys. 2011, 109, 064305. [CrossRef]

273. Di Francia, G.; Alfano, B.; La Ferrara, V. Conductometric gas nanosensors. J. Sens. 2009, $2009,659275$. [CrossRef]

274. Dmitriev, S.; Lilach, Y.; Button, B.; Moskovits, M.; Kolmakov, A. Nanoengineered chemiresistors: The interplay between electron transport and chemisorption properties of morphologically encoded $\mathrm{SnO}_{2}$ nanowires. Nanotechnology 2007, 18, 055707. [CrossRef]

275. Ponzoni, A.; Comini, E.; Sberveglieri, G.; Zhou, J.; Deng, S.Z.; Xu, N.S.; Ding, Y.; Wang, Z.L. Ultrasensitive and highly selective gas sensors using three-dimensional tungsten oxide nanowire networks. Appl. Phys. Lett. 2006, 88, 203101. [CrossRef]

276. Köck, A.; Tischner, A.; Maier, T.; Kast, M.; Edtmaier, C.; Gspan, C.; Kothleitner, G. Atmospheric pressure fabrication of $\mathrm{SnO}_{2}$-nanowires for highly sensitive $\mathrm{CO}$ and $\mathrm{CH}_{4}$ detection. Sens. Actuators B 2009, 138, 160-167. [CrossRef]

277. Wang, X.; Ding, Y.; Summers, C.J.; Wang, Z.L. Large-scale synthesis of six nanometer-wide ZnO nanobelts. J. Phys. Chem. B 2004, 108, 8773-8777. [CrossRef]

278. Lilach, Y.; Zhang, J.-P.; Moskovits, M.; Kolmakov, A. Encoding morphology in oxide nanostructures during their growth. Nano Lett. 2005, 5, 2019-2022. [CrossRef]

279. Dimaggio, E.; Pennelli, G. Reliable fabrication of metal contacts on silicon nanowire forests. Nano Lett. 2016, 16, 4348-4354. [CrossRef] [PubMed]

280. Hernandez-Ramirez, F.; Barth, S.; Tarancon, A.; Casals, O.; Pellicer, E.; Rodriguez, J.; Romano-Rodriguez, A.; Morante, J.R.; Mathur, S. Water vapor detection with individual tin oxide nanowires. Nanotechnology 2007, 18, 424016. [CrossRef] [PubMed]

281. Lin, Y.-F.; Jian, W.-B. The impact of nanocontact on nanowire based nanoelectronics. Nano Lett. 2008, 8, 3146-3150. [CrossRef]

282. Wu, Y.; Yang, P. Melting and welding semiconductor nanowires in nanotubes. Adv. Mater. 2001, 13, 520-523. [CrossRef]

283. Toimil Molares, M.E.; Balogh, A.G.; Cornelius, T.W.; Neumann, R.; Trautmann, C. Fragmentation of nanowires driven by Rayleigh instability. Appl. Phys. Lett. 2004, 85, 5337-5339. [CrossRef]

284. Wang, X.W.; Fei, G.T.; Wu, B.; Chen, L.; Chu, Z.Q. Structural stability of Co nanowire arrays embedded in the PAAM. Phys. Lett. A 2006, 359, 220-222. [CrossRef]

285. Guisbiers, G.; Pereira, S. Theoretical investigation of size and shape effects on the melting temperature of ZnO nanostructures. Nanotechnology 2007, 18, 435710.

286. Li, J.; Srinivasan, S.; He, G.N.; Kang, J.Y.; Wu, S.T.; Ponce, F.A. Synthesis and luminescence properties of ZnO nanostructures produced by the sol-gel method. J. Cryst. Grow. 2008, 310, 599-603. [CrossRef]

287. Wautelet, M. On the melting of polyhedral elemental nanosolids. Eur. Phys. J. Appl. Phys. 2005, 29, 51-54. [CrossRef]

288. Li, S.; Jiand, Q. Effect of size on the phase stability of nanostructures. In Chemical Sensors: Simulation and Modeling. Volume 1: Microstructural Characterization and Modeling of Metal Oxides; Korotcenkov, G., Ed.; Momentum Press: New York, NY, USA, 2012; pp. 363-396.

289. Strelcov, E.; Dmitriev, S.; Button, B.; Cothren, J.; Sysoev, V.; Kolmakov, A. Evidence of the self-heating effect on surface reactivity and gas sensing of metal oxide nanowire chemiresistors. Nanotechnology 2008, 19, 355502. [CrossRef] [PubMed]

290. Hui, L.; Pederiva, F.; Wang, B.L.; Wang, J.L.; Wang, G.H. How does the nickel nanowires melt? Appl. Phys. Lett. 2005, 86, 011913. [CrossRef]

291. Krishna Goswami, G.; Kar Nanda, K. Size-dependent melting of finite-length nanowires. J. Phys. Chem. C 2010, 114, 14327-14331. [CrossRef] 
292. Shaposhnik, A.V.; Shaposhnik, D.A.; Turishchev, S.Y.; Chuvenkova, O.A.; Ryabtsev, S.V.; Vasiliev, A.A.; Vilanova, X.; Hernandez-Ramirez, F.; Morante, J.R. Gas sensing properties of individual $\mathrm{SnO}_{2}$ nanowires and $\mathrm{SnO}_{2}$ sol-gel nanocomposites. Beilstein J. Nanotechnol. 2019, 10, 1380-1390. [CrossRef]

293. Deb, B.; Desai, S.; Sumanasekera, G.U.; Sunkara, M.K. Gas sensing behaviour of mat-like networked tungsten oxide nanowire thin films. Nanotechnology 2007, 18, 285501. [CrossRef]

294. Vomiero, A.; Bianchi, S.; Comini, E.; Faglia, G.; Ferroni, M.; Sberveglieri, G. Controlled growth and sensing properties of $\mathrm{In}_{2} \mathrm{O}_{3}$ nanowires. Crystal Growth Design 2007, 7, 2500-2504. [CrossRef]

295. Kim, Y.-S.; Hwang, I.-S.; Kim, S.-J.; Lee, C.-Y.; Lee, J.-H. CuO nanowire sensors for air quality control in automotive cabin. Sens. Actuators B 2008, 135, 298-303. [CrossRef]

296. Hwang, I.-S.; Kim, Y.-S.; Kim, S.-J.; Ju, B.-K.; Lee, J.-H. A facile fabrication of semiconductor nanowires gas sensor using PDMS patterning and solution deposition. Sens. Actuators B 2009, 136, 224-229. [CrossRef]

297. Hwang, I.-S.; Choi, J.-K.; Woo, H.-S.; Kim, S.-J.; Jung, S.-Y.; Seong, T.-Y.; Kim, I.-D.; Lee, J.-H. Facile control of $\mathrm{C}_{2} \mathrm{H}_{5} \mathrm{OH}$ sensing characteristics by decorating discrete $\mathrm{Ag}$ nanoclusters on $\mathrm{SnO}_{2}$ nanowire networks. ACS Appl. Mater. Interfaces 2011, 3, 3140-3145. [CrossRef]

298. Wang, N.; Cai, Y.; Zhang, R.Q. Growth of nanowires. Mater. Sci. Eng. R 2008, 60, 1-51. [CrossRef]

299. Varghese, O.K.; Grimes, C.A. Metal oxide nanoarchitectures for environmental sensing. J. Nanosci. Nanotechnol. 2003, 3, 277-293. [CrossRef] [PubMed]

300. Varghese, O.K.; Paulose, M.; Grimes, C.A. Long vertically aligned titania nanotubes on transparent conducting oxide for highly efficient solar cells. Nature Nanotechnol. 2009, 4, 592-597. [CrossRef] [PubMed]

301. Tian, Z.R.; Voigt, J.A.; Liu, J.; McKerzie, B.; McDermont, M.J.; Rodriguez, M.A.; Konishi, H.; Xu, H. Complex and oriented $\mathrm{ZnO}$ nanostructures. Nat. Mater. 2003, 2, 821-826. [CrossRef]

302. Wei, Y.; Wu, W.; Guo, R.; Yuan, D.; Das, S.; Wang, Z.L. Wafer-scale high-throughput ordered growth of vertically aligned ZnO nanowire arrays. Nano Lett. 2010, 10, 3414-3419. [CrossRef]

303. Djurisic, A.B.; Chen, X.; Leung, Y.H.; Ng, A.M.C. ZnO nanostructures: Growth, properties and applications. J. Mater. Chem. 2012, 22, 6526-6535. [CrossRef]

304. Kim, C.; Park, J.B.; Jee, H.G.; Lee, S.B.; Boo, J.H.; Kim, S.K.; Yoo, J.-B.; Lee, J.S.; Lee, H. Formation of Au nanostructures through an alumina mask by laser-assisted deposition. J. Nanosci. Nanotechnol. 2005, 5, 306-312. [CrossRef]

305. Srivastava, D.; Hendricks, T.R.; Lee, I. Step-edge like template fabrication of polyelectrolyte supported nickel nanowires. Nanotechnology 2007, 18, 245305. [CrossRef]

306. Lu, L.; Chen, J.; Li, L.; Wang, W. Direct synthesis of vertically aligned ZnO nanowires on FTO substrates using a CVD method and the improvement of photovoltaic performance. Nanoscale Res. Lett. 2012, 7, 293. [CrossRef]

307. Wang, X.; Kim, K.; Wang, Y.; Stadermann, M.; Noy, A.; Hamza, A.V.; Yang, J.; Sirbuly, D.J. Matrix-assisted energy conversion in nanostructured piezoelectric arrays. Nano Lett. 2010, 10, 4901. [CrossRef] [PubMed]

308. Chia, A.C.E.; LaPierre, R.R. Contact planarization of ensemble nanowires. Nanotechnology 2011, $22,245304$. [CrossRef]

309. Parthangal, P.; Cavicchi, R.; Zachariah, M. Design, fabrication and testing of a novel gas sensor utilizing vertically aligned zinc oxide nanowire arrays. MRS Proc. 2007, 951. [CrossRef]

310. Radha, B.; Jayaraj, D.; Kulkarni, G.U.; Heun, S.; Ercolani, D.; Sorba, L. Large-Area Ohmic Top Contact to Vertically Grown Nanowires Using a Free-Standing Au Microplate Electrode. ACS Appl. Mater. Interfaces 2012, 4, 4. [CrossRef] [PubMed]

311. Ahn, M.-W.; Park, K.-S.; Heo, J.-H.; Park, J.-G.; Kim, D.-W.; Choi, K.J.; Lee, J.-H.; Hong, S.-H. Gas sensing properties of defect-controlled ZnO-nanowire gas sensor. Appl. Phys. Lett. 2008, 93, 263103. [CrossRef]

312. Ahn, M.-W.; Park, K.-S.; Heo, J.-H.; Kim, D.-W.; Choi, K.J.; Park, J.-G. On-chip fabrication of ZnO-nanowire gas sensor with high gas sensitivity. Sens. Actuators B 2009, 138, 168-173. [CrossRef]

313. Yuon, S.K.; Ramgir, N.; Wang, C.; Subannajui, K.; Cimalla, V.; Zacharias, M. Catalyst-free growth of ZnO nanowires based on topographical confinement and preferential chemisorption and their use for room temperature CO detection. J. Phys. Chem. C 2010, 114, 10092-10100. [CrossRef]

314. McAleer, J.F.; Moseley, P.T.; Norris, J.O.W.; Williams, D.E. Tin dioxide gas sensors. 1. Aspects of the surface-chemistry revealed by electrical conductance variations. J. Chem. Soc. Faraday Trans. 1987, I83, 1323-1346. [CrossRef] 
315. Wang, B.; Zhu, L.F.; Yang, Y.H.; Xu, N.S.; Yang, G.W. Fabrication of a $\mathrm{SnO}_{2}$ nanowire gas sensor and sensor performance for hydrogen. J. Phys. Chem. C 2008, 112, 6643-6647. [CrossRef]

316. Kim, D.Y.; Son, J.Y. Horizontal ZnO nanowires for gas sensor application: Al-doping effect on sensitivity. Elecrochem. Solid State Lett. 2009, 19, j109-j111. [CrossRef]

317. Zach, M.P.; Ng, K.H.; Penner, R.M. Molybdenum nanowires by electrodeposition. Science 2000, 290, $2120-2123$. [CrossRef] [PubMed]

318. Nikoobakht, B.; Michaels, C.A.; Stranick, S.J. Horizontal growth and in situ assembly of oriented zinc oxide nanowires. Appl. Phys. Lett. 2004, 85, 3244. [CrossRef]

319. Nikoobakht, B. Toward industrial-scale fabrication of nanowire-based devices. Chem. Mater. 2007, 21, 27-32. [CrossRef]

320. Xu, S.; Ding, Y.; Wei, Y.; Fang, H.; Shen, Y.; Sood, A.K.; Polla, D.L.; Wang, Z.L. Patterned growth of horizontal ZnO nanowire arrays. J. Am. Chem. Soc. 2009, 131, 6670-6671. [CrossRef]

321. Qin, Y.; Yang, R.; Wang, Z.L. Growth of horizonatal ZnO nanowire arrays on any substrate. J. Phys. Chem. C 2008, 112, 18734-18736. [CrossRef]

322. Wang, X.; Aroonyadet, N.; Zhang, Y.; Mecklenburg, M.; Fang, X.; Chen, H.; Goo, E.; Zhou, C. Aligned epitaxial $\mathrm{SnO}_{2}$ nanowires on sapphire: Growth and device applications. Nano Lett. 2014, 14, 3014-3022. [CrossRef]

323. Shinde, P.V.; Saxena, M.; Singh, M.K. Recent developments in graphene-based two-dimensional heterostructures for sensing applications. In Fundamentals and Sensing Applications of 2D Materials; Rout, C.S., Late, D., Morgan, H., Eds.; Woodhead Publishing: Cambridge, MA, USA, 2019; pp. 407-436.

324. Korotcenkov, G. Black phosphorus-New nanostructured material for humidity sensors: Achievements and limitations. Sensors 2019, 19, 1010. [CrossRef]

325. Pakdel, A.; Zhi, C.; Bando, Y.; Golberg, D. Low-dimensional boron nitride nanomaterials. Mater. Today 2012, 15, 256-265. [CrossRef]

326. Yang, W.; Gan, L.; Li, H.; Zhai, T. Two-dimensional layered nanomaterials for gas-sensing applications. Inorg. Chem. Front. 2016, 3, 433-451. [CrossRef]

327. Goenka, S.; Sant, V.; Sant, S. Graphene-based nanomaterials for drug delivery and tissue engineering. J. Controll. Release 2014, 173, 75-88. [CrossRef]

328. Huang, X.; Tan, C.; Yin, Z.; Zhang, H. 25th anniversary article: Hybrid nanostructures based on two-dimensional nanomaterials. Adv. Mater. Proces. 2014, 26, 2185-2204. [CrossRef] [PubMed]

329. Wu, W.; Wang, L.; Li, Y.; Zhang, F.; Lin, L.; Niu, S.; Chenet, D.; Zhang, X.; Hao, Y. Piezoelectricity of single-atomic-layer $\mathrm{MoS}_{2}$ for energy conversion and piezotronics. Nature 2014, 514, 470-474. [CrossRef] [PubMed]

330. Kannan, P.K.; Late, D.J.; Morgan, H.; Rout, C.S. Recent developments in 2D layered inorganic nanomaterials for sensing. Nanoscale 2015, 7, 13293-13312. [CrossRef] [PubMed]

331. Anasori, B.; Lukatskaya, M.R.; Gogotsi, Y. 2D metal carbides and nitrides (MXenes) for energy storage. Nature Rev. Mater. 2017, 2,1-17. [CrossRef]

332. Martínez-Periñán, E.; Down, M.P.; Gibaja, C.; Lorenzo, E.; Zamora, F.; Banks, C.E. Antimonene: A novel 2D nanomaterial for supercapacitor applications. Adv. Energy Mater. 2018, 8, 1702606. [CrossRef]

333. Briggs, N.; Subramanian, S.; Lin, Z.; Li, X.; Zhang, X.; Zhang, K.; Xiao, K.; Geohegan, D.; Wallace, R.; Chen, L.-Q.; et al. A roadmap for electronic grade 2D materials. 2D Mater. 2019, 6, 022001. [CrossRef]

334. Rajkumar, K.; Rajendra Kumar, R.T. Gas sensors based on two-dimensional materials and its mechanisms. In Fundamentals and Sensing Applications of 2D Materials; Rout, C.S., Late, D., Morgan, H., Eds.; Woodhead Publishing: Cambridge, MA, USA, 2019; pp. 205-258.

335. Sun, Z.; Liao, T.; Dou, Y.; Hwang, S.M.; Park, M.S.; Jiang, L.; Kim, J.H.; Dou, S.X. Generalized self-assembly of scalable two dimensional transition metal oxide nanosheets. Nat. Commun. 2014, 5, 3813. [CrossRef]

336. Segev-Bar, M.; Haick, H. Flexible sensors based on nanoparticles. ACS Nano 2013, 7, 8366-8378. [CrossRef]

337. Samal, R.; Rout, C.S. Wearable and flexible sensors based on 2D and nanomaterials. In Fundamentals and Sensing Applications of 2D Materials; Rout, C.S., Late, D., Morgan, H., Eds.; Woodhead Publishing: Cambridge, MA, USA, 2019; pp. 437-463.

338. Chen, X.; Liu, J.; Jing, X. Self-assembly of $\mathrm{ZnO}$ nanosheets into flowerlike architectures and their gas sensing properties. Mater. Lett. 2013, 112, 23-25. [CrossRef] 
339. Zeng, Y.; Lin, S.; Gu, D.; Li, X. Two-dimensional nanomaterials for gas sensing applications: The role of theoretical calculations. Nanomaterials 2018, 8, 851. [CrossRef]

340. Velicky, M.; Toth, P.S. Fron two-dimensional materials to their heterostructures: An electrpchemist's perspective. Appl. Mater. Today 2017, 8, 68-103. [CrossRef]

341. Vargas-Bernal, R. Electrical properties of two-dimensional materials used in gas sensors. Sensors 2019, 19, 1295. [CrossRef] [PubMed]

342. Cho, B.; Yoon, J.; Lim, S.K.; Kim, A.R.; Kim, D.H.; Park, S.G.; Kwon, J.-D.; Lee, Y.-J.; Lee, K.-H.; Lee, B.H.; et al. Chemical sensing of 2D graphene/MoS2 heterostructure device. ACS Appl. Mater. Interfaces 2015, 7, 16775-16780. [CrossRef] [PubMed]

343. Thanh, T.D.; Chuong, N.D.; Hien, H.V.; Kshetri, T.; Tuan, L.H.; Kim, N.H.; Lee, J.H. Recent advances in two-dimensional transition metal dichalcogenides-graphene heterostructured materials for electrochemical applications. Prog. Mater. Sci. 2018, 96, 51-85. [CrossRef]

344. Shanmugasundaram, A.; Gundimeda, V.; Hou, T.; Lee, D.W. Realizing synergy between $\operatorname{In}_{2} \mathrm{O}_{3}$ nanocubes and nitrogen-doped reduced graphene oxide: An excellent nanocomposite for the selective and sensitive detection of CO at ambient temperatures. ACS Appl. Mater. Interfaces 2017, 9, 31728-31740. [CrossRef]

345. Yang, S.; Jiang, C.; Wei, S.-H. Gas sensing in 2D materials. Appl. Phys. Rev. 2017, 4, 021304. [CrossRef]

346. Liu, Y.; Zhang, S.; He, J.; Wang, Z.M.; Liu, Z. Recent progress in the fabrication, properties, and devices of heterostructures based on 2D materials. Nano-Micro Lett. 2019, 11, 13. [CrossRef]

347. Neri, G. Thin 2D: The new dimensionality in gas sensing. Chemosensors 2017, 5, 21. [CrossRef]

348. Tan, C.; Cao, X.; Wu, X.-J.; He, Q.; Yang, J.; Zhang, X.; Chen, J.; Zhao, W.; Han, S.; Nam, J.-H.; et al. Recent advances in ultrathin two-dimensional nanomaterials. Chem. Rev. 2017, 117, 6225-6331. [CrossRef]

349. Choi, S.-J.; Kim, I.-D. Recent developments in 2D nanomaterials for chemiresistive-type gas sensors. Electron. Mater. Lett. 2018, 14, 221-260. [CrossRef]

350. Joshi, N.; Hayasaka, T.; Liu, Y.; Liu, H.; Oliveira, O.N., Jr.; Lin, L. A review on chemiresistive room temperature gas sensors based on metal oxide nanostructures, graphene and 2D transition metal dichalcogenides. Microchim. Acta 2018, 185, 213. [CrossRef] [PubMed]

351. Ge, L.; Mu, X.; Tian, G.; Huang, Q.; Ahmed, J.; Hu, Z. Current applications of gas sensor based on 2-D nanomaterial: A mini review. Front. Chem. 2019, 7, 839. [CrossRef] [PubMed]

352. Late, D.J.; Bhat, A.; Rout, C.S. Fundamentals and properties of 2D materials in general and sensing applications. In Fundamentals and Sensing Applications of 2D Materials; Rout, C.S., Late, D., Morgan, H., Eds.; Woodhead Publishing: Cambridge, MA, USA, 2019; pp. 5-24.

353. Zhang, L.; Khan, K.; Zou, J.; Zhang, H.; Li, Y. Recent advances in emerging 2D material-based gas sensors: Potential in disease diagnosis. Adv. Mater. Interfaces 2019, 2019, 1901329. [CrossRef]

354. Boroujerdi, R.; Abdelkader, A.; Paul, R. State of the art in alcohol sensing with 2D materials. Nano-Micro Lett. 2020, 12, 33. [CrossRef]

355. Leonardi, S.G. Two-dimensional zinc oxide nanostructures for gas sensor applications. Chemosensors 2017, 5, 17. [CrossRef]

356. Kalanta-zadeh, K.; Vijayaraghavan, A.; Ham, M.-H.; Zheng, H.; Breedon, M.; Strano, M.S. Synthesis of atomically thin WO3 sheets from hydrated tungsten trioxide. Chem. Mater. 2010, 22, 5660-5666. [CrossRef]

357. Wells, A.F. Structural Inorganic Chemistry; Clarendon Press: Oxford, UK, 1984.

358. Enjalbert, R.; Galy, J. A refinement of the structure of $\mathrm{V}_{2} \mathrm{O}_{5}$. Acta Crystallogr. C 1986, 42, 1467-1469. [CrossRef]

359. Backes, C.; Abdelkader, A.M.; Alonso, C.; Andrieux-Ledier, A.; Arenal, R.J.; Azpeitia, L.; Balakrishnan, N.; Banszerus, L.; Barjon, J.; Bartali, R.; et al. Production and processing of graphene and related materials. 2D Mater. 2020, 7, 022001. [CrossRef]

360. Ji, F.; Ren, X.; Zheng, X.; Liu, Y.; Pang, L.; Jiang, J.; Liu, S. 2D-MoO $\mathrm{Mon}_{3}$ nanosheets for superior gas sensors. Nanoscale 2016, 8, 8696-8703. [CrossRef]

361. Kalanta-zadeh, K.; Ou, J.Z.; Daeneke, T.; Mitchell, A.; Sasaki, T.; Fuhrer, M.S. Two dimensional and layered transition metal oxides. Appl. Mater. Today 2016, 5, 73-89. [CrossRef]

362. Osada, M.; Sasaki, T. Two-dimensional dielectric nanosheets: Novel nanoelectronics from nanocrystal building blocks. Adv. Mater. 2012, 24, 210-228. [CrossRef] 
363. Zeng, Y.; Qiao, L.; Bing, Y.; Wen, M.; Zou, B.; Zheng, W.; Zhang, T.; Zou, G. Development of microstructure CO sensor based on hierarchically porous ZnO nanosheet thin films. Sens. Actuators B 2012, 173, 897-902. [CrossRef]

364. Qiao, P.-Y.; Zhang, L.-X.; Zhu, M.-Y.; Yin, Y.-Y.; Zhao, Z.-W.; Sun, H.-N.; Dong, J.-Y.; Bie, L.-J. Acetylene sensing enhancement of mesoporous $\mathrm{ZnO}$ nanosheets with morphology and defect induced structural sensitization. Sens. Actuators B 2017, 250, 189-197. [CrossRef]

365. Khan, R.; Raj, S.; Yun, J.H.; Yu, Y.-T.; Lee, J.I.; Lee, I.-H. Facile preparation of ZnO nanosheets and its photocatalytic activity in the degradation of rhodamine B dye under UV irradiation. Electron. Mater. Lett. 2016, 12, 784-788. [CrossRef]

366. Lou, Z.; Wang, L.; Wang, R.; Fei, T.; Zhang, T. Synthesis and ethanol sensing properties of $\mathrm{SnO}_{2}$ nanosheets via a simple hydrothermal route. Solid-State Electron. 2012, 76, 91-94. [CrossRef]

367. Zeng, W.; Wu, M.; Li, Y.; Wu, S. Hydrothermal synthesis of different $\mathrm{SnO}_{2}$ nanosheets with $\mathrm{CO}$ gas sensing properties. J. Mater. Sci. Mater. Electron. 2013, 24, 3701-3706. [CrossRef]

368. Wang, Z.; Wang, D.; Sun, J. Controlled synthesis of defect-rich ultrathin two-dimensional $\mathrm{WO}_{3}$ nanosheets for $\mathrm{NO}_{2}$ gas detection. Sens. Actuators $B$ 2017, 245, 828-834. [CrossRef]

369. Umar, A.; Alshahrani, A.A.; Algarni, H.; Kumar, R. CuO nanosheets as potential scaffolds for gas sensing applications. Sens. Actuators B 2017, 250, 24-31. [CrossRef]

370. Li, H.-H.; Li, Z.-Y.; Wu, X.-L.; Zhang, L.-L.; Fan, C.-Y.; Wang, H.-F.; Li, X.-Y.; Wang, K.; Sun, H.-Z.; Zhang, J.-P. Shale-like $\mathrm{Co}_{3} \mathrm{O}_{4}$ for high performance lithium/sodium ion batteries. J. Mater. Chem. A 2016, 4, 8242-8248. [CrossRef]

371. Li, Z.; Lin, Z.; Wang, N.; Wang, J.; Liu, W.; Sun, K.; Fu, Y.Q.; Wang, Z. High precision $\mathrm{NH}_{3}$ sensing using network nano-sheet $\mathrm{Co}_{3} \mathrm{O}_{4}$ arrays based sensor at room temperature. Sens. Actuators B 2016, 235, $222-231$. [CrossRef]

372. Wang, X.; Su, J.; Chen, H.; Li, G.D.; Shi, Z.; Zou, H.; Zou, X. Ultrathin $\operatorname{In}_{2} \mathrm{O}_{3}$ nanosheets with uniform mesopores for highly sensitive nitric oxide detection. ACS Appl. Mater. Interfaces 2017, 9, 16335. [CrossRef] [PubMed]

373. Rui, X.; Lu, Z.; Yin, Z.; Sim, D.H.; Xiao, N.; Lim, T.M.; Hng, H.H.; Zhang, H.; Yan, Q. Oriented molecular attachments through sol-gel chemistry for synthesis of ultrathin hydrated vanadium pentoxide nanosheets and their applications. Small 2013, 9, 716-721. [CrossRef] [PubMed]

374. Li, S.-M.; Zhang, L.-X.; Zhu, M.-Y.; Ji, G.-J.; Zhao, L.-X.; Yin, J.; Bie, L.-J. Acetone sensing of ZnO nanosheets synthesized using room-temperature precipitation. Sens. Actuators B 2017, 249, 611-623. [CrossRef]

375. Zhang, S.-L.; Lim, J.-O.; Huh, J.-S.; Noh, J.-S.; Lee, W. Two-step fabrication of ZnO nanosheets for high-performance VOCs gas sensor. Curr. Appl. Phys. 2013, 13, S156-S161. [CrossRef]

376. Hu, G.; Kang, J.; Ng, L.W.T.; Zhu, X.; Howe, R.C.T.; Jones, C.G.; Hersam, M.C.; Hasan, T. Functional inks and printing of two-dimensional materials. Chem. Soc. Rev. 2018, 47, 3265-3300. [CrossRef] [PubMed]

377. Kim, S.J.; Choi, S.J.; Jang, J.S.; Cho, H.J.; Koo, W.T.; Tuller, H.L.; Kim, I.D. Exceptional high-performance of Pt-based bimetallic catalysts for exclusive detection of exhaled biomarkers. Adv. Mater. 2017, 29, 1700737. [CrossRef]

378. Chen, Z.; Lin, Z.; Xu, M.; Hong, Y.; Li, N.; Fu, P.; Chen, Z. Effect of gas sensing properties by Sn-Rh codoped $\mathrm{ZnO}$ nanosheets. Electron. Mater. Lett. 2016, 12, 343-349. [CrossRef]

379. Yin, M.; Yao, Y.; Fan, H.; Liu, S. $\mathrm{WO}_{3}-\mathrm{SnO}_{2}$ nanosheet composites: Hydrothermal synthesis and gas sensing mechanism. J. Alloys Compd. 2018, 736, 322-331. [CrossRef]

380. Cao, Y.; He, Y.; Zou, X.; Li, G.-D. Tungsten oxide clusters decorated ultrathin $\mathrm{In}_{2} \mathrm{O}_{3}$ nanosheets for selective detecting formaldehyde. Sens. Actuators B 2017, 252, 232-238. [CrossRef]

381. Xu, Y.; Cheng, C.; Du, S.; Yang, J.; Yu, B.; Luo, J.; Yin, W.; Li, E.; Dong, S.; Ye, P.; et al. Contacts between twoand three-dimensional materials: Ohmic, Schottky, and p-n heterojunctions. ACS Nano 2016, 10, 4895-4919. [CrossRef]

382. Sun, P.; Zhao, W.; Cao, Y.; Guan, Y.; Sun, Y.; Lu, G. Porous $\mathrm{SnO}_{2}$ hierarchical nanosheets: Hydrothermal preparation, growth mechanism, and gas sensing properties. CrystEngComm 2011, 13, 3718-3724. [CrossRef]

383. Rahmani, M.B.; Yaacob, M.H.; Sabri, Y.M. Hydrogen sensors based on $2 \mathrm{D} \mathrm{WO}_{3}$ nanosheets prepared by anodization. Sens. Actuators B 2017, 251, 57-64. [CrossRef] 
384. Li, Z.; Wang, N.; Lin, Z.; Wang, J.; Liu, W.; Sun, K.; Fu, Y.Q.; Wang, Z. Room-temperature high-performance $\mathrm{H}_{2} \mathrm{~S}$ sensor based on porous $\mathrm{CuO}$ nanosheets prepared by hydrothermal method. ACS Appl. Mater. Interfaces 2016, 8, 20962-20968. [CrossRef]

385. Yu, T.; Cheng, X.; Zhang, X.; Sui, L.; Xu, Y.; Gao, S.; Zhao, H.; Huo, L. Highly sensitive $\mathrm{H}_{2} \mathrm{~S}$ detection sensors at low temperature based on hierarchically structured $\mathrm{NiO}$ porous nanowall arrays. J. Mater. Chem. A 2015, 3, 11991-11999. [CrossRef]

386. Li, G.; Wang, X.; Liu, L.; Liu, R.; Shen, F.; Cui, Z.; Chen, W.; Zhang, T. Controllable synthesis of 3D Ni(OH $)_{2}$ and $\mathrm{NiO}$ nanowalls on various substrates for high-performance nanosensors. Small 2015, 11, 731-739. [CrossRef]

387. Wang, X.; Yao, S.; Wu, X.; Shi, Z.; Sun, H.; Que, R. High gas sensor and supercapacitor performance of porous $\mathrm{Co}_{3} \mathrm{O}_{4}$ ultrathin nanosheets. RSC Adv. 2015, 5, 17938-17944. [CrossRef]

388. Choi, S.-J.; Jang, J.-S.; Park, H.J.; Kim, I.-D. Optically sintered $2 \mathrm{D} \mathrm{RuO}_{2}$ nanosheets: Temperature-controlled $\mathrm{NO}_{2}$ reaction. Adv. Funct. Mater. 2017, 27, 1606026. [CrossRef]

389. Bag, A.; Lee, N.-E. Gas sensing with heterostructures based on two-dimensional nanostructured materials: A review. J. Mater. Chem. C 2019, 7, 13367. [CrossRef]

390. Yu, H.; Yang, T.; Zhao, R.; Xiao, B.; Li, Z.; Zhang, M. Fast formaldehyde gas sensing response properties of ultrathin $\mathrm{SnO}_{2}$ nanosheets. RSC Adv. 2015, 5, 104574-104581. [CrossRef]

391. Liu, X.; Sun, Y.; Yu, M.; Yin, Y.; Du, B.; Tang, W.; Jiang, T.; Yang, B.; Cao, W.; Ashfold, M.N.R. Enhanced ethanol sensing properties of ultrathin $\mathrm{ZnO}$ nanosheets decorated with $\mathrm{CuO}$ nanoparticles. Sens. Actuators B 2018, 255, 3384-3390. [CrossRef]

392. Hoa, N.D.; El-Safty, S.A. Synthesis of mesoporous NiO nanosheets for the detection of toxic NO2 gas. Chem. Eur. J. 2011, 17, 12896-12901. [CrossRef] [PubMed]

393. Li, D.J.; Huang, Z.; Hwang, T.H.; Narayan, R.; Choi, J.W.; Kim, S.O. Atomic thin titania nanosheet-coupled reduced graphene oxide $2 \mathrm{D}$ heterostructures for enhanced photocatalytic activity and fast lithium storage. Electron. Mater. Lett. 2016, 12, 211-218. [CrossRef]

394. Wang, F.; Seo, J.-H.; Luo, G.; Starr, M.B.; Li, Z.; Geng, D.; Yin, X.; Wang, S.; Fraser, D.G.; Morgan, D.; et al. Nanometre-thick single-crystalline nanosheets grown at the water-air interface. Nat. Commun. 2016, 7, 10444. [CrossRef] [PubMed]

395. Tan, C.L.; Zhang, H. Wet-chemical synthesis and applications of non-layer structured two-dimensional nanomaterials. Nat. Commun. 2015, 6, 7873. [CrossRef] [PubMed]

396. Cheng, W.R.; He, J.F.; Yao, T.; Sun, Z.H.; Jiang, Y.; Liu, Q.H.; Jiang, S.; Hu, F.C.; Xie, Z.; He, B.; et al. Half-unit-cell alpha $\mathrm{Fe}_{2} \mathrm{O}_{3}$ semiconductor nanosheets with intrinsic and robust ferromagnetism. J. Am. Chem. Soc. 2014, 136, 10393-10398. [CrossRef]

397. Zhong, Y.T.; Yang, Y.J.; Ma, Y.; Yao, J.N. Controlled synthesis of ultrathin lamellar $\mathrm{Eu}_{2} \mathrm{O}_{3}$ nanocrystals: Self-assembly of 1D nanowires to 2D nanosheets. Chem. Commun. 2013, 49, 10355-10357. [CrossRef] [PubMed]

398. Xu, L.; Zhou, X.; Yu, Y.; Tian, W.Q.; Ma, J.; Lei, S. Surface confined crystalline two-dimensional covalent organic frameworks via on-surface schiff-base coupling. ACS Nano 2013, 7, 8066-8073. [CrossRef] [PubMed]

399. Sun, Y.; Lei, F.; Gao, S.; Pan, B.; Zhou, J.; Xie, Y. Atomically thin tin dioxide sheets for efficient catalytic oxidation of carbon monoxide. Angew. Chem. 2013, 125, 10763-10766. [CrossRef]

400. Dral, A.P.; ten Elshof, J.E. 2D metal oxide nanoflakes for sensing applications: Review and perspective. Sens. Actuators B 2018, 272, 389-392. [CrossRef]

401. Huang, J.; Wu, Y.; Gu, C.; Zhai, M.; Sun, Y.; Liu, J. Fabrication and gas-sensing properties of hierarchically porous $\mathrm{ZnO}$ architectures. Sens. Actuators B 2011, 155, 126-133. [CrossRef]

402. Alenezi, M.R.; Alshammari, A.S.; Alzanki, T.H.; Jarowski, P.; Henley, S.J.; Silva, S.P.R. ZnO nanodisk based UV detectors with printed electrodes. Langmuir 2014, 30, 3913-3921. [CrossRef] [PubMed]

403. Frisenda, R.; Navarro-Moratalla, E.; Gant, P.; De Lara, D.P.; Jarillo-Herrero, P.; Gorbachev, R.V.; Castellanos-Gomez, A. Recent progress in the assembly of nanodevices and van der Waals heterostructures by deterministic placement of 2D materials. Chem. Soc. Rev. 2018, 47, 53-68. [CrossRef] [PubMed]

404. Tanaka, T.; Fukuda, K.; Ebina, Y.; Takada, K.; Sasaki, T. Highly organized self-assembled monolayer and multilayer films of titania nanosheets. Adv. Mater. 2004, 16, 872-875. [CrossRef] 
405. Akatsuka, K.; Haga, M.; Ebina, Y.; Osada, M.; Fukuda, K.; Sasaki, T. Construction of highly ordered lamellar nanostructures through Langmuir-Blodgett deposition of molecularly thin titania nanosheets tens of micrometers wide and their excellent dielectric properties. ACS Nano 2009, 3, 1097-1106. [CrossRef]

406. Miao, J.; Chen, C.; Meng, L.; Lin, Y.S. Self-assembled monolayer of metal oxide nanosheet and structure and gas-sensing property relationship. ACS Sens. 2019, 4, 1279-1290. [CrossRef]

(c)

(C) 2020 by the author. Licensee MDPI, Basel, Switzerland. This article is an open access article distributed under the terms and conditions of the Creative Commons Attribution (CC BY) license (http://creativecommons.org/licenses/by/4.0/). 